IN-SITU MONITORING OF ADDITIVE MANUFACTURING USING DIGITAL

IMAGE CORRELATION

By

Martina B Jani

A Thesis Submitted to the Faculty of Embry-Riddle Aeronautical University

In Partial Fulfillment of the Requirements for the Degree of

Master of Science in Aerospace Engineering

December 2021

Embry-Riddle Aeronautical University

Daytona Beach, Florida 


\title{
IN-SITU MONITORING OF ADDITIVE MANUFACTURING USING DIGITAL IMAGE CORRELATION
}

\author{
By
}

\author{
Martina B Jani
}

This Thesis was prepared under the direction of the candidate's Thesis Committee Chair, Dr. Sirish Namilae, Department of Aerospace Engineering, and has been approved by the members of the Thesis Committee. It was submitted to the Office of the Senior Vice President for Academic Affairs and Provost and was accepted in partial fulfillment of the requirements for the Degree of Master of Science in Aerospace Engineering.

\section{THESIS COMMITTEE}

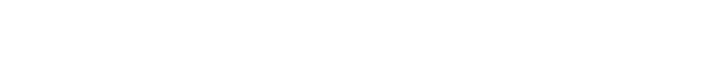
Chairman, Dr. Sirish Namilae

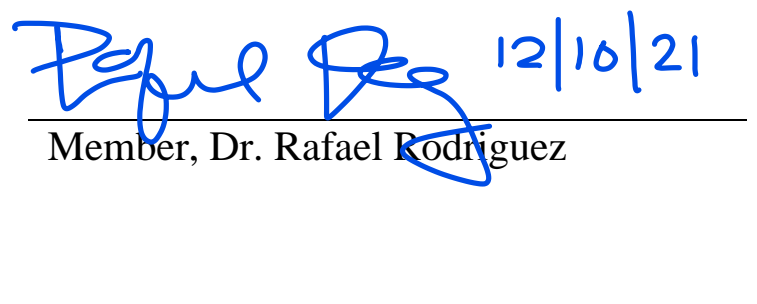

Graduate Program Coordinator, Dr. Daewon Kim

Digitally signed by James $\mathrm{W}$. James W. Gregory Gregory

Dean of the College of Engineering, Dr. Gregory W. James

Associate Provost of Academic Support, Dr. Christopher Grant
Marwan Al-Haik Digitally signed by Marwan Al-Haik

Member, Dr. Marwan Al-Hiak

Date

Date

Date 


\section{ACKNOWLEDGEMENTS}

I have received a great deal of support and assistance throughout the thesis journey. First and foremost, I would like to thank my advisor, Dr. Sirish Namilae whose expertise helped me to formulate a thesis problem and plan my research approach. He has been very supportive in including different research methodologies and avail me of all the necessary equipment.

I would like to thank Dr. Marwan Al-Haik for the provision of a digital image correlation camera and thermal camera which were prominent for this project. I would like to thank Dr. Rafael Rodriguez for helping me with his expertise in additive manufacturing. I would like to thank Dr. Dae Won Kim for assisting and providing a laser displacement sensor. I would also like to extend my thanks to Dr. Jeff Brown for providing me the infrared camera. Then I would like to thank Dr. Sandra Boetcher for allowing me access to digital scanning microscopy machine. I would also like to thank Troxler Casey for assisting me with DSC test.

My research group always supported and motivated me with innovative ideas. I would like to extend my gratitude to my family for their emotional support. I would like to thank my friends for cheering me up during highs and lows. Finally, I would like to express my gratitude to the Almighty and my spiritual master Gurudev Sri Sri Ravishankarji. His principles made all situations much simpler. 


\begin{abstract}
Advances in additive manufacturing over the past decade have led to applications in multiple fields. In particular, additive manufacturing answers the need for high flexibility in designing complex structures, however, the rapid thermal fluctuations during processing lead to numerous defects and processing-induced residual stresses. In this research, an in-situ approach using Digital Image Correlation (DIC) is developed to monitor the deformation during the processing, and thereby analyze the formation of defects and residual stresses. DIC is a visual technique that compares the changes in speckle pattern in consecutive images of a specimen to determine the displacements and strains. This research aims to utilize the novel in-situ approach to investigate the processing-induced deformations due to variations in two process parameters: layer resolution and print temperature. Preliminary results show how defects like warping and missing material caused strain to decrease. Followed by strain evolution for specimens with different thicknesses which revealed maximum strain for the thinnest specimen. Finally, temperature evolution was observed for each layer and compared to with previous layer temperature for all the combinations of thickness and temperature. Current results are for a PLA specimen with pre-printed speckles. In the future, these concepts can be applied to composite printing to understand the evolution of defects such as voids and delamination during processing.
\end{abstract}


TABLE OF CONTENTS

ACKNOWLEDGEMENTS................................................. iii

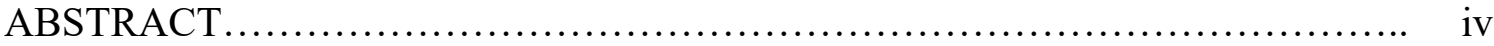

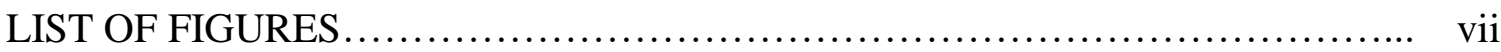

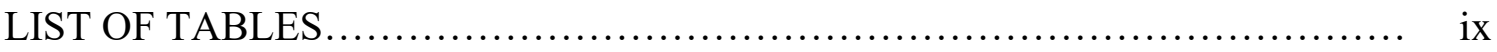

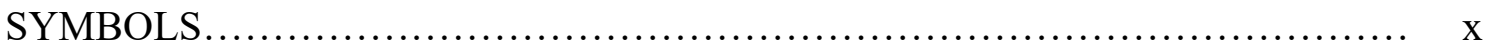

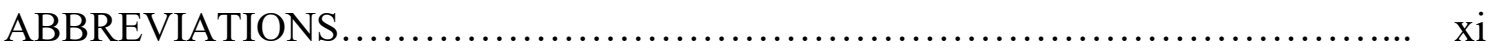

1. Introduction 1

1.1. Additive Manufacturing in the Aerospace Industry......................... 1

1.2. Motivation for this Research.............................................. 3

1.3. Objectives.......................................................... 5

2. Literature Review............................................................ 7

2.1. Review of Additive Manufacturing..................................... 7

2.2. Applications, Advantages, and Disadvantages of Additive Manufacturing..... 9

2.3. Polylactic Acid Properties................................................. 12

2.4. Influence of Print Parameters on 3D Printed Part........................... 13

2.5. In-Situ Methods for Additive Manufacturing................................ 15

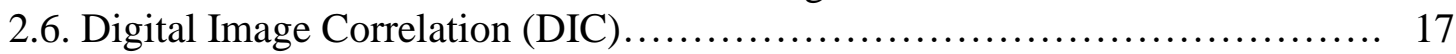

2.6.1. Comparison of 2D-DIC and 3D-DIC ............................. 18

2.6.2. DIC for Strain Measurements........................................ 19

2.6.3. Correction of Out of Plane Strain in 2D-DIC ........................... 20

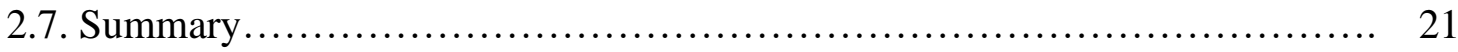

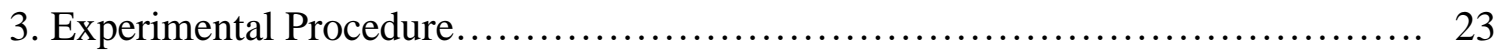

3.1. Material, Equipment, and Software.................................... 23

3.1.1. Marble PLA ........................................................ 23

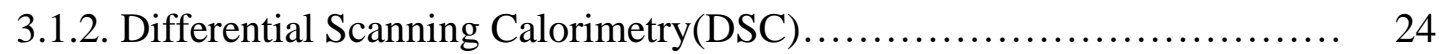

3.1.3. Creality Ender 5 Plus 3D Printer.................................. 25

3.1.4. DIC Lens and Camera............................................ 26

3.1.5. Laser Displacement Sensor.......................................... 27

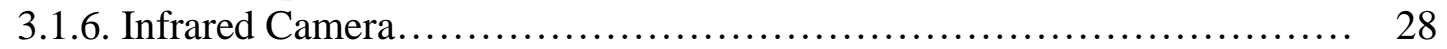

3.1.7. SKYSCAN X-Ray Microtomography Machine......................... 28

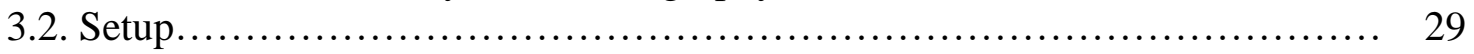

3.2.1. Setup for In-Situ Strain Observation................................. 29

3.2.2. Setup for In-Situ Temperature Observation............................ 30

3.3. Print Algorithm........................................................... 31

3.4. Correction of Out-of-Plane Strains..................................... 32 


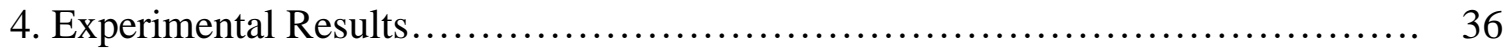

4.1. Detecting Print Defects using DIC .................................. 36

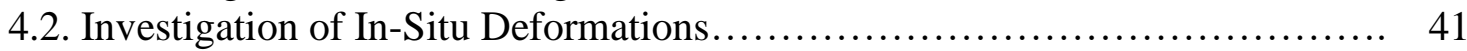

4.2.1. Deformations in the Specimen with $0.15 \mathrm{~mm}$ Thickness.................. 42

4.2.2. Deformations in the Specimen with $0.20 \mathrm{~mm}$ Thickness.................. 45

4.2.3. Deformations for Specimens with $0.25 \mathrm{~mm}$ Thickness................... 47

4.3. Infrared Camera Analysis................................................ 49

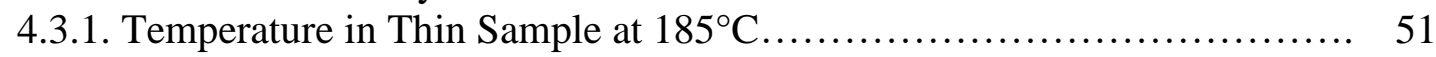

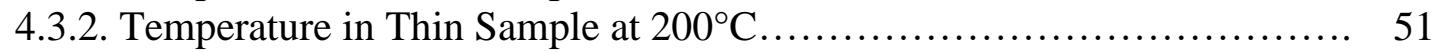

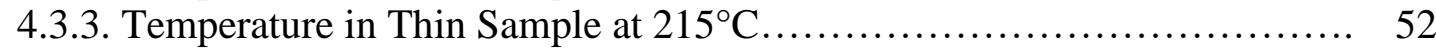

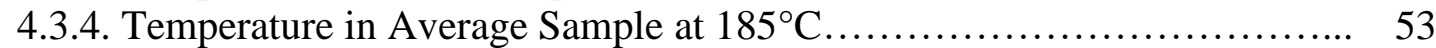

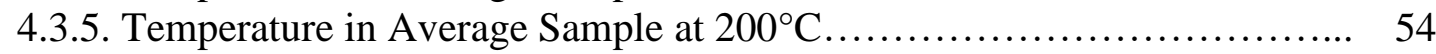

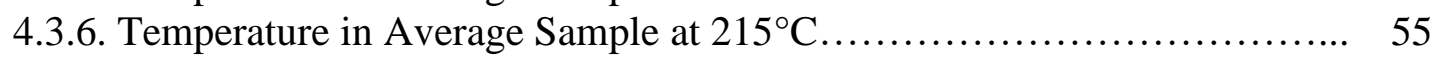

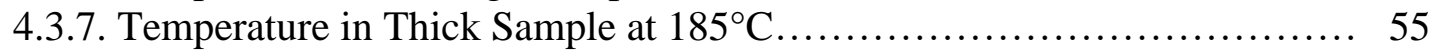

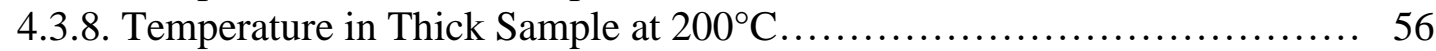

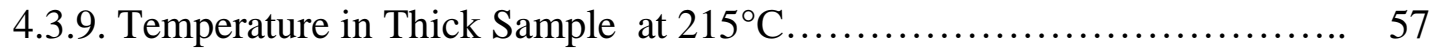

4.4. Parametric Analysis of Thickness Variation................................ 58

4.5. Parametric Analysis of Temperature Variation........................... 62

5. Conclusions and Future Work.............................................. 68

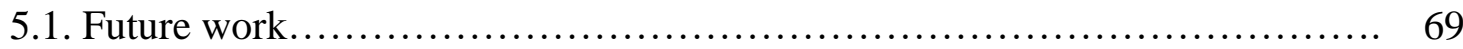

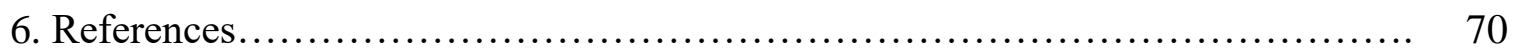

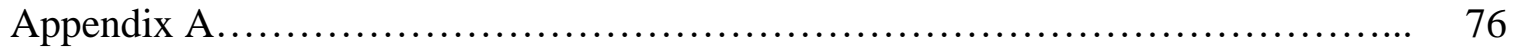

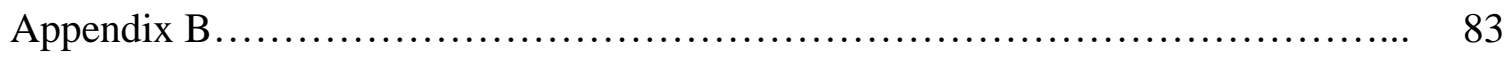




\section{LIST OF FIGURES}

Figure Page

1.1 Trend of additive manufacturing, (Wohlers, 2021)....................... 2

1.2 Warping effect on 3D printed PLA................................... 4

1.3 DefectsPockmarks and missing material.................................. 4

2.1 Classification of 3D Printing Processes (Wong \& Hernandez, 2012)........... 8

2.2 Schematic of FDM................................................ 9

2.3 Gap and the oozing effect observed in 3D printed PLA (Haq et al., 2019)...... 12

3.1. Marble PLA filament............................................. 24

3.2 DSC machine to obtain melting point of PLA............................. 24

3.3 Melting temperature range obtained through DSC ....................... 25

3.4 Creality Ender 5Plus 3D Printer.................................... 26

3.5 Monochromatic DIC camera and lens.................................. 27

3.6 Laser displacement sensor........................................ 27

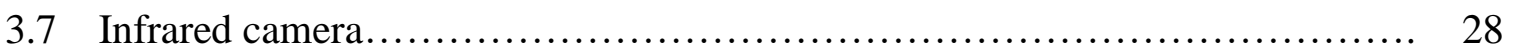

$3.8 \quad$ X-Ray Tomography.............................................. 29

3.9 Print setup with DIC and Laser sensor.................................. 30

3.10 Infrared camera capturing thermal data................................ 31

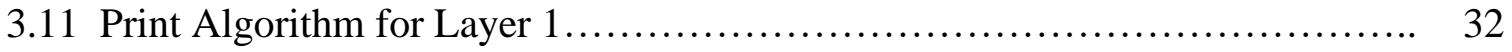

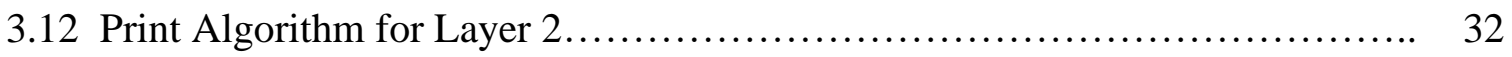

3.13 Out-of-Plane Translation of Image, (Michael Sutton, 2008)................ 33

4.1 Compressive Strain in Section 31 along X- direction..................... 37

4.2 Compressive Strain in Section 31 along Y-direction...................... 38 
Figure $\quad$ Page

4.3 Warping Captured by DIC and Compressive X-strains through Analysis....... 38

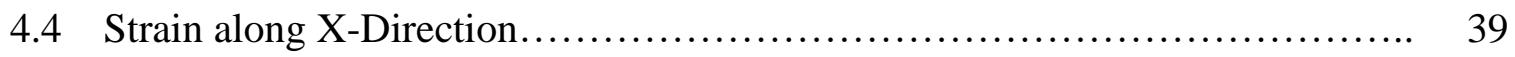

4.5 Under-Extrusion in Section 2 through DIC Camera........................ 40

4.6 X-Ray image for under-extruded section placed horizontally................ 41

4.7 Location of Each Printed Section.................................. 42

4.8 Strain Contours along the X-Direction.............................. 43

4.9 Strain Contours along the Y-Direction............................... 44

4.10 Strain Evolution for $0.20 \mathrm{~mm}$ Specimen in X -direction................... 46

4.11 Strain Evolution for $0.20 \mathrm{~mm}$ Specimen along Y-direction................. 47

4.12 Strain for $0.25 \mathrm{~mm}$ Specimen along X-direction........................ 48

4.13 Strain for $0.25 \mathrm{~mm}$ Specimen along Y-direction......................... 49

4.14 Temperature of Each Section in Real-Time using FLIR A655 SC........... 50

4.15 Temperature Evolution for $0.15 \mathrm{~mm}$ Sample at $185^{\circ} \mathrm{C} \ldots \ldots \ldots \ldots \ldots \ldots \ldots \ldots \ldots \ldots \ldots$

4.16 Temperature Evolution for $0.15 \mathrm{~mm}$ Sample at $200{ }^{\circ} \mathrm{C} \ldots \ldots \ldots \ldots \ldots \ldots \ldots \ldots . . \ldots 2$

4.17 Temperature Evolution for $0.15 \mathrm{~mm}$ Specimen at $215^{\circ} \mathrm{C} \ldots \ldots \ldots \ldots \ldots \ldots \ldots . . \ldots 3$

4.18 Temperature Evolution for $0.20 \mathrm{~mm}$ Sample at $185^{\circ} \mathrm{C} \ldots \ldots \ldots \ldots \ldots \ldots \ldots \ldots . \ldots 4$

4.19 Temperature Evolution for $0.20 \mathrm{~mm}$ Sample at $200{ }^{\circ} \mathrm{C} \ldots \ldots \ldots \ldots \ldots \ldots \ldots \ldots . \ldots . \ldots . \ldots . \ldots$

4.20 Temperature Evolution for $0.20 \mathrm{~mm}$ Sample at $215^{\circ} \mathrm{C} \ldots \ldots \ldots \ldots \ldots \ldots \ldots \ldots . . \ldots 5$

4.21 Temperature Evolution for $0.25 \mathrm{~mm}$ Sample at $185{ }^{\circ} \mathrm{C} \ldots \ldots \ldots \ldots \ldots \ldots \ldots \ldots \ldots . \quad 56$

4.22 Temperature Evolution for $0.25 \mathrm{~mm}$ Sample at $200{ }^{\circ} \mathrm{C} \ldots \ldots \ldots \ldots \ldots \ldots \ldots \ldots \ldots$

4.23 Temperature Evolution for $0.25 \mathrm{~mm}$ Sample at $215^{\circ} \mathrm{C} \ldots \ldots \ldots \ldots \ldots \ldots \ldots \ldots . \ldots \ldots$

4.24 Strain along X-Direction in Section 1 for Different Thicknesses............. 59 
Figure $\quad$ Page

4.25 Strain along X- Direction for Section 2 for Different Thicknesses............ 60

4.26 Strain along X- Direction for Section 3 for Different Thicknesses............ 60

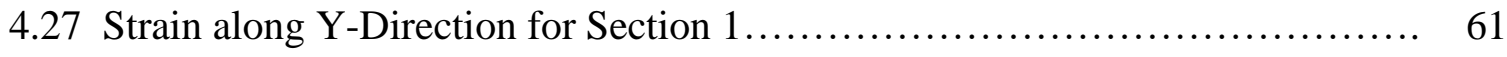

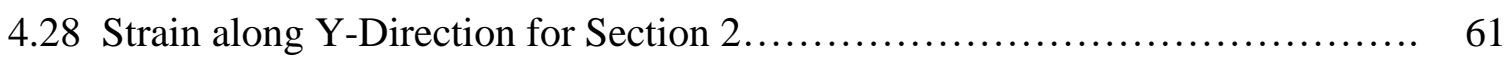

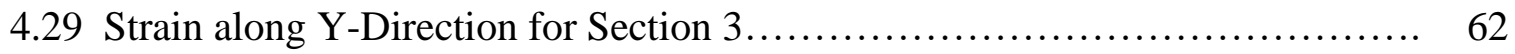

4.30 Strain along X-Direction for Section 1 for $0.15 \mathrm{~mm}$ Thickness............. 63

4.31 Strain along X-Direction for Section 2 for $0.15 \mathrm{~mm}$ Thickness.............. 63

4.32 Strain along Y- Direction for Section 3 for $0.15 \mathrm{~mm}$ Thickness............... 64

4.33 Strain along Y- Direction for Section 1 for $0.15 \mathrm{~mm}$ Thickness.............. 65

4.34 Strain along Y-Direction for Section 2 for $0.15 \mathrm{~mm}$ Thickness................ 66

4.35 Strain along Y- Direction for Section 3 for $0.15 \mathrm{~mm}$ Thickness.............. 66

4.36 Temperature Evolution for Various Print Temperature...................... 67 


\section{List of Tables}

Table Page

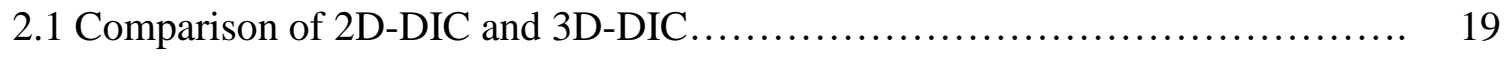

3.1 Test Matrix ........................................................ 34 
SYMBOLS

$X \quad \mathrm{X}$-cordinate of the Object

$Y \quad$ Y-cordinate of the Object

Z Distance between Object and Lens

$\Delta Z \quad$ Out-of-Plane Translation

$M_{T} \quad$ Magnification factor

$U$ Displacememt along X-direction

V Displacement along Y-direction

$\Delta \varepsilon_{x x}$ Change in Strain along X-direction

$\Delta \varepsilon_{y y}$ Change in Strain along Y-Direction

$x_{s} \quad \mathrm{X}$-cordinate of Image

$y_{s} \quad$ Y-cordinate of Image 


\begin{tabular}{ll} 
& \multicolumn{1}{c}{ ABBREVIATIONS } \\
ASTM & American Socienty for Testing and Materials \\
COVID-19 & Corona Virus Infectious Disease - 2019 \\
ABS & Acrylonitrile - Butadiene - Styrene \\
PLA & Polylactic Acid \\
FDM & Fused Deposition Modelling \\
DIC & Digital Image Correlation \\
CMOS & Complementary Metal-Oxide Semiconductor \\
CAD & Computer-Aided Design \\
SL & Stereolithography \\
NASA & National Aeronautics and Space Administration \\
SEM & Scanning Electron Microscope \\
CNT & Carbon Nanotube \\
CFR & Carbon-Fiber-Reinforced \\
TGA & Thermogravimetric Analysis \\
CCD & Charge-Couple Device \\
FOV & Field of View \\
FBG & Fiber Bragg Grating \\
\hline
\end{tabular}




\section{Introduction}

This chapter introduces the research problem, current state-of-art and, limitations of additive manufacturing. Subsequently, the motivation to overcome limitations has been presented with research objectives. Finally, the flow of the thesis has been mentioned to give the reader an idea of how the thesis will proceed.

\subsection{Additive Manufacturing in the Aerospace Industry}

Additive manufacturing as defined by ASTM F42 Technical committee is "a process of joining materials to make objects from 3D model data, usually layer upon layer, as opposed to subtractive manufacturing methodologies” (ASTM, 2012,p.2). Additive manufacturing is one of the rapidly growing industries based on various forecast reports.

“Additive Manufacturing Trend Report 2021” published by 3D Hubs in April 2021, revealed a market size of 12.6 billion USD in the year 2020 and is expected to grow at a $17 \%$ compounded growth rate in upcoming years (Hubs, 2021). Wohler's report updated on March 2021 exhibited logarithmic increment in the production of additively manufactured parts as shown in Figure1.1. The usage of additively manufactured parts started rising considerably after 2010 with more than $400 \%$ increment in sales within one decade. It is noticeable that the trend revealed a $7.5 \%$ increment despite the uncertainties of the COVID-19 pandemic (Wohlers, 2021).

The developing field of additive manufacturing has successfully captivated the attention of automotive, aerospace, and architectural field as well, on top of being popular in biomedical and consumer products industries. The aerospace industry is one of the largest consumers employing additive manufacturing techniques after consumer industry, automotive, and medical industry (Kalender et al., 2019). In case of the aerospace 
industry lightweight, high reliability, and economically manufactured parts are a priority. In addition, high strength to density ratio, extreme outer space environmental conditions, structural stability, and complex geometries are important requirements as well.

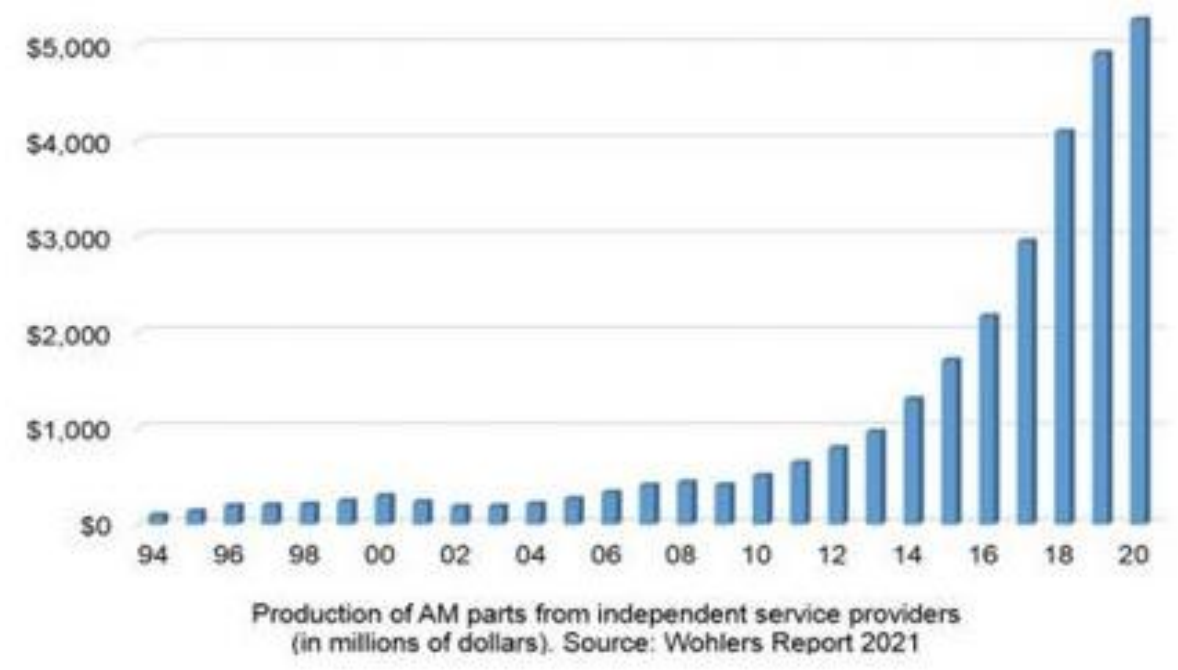

Figure 1.1 Trend of additive manufacturing (Wohlers, 2021).

Materials commonly used in the 3D print prototypes and/or final parts in the aerospace industry are metallic alloys such as nickel-cobalt superalloys, titanium alloys, as well as, carbon fiber reinforced polymer composites (Kalender et al., 2019; Murr, 2016; Uhlmann et al., 2015).

Composites like carbon fiber thermoplastic and glass fiber polymer have several advantages like high specific strength and stiffness, corrosion resistance, fatigue resistance, moisture absorption capacities, and capabilities to maintain dimensional stability in an outer space environment (Mangalgiri, 1999). Polymers such as Acrylonitrile Butadiene Styrene (ABS) and Polylactic Acid (PLA) are commonly used in consumer applications in the additive sector. 
Researchers have been working on 3D printing of reinforced polymer to obtain better mechanical properties and dimensional accuracy as compared to pure thermoplastic. Materials such as onyx and carbon fiber are printed using a composite printer defining different infill patterns, infill densities, and other print parameters. It has been consistently found that those printed composites have a high level of porosity, visible lines on the surface, delamination problems, the gap between printed lines, and weak bonds (Blok et al., 2018; Chacón et al., 2019; Van Der Klift et al., 2016; Yasa \& Ersoy, 2019).

\subsection{Motivation for this Research}

The motivation of this research work comes from the defects observed in 3D printed composites. Poor bonding, porosity, roughness, warping, delamination can severely degrade the quality of printed parts in terms of their mechanical performance, outer space environment application, aesthetics, and desired dimensional accuracy for aerospace applications. Possible reasons for these, shortcomings can be residual stresses due to uneven cooling, print parameters, printer setup, and so forth.

If causes behind these shortcomings, such as thermal expansion, cure pattern, cure shrinkage, material extrusion, etc can be evaluated, it is possible to eliminate or reduce those print defects and attain better print quality. The composite printer uses a similar approach of fused deposition modeling as regular thermoplastic 3D printers. Defect formation in the specimen printed by a non-composite Fused Deposition Modelling (FDM) type printer also occurs due to improper printer settings, cooling rates, and print parameters as shown in the following pictures. 


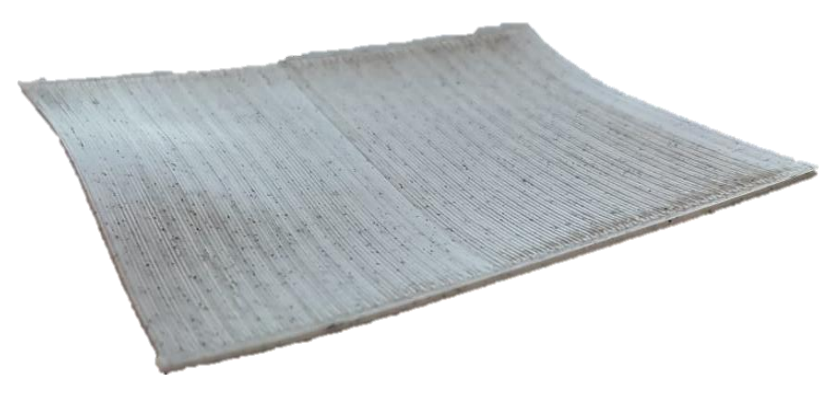

Figure 1.2 Warping effect on 3D printed PLA

Figure 1.2 depicts a specimen made from Polylactic acid with a warping effect due to lack of proper build plate temperature. Missing material, rough surface finish, and pockmarks observed in Figure 1.3(a) and Figure 1.3(b) can be attributed to poor build plate leveling, large z offset, retraction issues, and moistened filament.
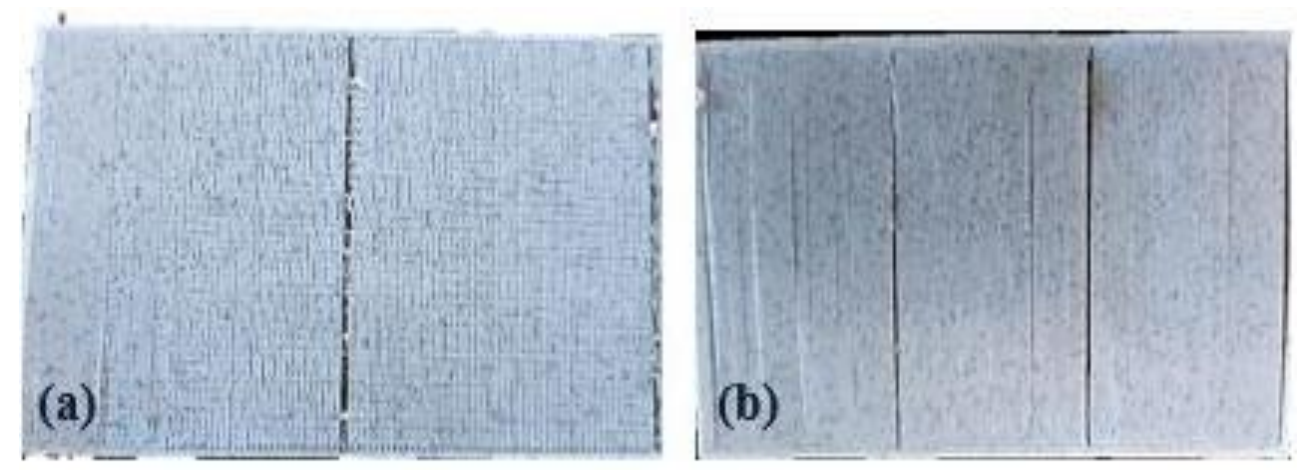

Figure 1.3(a) Pockmarks and missing material in 3D printed PLA (b) Improper binding of filament

Similarly, the oozing effect is another defect due to higher print temperatures than required which causes the nozzle to keep extruding even while the extruder is translating 
to another location. It can be noticed that several reasons contribute to defects in additively manufactured parts.

To evaluate those factors, it is necessary to observe printing in real-time and catch defect formation. Several researchers (Craeghs et al., 2012; Holzmond \& Li, 2017; Kousiatza \& Karalekas, 2016) implemented Fiber Bragg Grating sensors, Digital Image Correlation (DIC) camera and, high-speed Complementary Metal Oxide Semiconductor (CMOS) camera for in-situ defect observation.

While the objective is partially shared with the above publications the methodology and algorithms used in the work are unique. In this thesis, we utilize Digital Image Correlation (DIC) to characterize the formation of defects in real-time. Additionally, we explore the thermal strain evolution and temperature gradients in-situ during the printing of the polymer.

\subsection{Objectives}

This research collaboratively employs digital image correlation with additive manufacturing to characterize 3D printing in real-time. A unique algorithm has been developed which captures the print specimen in three parts and then compares the evolution of strain in each part with respect to time. An infrared camera has also been utilized to capture the thermal effects on each section for different layers of the thermoplastic specimen.

Objectives of this research work are:

1. Develop a methodology for in-situ characterization of FDM additive manufacturing. 
2. Capture the evolution of processing defects in real-time, which can potentially be utilized to correct the process parameters and mitigate defects.

3. Parametrically analyze the influence of print parameters and temperature evolution on the in-situ thermal strain development is commonly used printing material like Polylactic Acid (PLA). 


\section{Literature Review}

This chapter summarises the important concepts regarding research work such as digital image correlation, defect formation, print parameters and in-situ methods researched by several authors.

\subsection{Review of Additive Manufacturing}

The additive manufacturing process often includes the following steps: (a) generation of the computer-aided model, (b) generating tool path of the model, (c) obtaining the printed object of conceptual design using a 3D printer, (d) post-printing processes such as heat treatments and sintering.

The computer model can be designed using software such as SOLIDWORKS, CATIA, AUTOCAD (Mwema \& Akinlabi, 2020). A Computer-Aided Design (CAD) model is further tessellated into a triangular mesh to account for intricate shapes present in the model using stereolithography file format invented by 3D Systems Inc $(\mathrm{Hu}$, 2017). Tessellated model is transferred to a slicer software, where specific machine parameters like print speed, print temperature, tool path directions and, so forth are set in terms of G-code file.

Additive manufacturing is interchangeably called rapid prototyping due to its former primary purpose to rapidly replicate designed models. However, additive manufacturing now has evolved from its initial role of prototyping technique to a direct manufacturing process (Cooper, 2001). Different additive processes are classified based on input form of filament or material such as solid, liquid, and powder as shown in Figure 2.1.

Powder-based processes namely 3DP, Prometal, Selective latex sintering uses metal or ceramic powder as base metals. Binder or laser is used to sinter and cast desired 
geometry from the material. Laminated object manufacturing is a combination of additive and subtractive manufacturing. Under the application of heat and pressure, material layers are joined as a whole and then shaped into required geometry using a carbon dioxide laser.

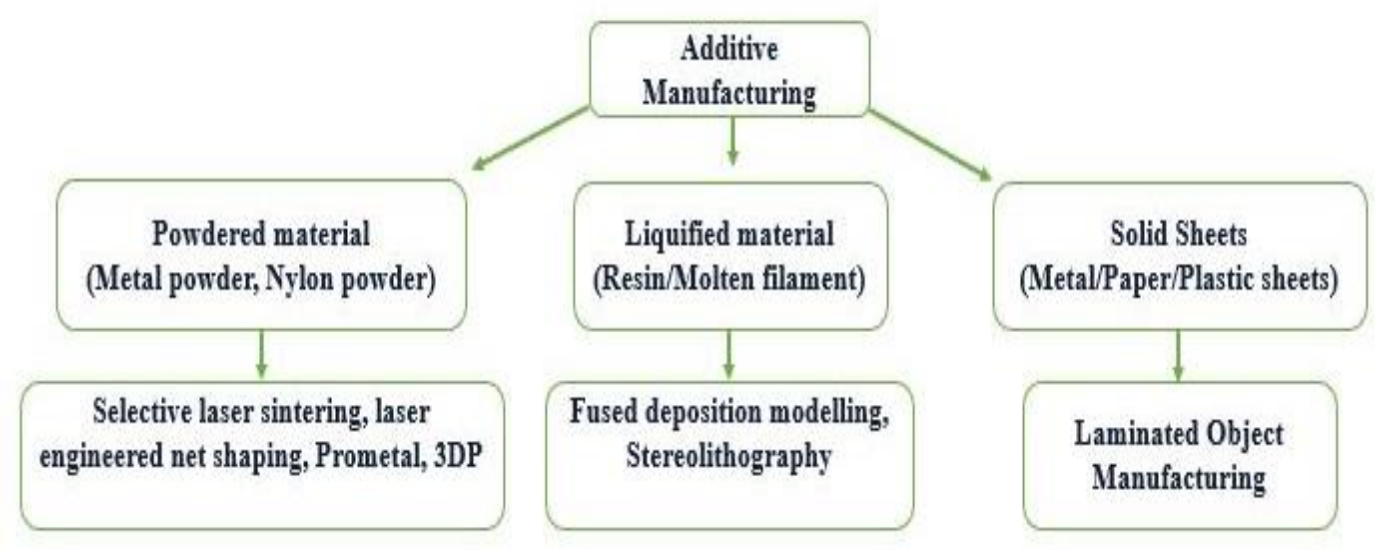

Figure 2.1 Classification of 3D Printing Processes (Wong \& Hernandez, 2012).

Liquid-based processes can be categorized based on polymerization and melting. The polymerization process typically assembles the liquid to obtain solidified objects by chemical bonding. While, melting process places, molten material on the build plate where it solidifies at an ambient or set temperature (Wong \& Hernandez, 2012). Considering the historical background, these liquid-based methods were the pioneers in the additive industry.

Additive manufacturing began with the discovery of stereolithography (SL), "a process to build 3-dimensional part based on cross-section pattern generated at the chosen surface", in 1986 by (Hull, 1984). Commercialization of this process by 3D SYSTEMS® followed the development of further variants of the SL process by firms like NTT Data 
CMET, D-MEC, Electro-Optical Systems, and Quadrax propelled additive manufacturing around the world (Wohlers \& Gornet, 2014).

Within five years of the invention of stereolithography, Stratasys ${ }^{\circledR}$ introduced the fused deposition modeling technique in 1991, which deposits melted material, layer-bylayer to fabricate the 3- dimensional object (Wohlers \& Gornet, 2014). Figure 2.2 depicts the schematic for the FDM process.

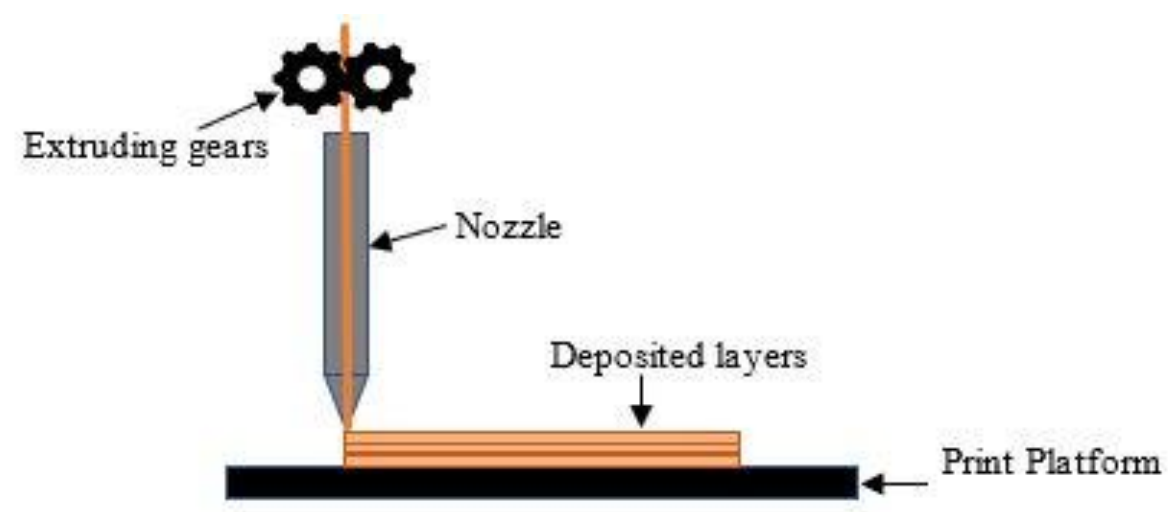

Figure 2.2 Schematic of FDM.

FDM printer nozzle is capable of navigating along XY plane to deposit material, using stepper motors, while platform shifts in the z-direction to accommodate new layers. In some printers, the print bed moves in the XY plane while the extruder translates in the $\mathrm{Z}$ direction. Also, FDM printers come with dual extruders to have multicolor components

\subsection{Applications, Advantages, and Disadvantages of Additive Manufacturing}

Additive manufacturing has been used in numerous aerospace applications. 3D Printed Leap engine nozzle made from cobalt chrome by GE aviation has successfully cleared ground level tests for its application in civil aircraft (Kalender et al., 2019). 
Eurostar E3000 satellite uses 3D Printed aluminum bracket manufactured by Airbus (Shapiro et al., 2016).

The fused deposition modeling technique is not limited to the earth's environment. In 2014, NASA sent a zero-gravity 3D Printer based on FDM technology on International Space Station, which successfully collected printed tensile, compression, flexural and other mechanical test coupons to further investigate their properties from the microgravity environment (Bean et al., 2015).

In the aerospace industry designed components are complex to manufacture and require lightweight and high strength, where additively manufactured parts are the best fit (S. L. N. Ford, 2014). Cost reduction is another benefit due to negligible scrap, minimum inventory, easy storage, reduced power requirements, limits to no pre-processing, and faster manufacturing of final products as compared to conventional processes (Despeisse \& Ford, 2015; S. Ford \& Despeisse, 2016; Sirichakwal \& Conner, 2016).

Boeing company implemented laser sintering techniques for 787 Dreamliner aircraft's numerous parts and was able to earn a profit of $\$ 3$ million per aircraft. GE aviation achieved a $25 \%$ weight reduction in nozzle weight, European Space agency could reduce the weight of the antenna by $56 \%$ due to 3D printed part. Many other companies like Lockheed Martin, Roll-Royce, Caterpillar, etc, also prefer additive manufacturing for light-weighted parts.

Other industrial sectors such as biomedical, architectural, and automotive employ additive manufacturing for drug development, non-bioactive implants, architectural modeling, customized car seats, car chassis and so forth (Pravin \& Sudhir, 2018; Wong \& Hernandez, 2012; Yan et al., 2018). Recently, 3D printed personal protective equipment 
kit, isolation chamber, COVID-19 specimen collectors, and ventilators aided significantly to mitigate emergencies that arose in pandemic (Kumar \& Pumera, 2021)

A unique advantage of additive manufacturing is the ability to print one single unit compared to several separate units assembled using rivets and other joints. Additionally, complex optimized shapes can be printed which results in weight savings. Customized parts, faster production (for limited demand), with reduced cost and weight can be attained (S. Ford \& Despeisse, 2016; S. L. N. Ford, 2014; Kalender et al., 2019) using these approaches.

On the contrary, additive manufacturing has several flaws which limit it from being considered as the most versatile and robust manufacturing technique as compared to conventional production methods. Poor bonding of layers, presence of pores, poor surface finish, oozing effect, wall gaps, missing material, dimensional inaccuracies, residual stress due to non-uniform cooling, and post-processing requirements make it less efficient (Altıparmak et al., 2021; Haq et al., 2019; Holzmond \& Li, 2017).

Additionally, mass production is challenging due to the limited availability of printers that produce in bulk. The size of the component is restricted based on the print bed and nozzle capacities. The availability of alloying techniques to increase part strength is quite limited. It requires a high initial investment for printers and materials for aerospacespecific applications to develop precise and accurate parts (S. Ford \& Despeisse, 2016; S. L. N. Ford, 2014). Finally, defining standards and qualification regulations integral to the aerospace sector is difficult due to continuous innovation in this field. 

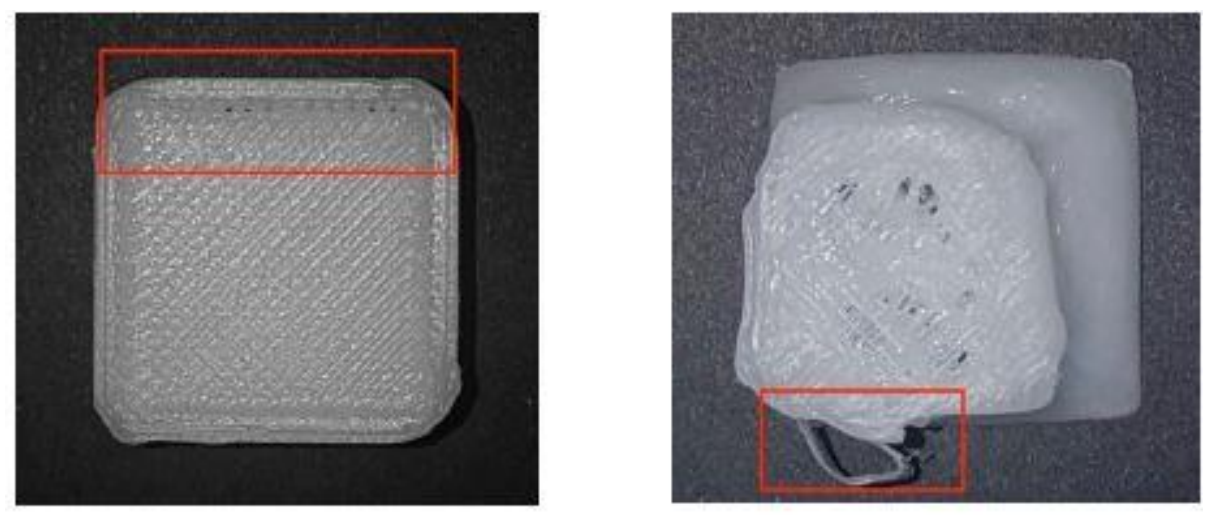

Figure 2.3 Gap and the oozing effect observed in 3D printed PLA (Haq et al. ,2019).

\subsection{Polylactic Acid Properties}

Polylactic acid (PLA) is the primary material used for 3D printing in this thesis. Polylactic acid is a thermoplastic polyester with the chemical formula $\left(\mathrm{C}_{3} \mathrm{H}_{4} \mathrm{O}_{2}\right)_{n}$. It was first synthesized by American Chemist Wallace Carothers in 1932. Several reviews discuss PLA and its use in additive manufacturing (Farah et al., 2016). Considering the chemical composition, polymerization processes such as polycondensation and ringopening polymerization are employed for the synthesis of PLA from lactic acid under high pressure and temperature conditions (Lasprilla et al., 2012).

The glass transition temperature and the melting point of PLA highly influence the mechanical behavior of PLA (Bouapao et al., 2009) which were reported to be $55^{\circ} \mathrm{C}$ and $165^{\circ} \mathrm{C}$ respectively by (Mehta et al., 2005). Mechanical properties like yield strength, elastic modulus, tensile strength, flexural strength, and ultimate strength for PLA are 59 MPa, $3500 \mathrm{MPa}, 70 \mathrm{MPa}, 106 \mathrm{MPa}$, and $73 \mathrm{MPa}$ respectively (Farah et al., 2016). 


\subsection{Influence of Print Parameters on 3D Printed Part}

As mentioned earlier, additive manufacturing has limitations in a wide range of applications, especially ones which require higher strength, larger span, and continuous loading in changing environmental conditions. Therefore, several research efforts are focused on analyzing and improving the process parameters for such applications. We focus this survey on PLA because that is the material used in this thesis.

Mechanical properties like tensile strength, flexural strength, elongation are often influenced by process and design parameters like print speed, liquefier temperature, layer height, platform temperature, infill density, infill pattern, and print orientation. It was observed that at $136{ }^{\circ} \mathrm{C}$ print temperature, $0.12 \mathrm{~mm}$ layer resolution, and $22 \mathrm{~mm} / \mathrm{s}$ print speed, PLA yields the best dimensional accuracy, which otherwise results in the overheated part, oozing effect, missing materials, and poor surface finish in case of other combination of print parameters (Haq et al., 2019).

In terms of mechanical properties, minimum layer height with higher print speed gives a more ductile part for flat orientation. Upright print orientation is not desirable for better mechanical performance (Chacón et al., 2017). Considering the role of defects in expected mechanical properties, researchers observed a reduction of $20.5 \%$ in tensile strength and $9.6 \%$ in modulus respectively, due to missing material in extruded PLA specimen (Fayazbakhsh et al., 2019).

The temperature is another important element to influence part properties, nonuniform temperature gradients and uneven cooling due to reheating of already printed layer induce residual stress on the component. Line defects due to line-by-line deposition 
of melted PLA, air gaps between layers, and poor bonding due to insufficient platform temperature can leave defected parts (Naveed, 2021; Wickramasinghe et al., 2020).

Print direction is another parameter causing crack length varying from $0.7 \mathrm{~mm}$ to 1.2 $\mathrm{mm}$ for $0^{\circ}, 30^{\circ}$, and $60^{\circ}$ raster angles. Lateral and $45^{\circ}$ print orientation led to negligible external defects and minimum internal defects. Longitudinally printed layers show lower peak temperatures as compared to a part printed along the lateral direction, where extruder remains in close proximity of printed part for a longer duration.

Influence of temperature on mesostructure and mechanical properties unveiled that neck growth highly depends on temperature, layers which are at the bottom exhibits better bonding and smaller pores as compared to top layers. Bottom layers experience higher temperatures above glass transition for a longer period of time (Naveed, 2021; Sun et al., 2008) .

Researchers carried out an experimental analysis of the effects of infill density, infill pattern, print speed, print temperature, and material reinforcement on mechanical and physical properties of the additively manufactured part. Initially, they observed just a few parameters like print speed, density, and temperature and they found out that maximum $(100 \%)$ infill density, $90 \mathrm{~mm} / \mathrm{s}$ print speed, and $215^{\circ} \mathrm{C}$ print temperature yield maximum tensile modulus.

Through Scanning Electron Microscopy (SEM) images it was observed that $90 \mathrm{~mm} / \mathrm{s}$ speed enables the best layer arrangement. Next, they fixed those parameters to check for a better infill pattern which turned out to be linear, and finally the reinforcement considerations, they compared pure PLA, PLA-CFR, ABS-CFR, ABS-CNT, and pure ABS specimen. PLA-CFR part revealed the best mechanical properties (tension, bending, 
and compression) as compared to other combinations and pure material. They also performed Thermogravimetric (TGA) analysis to obtain the volume fraction of reinforcement (Abeykoon et al., 2020).

Another ersearchers carried out an experimental study to obtain the ideal print parameters (infill density, raster angle, layer resolution, and extruder temperature) to obtain maximum mechanical properties (yield strength, ultimate tensile strength, modulus of elasticity, toughness, and elongation at break). It was found that to obtain better mechanical properties higher temperature and lower layer resolution are needed, while to reduce porosity lower temperature and thicker layer size are needed (Haq et al., 2019).

\subsection{In-Situ Methods for Additive Manufacturing}

Many researchers have recently been focusing on attempts to capture additive manufacturing in real-time so that defect formation can be monitored and proactively mitigated. In-situ techniques are important in this situation as ex-situ techniques are applicable only after the component is built.

Optical techniques involving the use of a Charged-Coupled Device (CCD) camera, high-speed camera, infrared camera are a popular part of in-situ techniques. Researchers implemented optical monitoring techniques for layer-wise laser melting process to detect defects in actual time. A unique method called "mapping of pool data" enabled mapping melt pool data in space, simultaneously with mapping laser beam position. They have considered the effect of temperature on inducing thermal stresses during selective laser melting and found out that overhang zones experience overheating which caused deformation (Craeghs et al., 2012). 
Kousiatza and coworkers have implemented Fiber Bragg Grating (FBG) sensors to obtain in-situ real-time monitoring of strain and temperature variation in additive manufacturing. FBG sensors were embedded within the specimen at different locations and were connected with thermocouples. As the material layer gets consolidated sensor responds to the changes in strain and temperature. Residual strain values may alter based on specimen position on the print bed (Kousiatza \& Karalekas, 2016).

Researchers have developed in-situ temperature measurement techniques during fused deposition modeling of PLA as bonding between layers is influenced by thermal energy. They considered the sensitivity of thermal energy for each layer of the part based on platform temperature and print speed. Due to deposition of the next layer on the existing layer, reheating of filament takes place. Print speed also influences the rate of cooling and these analyses can further help to detect defects based on improper bonding influenced by thermal energy (Vanaei et al., 2021).

As per a survey conducted by (Cunha et al., 2021), it was found that Digital image correlation is the most popular technique for in-situ measurements. Holzmond and coworkers (Holzmond \& Li, 2017) have implemented a new approach to capture in-situ defects in additively manufactured parts. They used a combination of wood fill filament and PLA to have an inbuilt speckle pattern due to wood fill.

They captured part after every layer. G code for the part was converted into Visualization Toolkit form to obtain point cloud coordinates. The correlation of these cloud coordinates with the CAD model unveils the defect present in the geometry of the part being printed. It was observed that an increase in layers caused a rise in the global defect. 


\subsection{Digital Image Correlation (DIC)}

Digital Image Correlation was first introduced by Peters and Rafson in 1982 for stress analysis. It is an optical non-contact method that can measure full-field displacement and strain on a specimen without damaging it. DIC works on the principle of capturing and comparing, an original and deformed image that is captured after a certain period.

To be compared precisely, each image is divided into a subset of pixels. This subset is matched in all the images captured after the reference image to track the displacement of those pixel positions (Yoneyama \& Murasawa, 2009). Figure 2.4 depicts the movement of the speckle pattern after a time $t_{1}$.
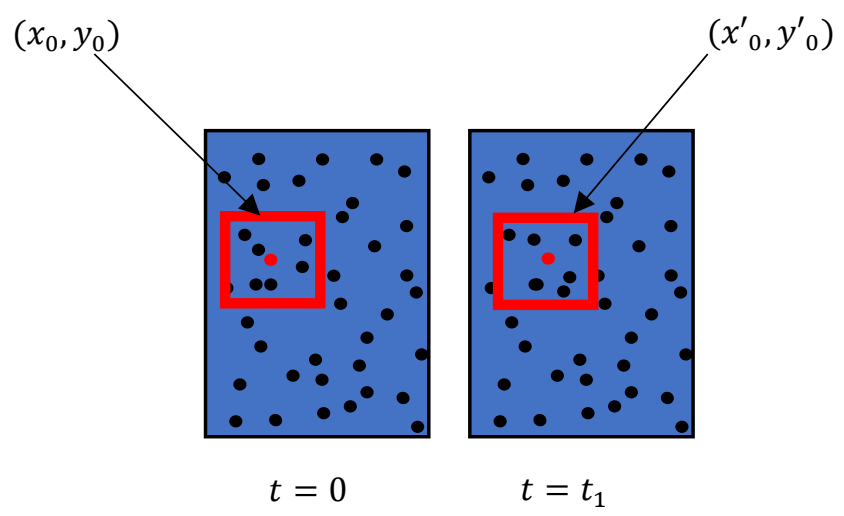

Figure 2.4 Matching speckles after time $t_{1}$

Digital images can be acquired through sources like Charged coupled device (CCD) cameras, microscopes, macroscopic or high-speed cameras (Lord, 2010). These images are further processed in commercial or open-source, analysis software such as VIC-2D, HOLO3, ARAMIS, LAVision, Ncorr, pydic (Belloni et al., 2019). It is crucial to have a quality speckle pattern to obtain a good uncertainty ratio for strain measurements. 
To ensure good quality, speckle pattern should be of a contrasting color as compared to specimen, as software can only detect recognize contrasting fields and then use bilinear interpolation those. They should be non-uniformly distributed and non-repetitive to avoid the aliasing effect (Correlated Solutions $\left.{ }^{\circledR}\right)$. Once, the quality pattern is obtained, the gray level of the pixel is calculated using bilinear or cubic interpolation. Finally, a crosscorrelation criterion is implemented to account for the displacement as shown.

$$
C\left(x, y, x^{\prime}, y^{\prime}\right)=\frac{\Sigma F(x, y) G\left(x^{\prime}, y^{\prime}\right)}{\sqrt{F(x, y)^{2} \Sigma G\left(x^{\prime}, y^{\prime}\right)^{2}}}
$$

Here $F(x, y)$ and $G\left(x^{\prime}, y^{\prime}\right)$ represents gray levels for undeformed and deformed images for a selected subset, and correlation coefficient $\mathrm{C}$ is a function of deformation parameter (Yoneyama \& Murasawa, 2009). The Digital Image Correlation technique offers some benefits over conventional strain measurement techniques. Firstly, there is no chance of damaging the specimen as DIC is the non-contact method to gauge strain. Strain can be observed in 3 dimensions instead of focusing on the direction (Kahn-Jetter \& Chu, 1990).

Full-field strain can be obtained not just on selected points (Wang et al, 2010). A strain gauge is limited to certain shapes when it comes to strain measurement and can only be used once at a time which is the opposite in the case of the DIC system. Finally, preparation time is lesser in the DIC test as compared to extensometer placement (Górszczyk et al., 2019).

\subsubsection{Comparison of 2D-DIC and 3D-DIC}

The following table provides reviewed comparison of 2D-DIC and 3D-DIC from literature, to decide the choice of DIC system for this research work. 
Table 2.1

Benefits and limitations of two-dimensional and three-dimensional systems

\begin{tabular}{|l|l|l|}
\hline No. & 2D-DIC & 3D-DIC \\
\hline 1 & A single-camera acquires images. & $\begin{array}{l}\text { A stereo camera setup acquires } \\
\text { images. }\end{array}$ \\
\hline 2. & Captures only in-plane coordinates. & $\begin{array}{l}\text { Considers out of plane coordinates } \\
\text { too. }\end{array}$ \\
\hline 3. & $\begin{array}{l}\text { The camera needs to be positioned } \\
\text { perpendicular to the specimen. }\end{array}$ & Cameras can be placed at an angle. \\
\hline 4. & $\begin{array}{l}\text { Calibration is not required for image } \\
\text { analysis. }\end{array}$ & $\begin{array}{l}\text { Calibration is compulsory to analyze } \\
\text { images. }\end{array}$ \\
\hline 5. & $\begin{array}{l}\text { Image correlation error between different } \\
\text { frames (Nguyen, 2017). }\end{array}$ & $\begin{array}{l}\text { The error occurs in the } \\
\text { reconstruction of images from both } \\
\text { cameras (Nguyen, 2017). }\end{array}$ \\
\hline 6. & $\begin{array}{l}\text { Reduced computational complexity and } \\
\text { reduced analysis time (Gamboa B.et al., } \\
\text { 2019). }\end{array}$ & $\begin{array}{l}\text { Complex computation and more } \\
\text { analysis time. }\end{array}$ \\
\hline
\end{tabular}

There are benefits and limitations of both systems, based on their application. For instance, 3D-DIC gives larger uncertainty of displacement along the vertical direction as compared to 2D displacement for a membrane under inflation. Therefore, in case of high magnification or highly controlled environment, high-speed experiments,3D-DIC may not be the best choice (Nguyen, 2017). Similarly, for a 2D-DIC displacement of a larger field area, out-of-plane measurement and complex geometries would tend to give errored results.

\subsubsection{DIC for Strain Measurements}

DIC is extensively used in the testing labs for measuring in-plane strain during the tensile testing of material. Wang and coworkers observed tensile testing of sheet metal using a DIC system and found that DIC is capable of yielding accurate and reliable results. DIC demonstrated necking of the tensile specimen which is difficult to account for in conventional methods (Wang et al., 2010). 
Plastic zone of low carbon steel specimen was observed using DIC under uniaxial test and true stress-strain curves were obtained (Zhu et al., 2015). It was noticed that the region that has not entered the plastic zone stays in a constant deformed zone and the region that is in process of entering the plastic zone demonstrates axial plastic deformation due to displacement of the testing machine.

DIC is not limited to metallic materials. Researchers successfully carried-out testing of coupons made out of rock, soil, HMA (Hot-Mixed Asphalt), and geogrids under compression, bending, and indirect tensile tests (Górszczyk et al., 2019) .DIC was implemented to obtain residual stress evolution on composite with symmetric and asymmetric layups and accounted for dimensional inaccuracy during the cure cycle (Chava \& Namilae, 2021).

\subsubsection{Correction of Out of Plane Strain in 2D-DIC}

As observed in a comparison of 2D-DIC and 3D-DIC, 2D-DIC is quite sensitive towards out-of-plane translation, if the camera or specimen moves in the z-direction. It can result in pseudo-strains. Therefore, researchers have come up with innovations to mitigate the effect of out-of-plane translation and apply correction formulas to eliminate pseudo strain.

Researchers used pin-hole equation to obtain the translated image positions for known out-of-plane translation and calculated pseudo- displacements and pseudo strain which can be subtracted from total observed displacement and strain. They found out that if the camera is positioned to the maximum possible distance error occurring due to translation can be reduced (Sutton et al., 2008). 
Reseachers focused-on factors like geometric distortion of lens, self-healing, and temperature variation in camera which leads to error in strain measurement by DIC camera due to out-of-plane movements. They implemented standards DIC lens with a bilateral telecentric lens to compare the sensitivity of out-of-plane translation and found out that bilateral lenses yield insensitivity to those thermal and geometrical factors, giving accurate strain results as verified in an aluminum tensile test (Pan et al., 2013).

Tay and cowrkers proposed correction for apparent-in-plane displacement using pinhole camera equation and implemented them for strain calculation on a translated plate, cantilever beam loaded at free end and plate with steps and observed that this correction method yields accurate results. As described by one of the literature, there can be three ways in their research work to mitigate the effect of out-of-plane motion (Tay et al., 2005).

Firstly, by controlling the perpendicularity of the camera using external alignments, next, they implemented numerical alignment which transforms non-perpendicular image to perpendicular image. Finally, they compared results from these methods with results obtained by compensating apparent strain using the equation given by (Pan et al., 2013) and found out that compensating method yielded the most accurate result as compared to physical and numerical alignments (Wittevrongel et al., 2015).

\subsection{Summary}

From the background literature reviews, it is clear that additive manufacturing is the next generation fabrication method for the aerospace industry. However, certain flaws like defective printing lack of standardization, and limited part production need to be 
addressed in future research. One of those limitations, print defect, can be monitored through in-situ processes.

Real-time optical methods like, digital image correlation, Fiber Bragg Grating sensors, and thermocouples have been applied for instantaneous defect detection. Print parameters and printing conditions are two main contributing factors for the development of defects in 3D printed parts. In this thesis, a DIC-based in-situ monitoring method is developed, and parametric analysis of print parameters is conducted as described in the subsequent chapters. 


\section{Experimental Procedure}

The experimental methodology for in-situ monitoring of additive manufacturing can be divided into the following steps:

1. Set up of the 3D printer, DIC, and Thermal camera.

2. Monitor the strain and temperature evolution during printing of the PLA plate.

3. Analyze the images in VIC-2D software and Research IR.

4. Post-situ characterization using X-Ray microtomography.

\subsection{Material, Equipment, and Software}

This section presents list of equipments with their specification which were used to conduct all the experiments. Some equipments requires processing software along which has been included in this section as well. Finally, the correction formulas implemented to account for the out-of-plane translation of sample placed on print platfrom from DIC lenses have been presented at the end.

\subsubsection{Marble PLA}

Polylactic acid (PLA) is a popular 3D printing filament due to its numerous benefits such as availability of a range of colors, recyclability, corrosion resistance, inertness, low cost, and ease of manufacturing. The filament used here is Marble PLA with a black and white pattern on the filament, which is procured from Enotepad®. The black dots on the white background serve as speckles for the DIC analysis. Recommended print temperature and platform temperature ranges from $200^{\circ} \mathrm{C}-230^{\circ} \mathrm{C}$ and $60^{\circ} \mathrm{C}-80^{\circ} \mathrm{C}$ respectively. 


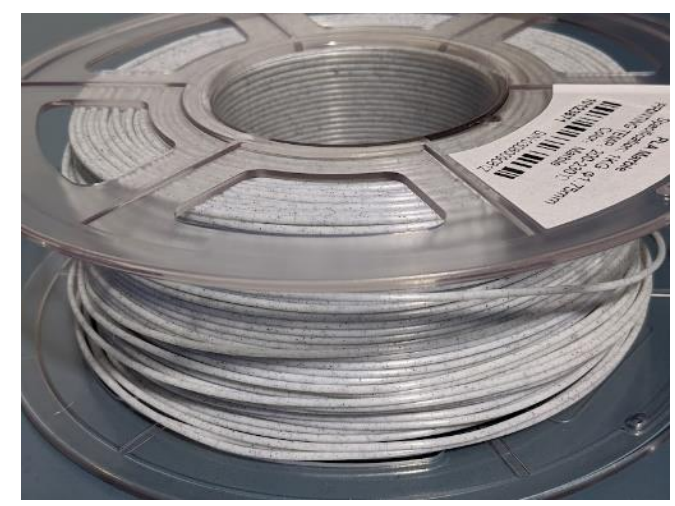

Figure 3.1. Marble PLA filament

\subsubsection{Differential Scanning Calorimetry (DSC)}

Differential Scanning calorimetry procured by METTLER TOLEDO® enables

physical properties of a material based on its property changes with respect to temperature. The melting point for PLA was obtained using a DSC setup. Based on the average of two tests, the melting point of the sample used in this research ranges between $150^{\circ} \mathrm{C}-160^{\circ} \mathrm{C}$ as illustrated in Figure 3.3.

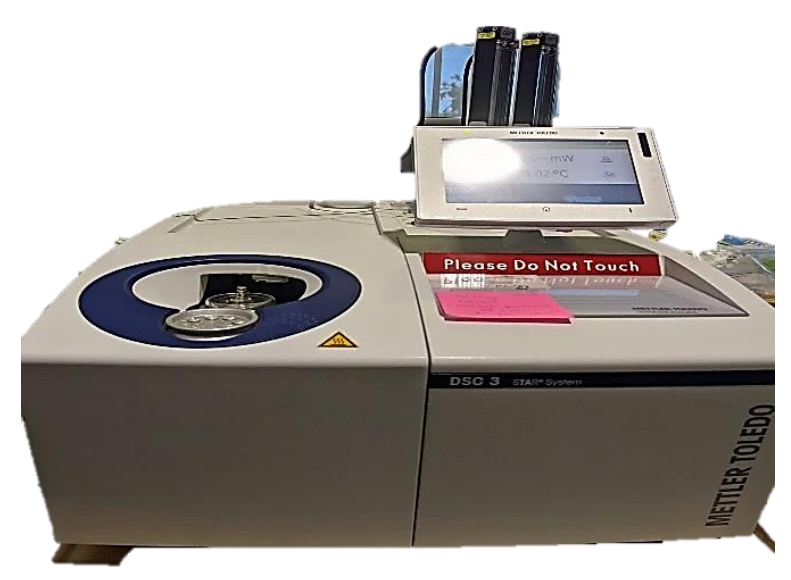

Figure 3.2 DSC machine to obtain melting point of PLA 


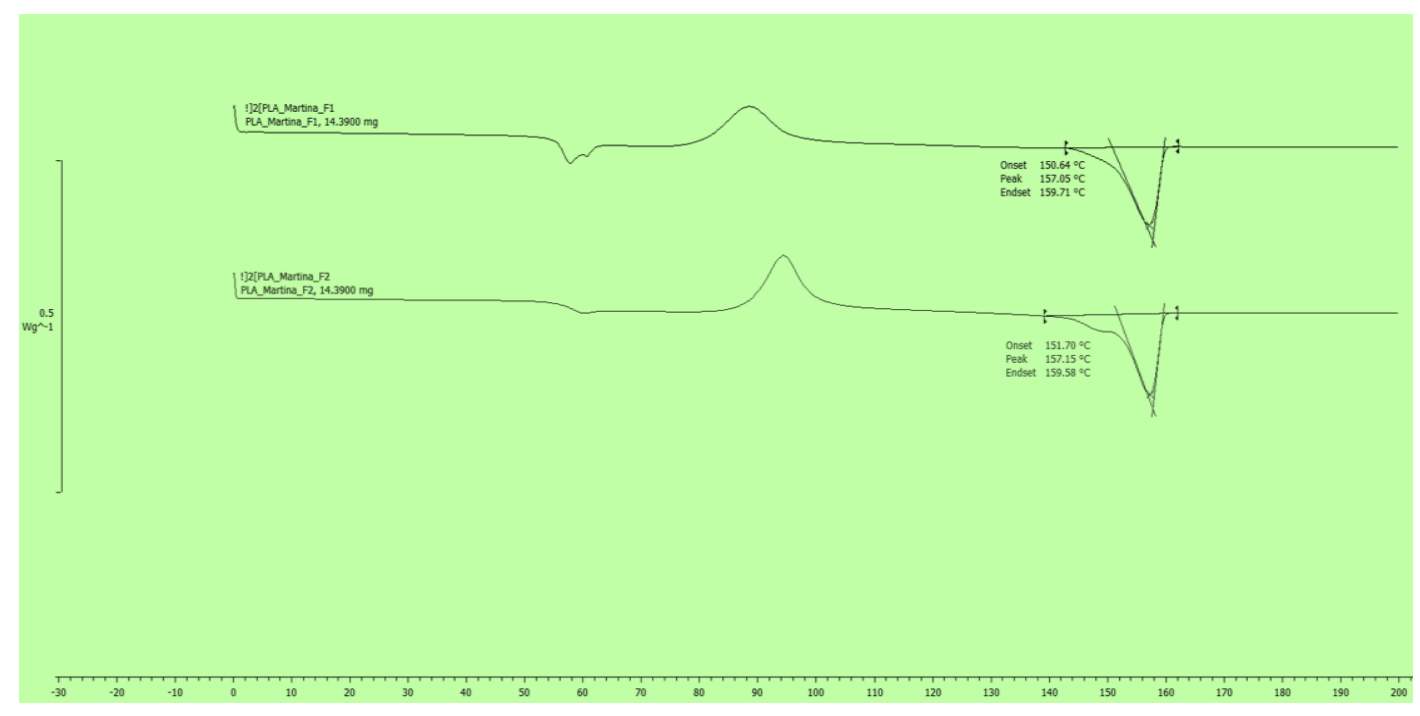

Figure 3.3 Melting temperature range obtained through DSC

\subsubsection{Creality Ender 5 Plus 3D Printer}

Ender 5 Plus 3D printer enables a maximum print size of $350 \mathrm{~mm} \times 350 \mathrm{~mm} \times 400$ mm. It is an FDM-type printer with a print accuracy of $+/-0.1 \mathrm{~mm}$. Few other features like dual $\mathrm{Z}$ axes, BL touch, and filament sensor helps to ensure good print quality. The outer frame structure makes it convenient to set up the DIC and thermal camera around it.

Creality slicer 4.8.0 has been used to convert the CAD model to a G- Code which guides machine tool movements in the direction of CAD model shape. Features like layer height, print speed, print temperature, and various print-related settings have been updated using this software.

Creality slicer has also played an important role to accommodate dwell time after printing each section of each layer to enable real-time strain evolution of the PLA sample. 


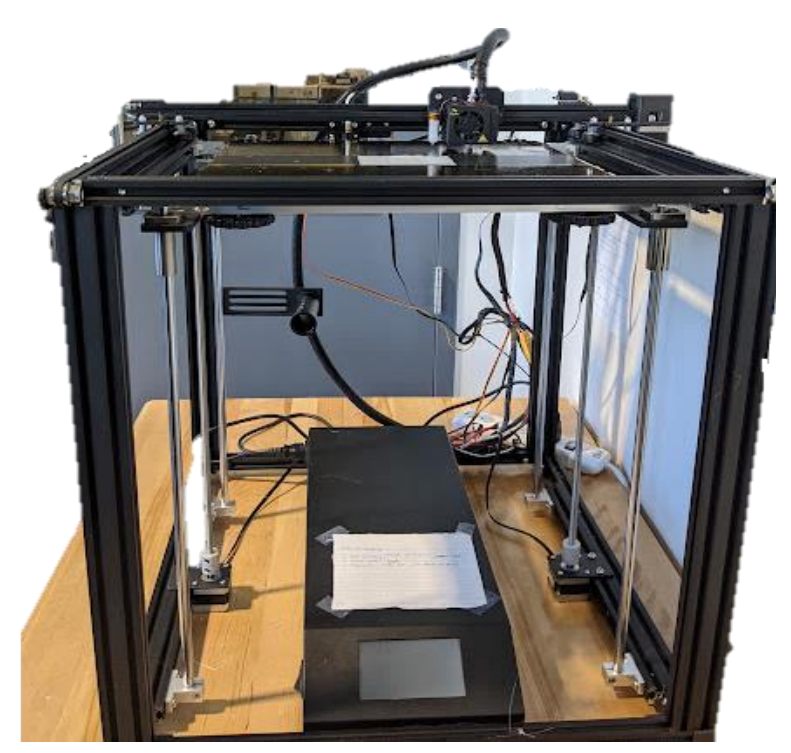

Figure 3.4 Creality Ender 5Plus 3D Printer

\subsubsection{DIC Lens and Camera}

DIC camera with an in-plane resolution of $0.00002 *$ Field of View (FOV) and strain range $0.010 \%$ to $>2000 \%$ has been used along with a lens of $50 \mathrm{~mm}$ focal length. This 2D DIC system is manufactured by Correlated solutions and includes VIC-Snap acquisition software which can capture images at set time interval.

VIC-2D is the analysis software which uses the imgae captured by VIC-Snap for further anlaysis. In case of 2D-DIC no calibration is required, hence, first image is chosen as the reference image and dimension of the length of specimen was defined in software. Next, area of unteres, where strain evolution has to be observed for is sleected and starting point of analysis is picked. This software calculated for the deformationa and further post-processing tools enable strain analysis for the sample along $\mathrm{x}$ and $\mathrm{y}$ direction respectively. 


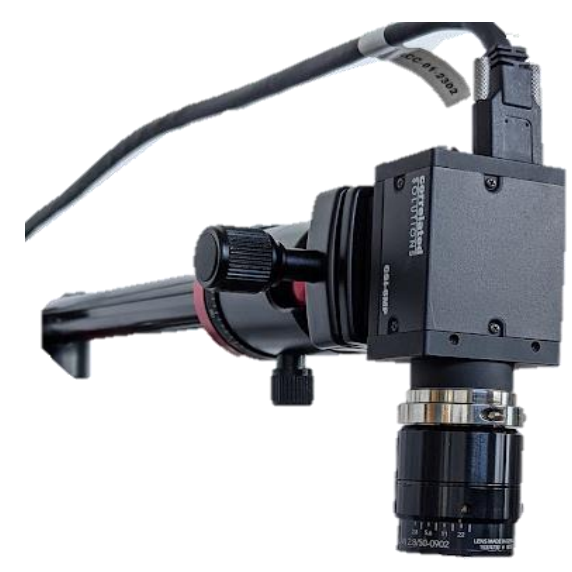

Figure 3.5 Monochromatic DIC camera and lens

\subsubsection{Laser Displacement Sensor}

MICROTRAK 4 laser displacement sensor encompasses position sensitive device and laser light-emitting source and measures the thickness, height, vibration of the target object. In this case, the laser displacement sensor was used to measure the layer thickness of the PLA sample to verify the print accuracy as that thickness was used to eliminate out-of-plane displacement error caused in 2D DIC.

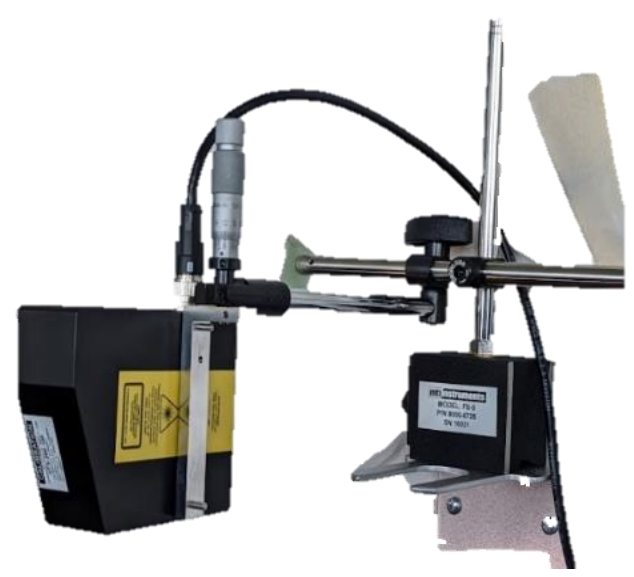

Figure 3.6 Laser displacement sensor 


\subsubsection{Infrared Camera}

An Infrared camera captures the temperature of an object based on infrared energy intensities of the heat-emitting object. FLIR A655 SC thermal camera was used to capture the temperature and cooling rate of part in real-time. This camera is capable of capturing temperature ranges from $-40^{\circ} \mathrm{C}$ to $650^{\circ} \mathrm{C}$ with an accuracy of $+/-2 \%$. The resolution of this camera is $640 \times 480$ with an f-number value of 1 . Research IR software allows capturing thermal images and post-processing them to obtain localized temperature distribution.

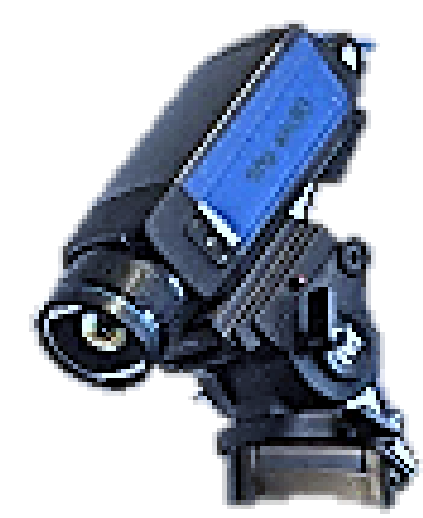

Figure 3.7 Infrared camera

\subsubsection{SKYSCAN X-Ray Microtomography Machine}

Defects like porosity, line defect in PLA samples during printing and curing were observed in the SKYSCAN X-ray microtomography machine after processing. The selected region from the sample was cut out and placed on a rotary stage to obtain 360 degrees view of the section. As PLA has a relatively low density, a low input voltage of $30 \mathrm{~V}$ was selected for the X-ray source. 


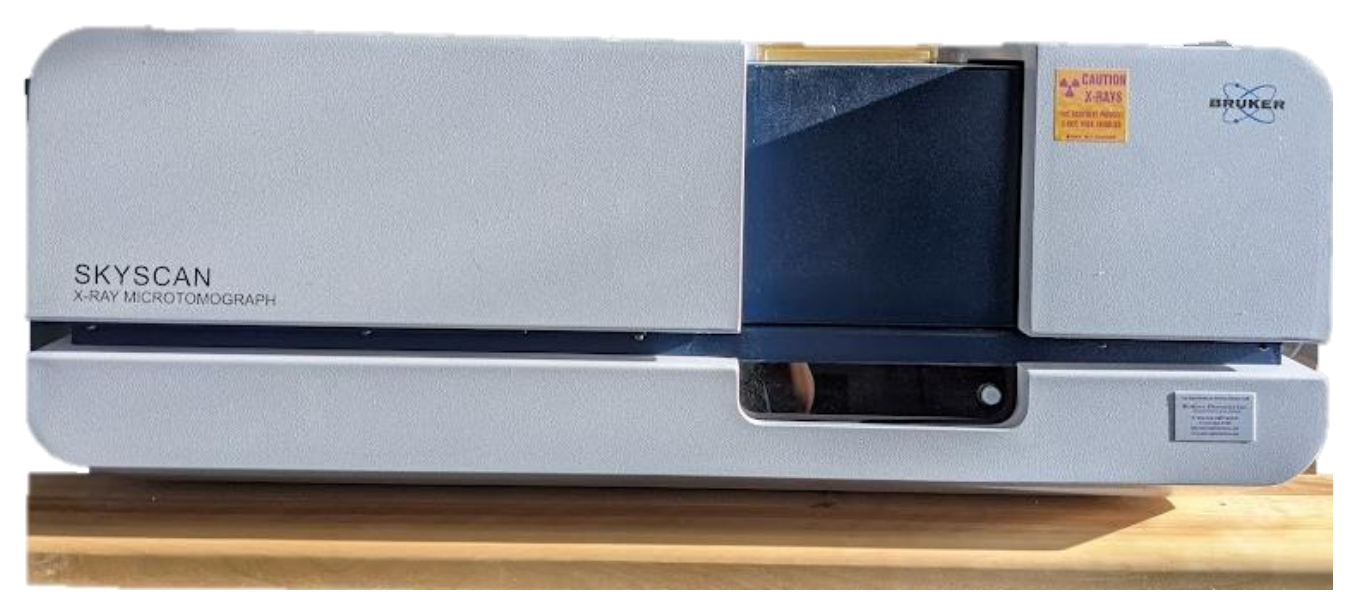

Figure 3.8 X-Ray Tomography

\subsection{Setup}

Two different setups were used for real-time observation of 3D printing. The first setup observes strain in actual time whereas the second setup repeats previously performed an experiment to observe temperature evolution as the specimen gets printed.

\subsubsection{Setup for In-Situ Strain Observation}

Figure 3.9 depicts a setup with a DIC camera placed perpendicularly on the printer to avoid any distortion of strain in captured images. External light source on the left side has been provided to have better exposure during any time of the day. Laser displacement sensor focuses on print bed to measure the layer thickness which 2D-DIC cannot measure.

Sample has been set to be printed at the center of the platform, assuming uniform heat distribution of platform temperature. Laser sensor need to be operated through it's software to plot fluctuations along Z-direction with respect to time. Hence, external computer system was used with the setup. 


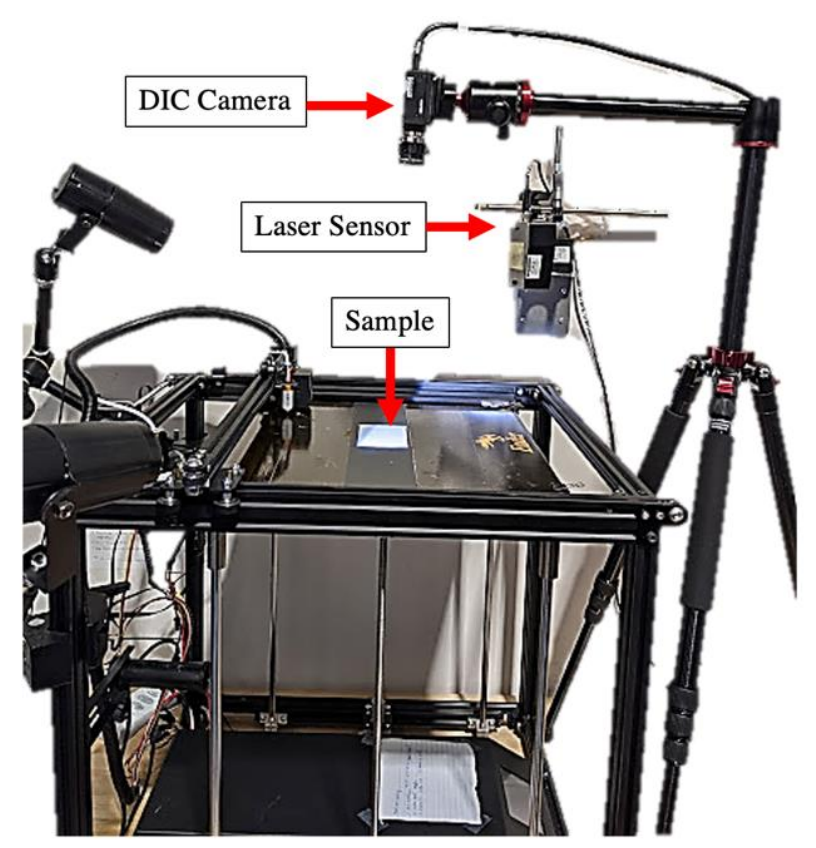

Figure 3.9 Print setup with DIC and Laser sensor

\subsubsection{Setup for In-Situ Temperature Observation}

The specimen was observed for temperature evolution in real-time using an infrared camera. The algorithm for specimen observation was kept the same as in the first setup, while the DIC camera was replaced by FLIR A65SC as revealed in Figure 3.10. In this case external light source and laser displacement sensor were not required.

This setup requires the infrared camera to be operated through the Research IR software. Hence external computer system was used along with this setup which can capture the images through software in real-time and can also select the region of interest to get focused temperature evolutionin each section. Specimen is again positioned at center of the platfrom to capture the effect of set platfrom and print temperatures. 


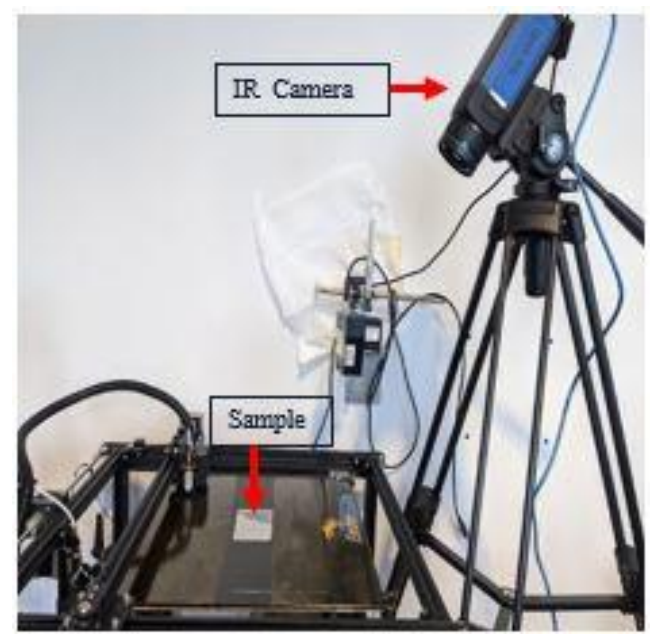

Figure 3.10 Infrared camera capturing thermal data.

\subsection{Print Algorithm}

To observe the additive manufacturing of PLA in real-time it is necessary to synchronize the camera timing with extruder movement. Otherwise, it is difficult to capture a specimen when the extruder is on top of it so a unique algorithm has been programmed which allows the extruder to move away from the camera frame and dwell for 5 seconds while the camera captures the printed section. Here each layer of size 96 $\mathrm{mm} \times 60 \mathrm{~mm} \times \mathrm{H} \mathrm{mm}(\mathrm{H}$ is varies based on layer resolution) has been divided into three sections of the same size.

Therefore, the extruder prints one section dwells for 5 seconds and comes back to print the next section. This process repeats until all the nine sections for layers are printed. Figure 3.11 schematically shows the print algorithm for the first layer with three sections. The leftmost figure can be named as Section 1 layer 1, the middle figure as Section 2 layer 1, and similarly the rightmost figure as Section 3 layer 1. Likewise, Figure 3.12 depicts the same print algorithm for layer 2 as follows: 

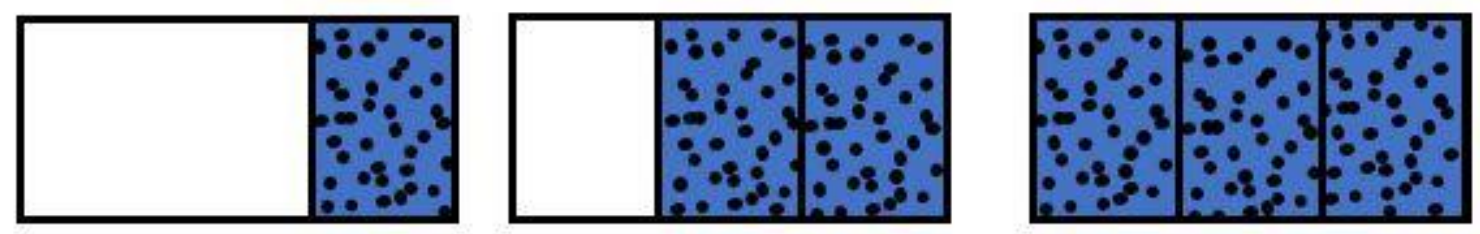

Section 1, Layer 1

Section 2, Layer 1

Section 3, Layer 1

Figure 3.11 Print Algorithm for Layer 1

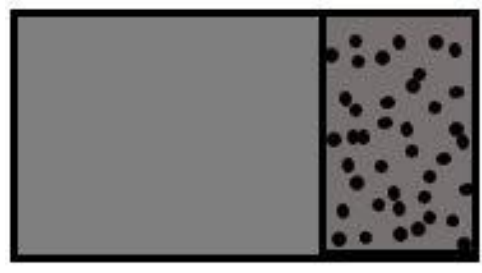

Section 1, Layer2

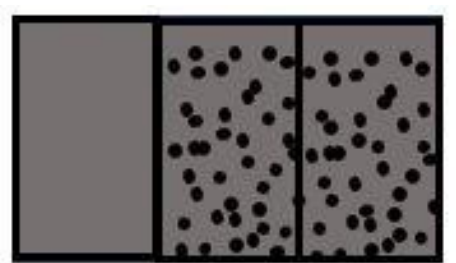

Section 2, Layer2

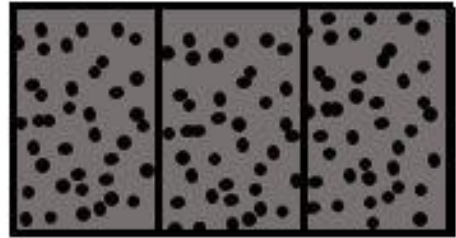

Section 3, Layer2

Figure 3.12 Print Algorithm for Layer 2

\subsection{Correction of Out-of-Plane Strains}

2D DIC consists of only one lens and therefore it can't capture the depth or height of the specimen. However, in additive manufacturing, whenever a new layer is added, the print bed shifts downwards by a distance of layer height to accommodate the next layer on the already printed layer.

Therefore, strain captured by 2D camera contains some error included in it as specimen goes out of the plane. But it is possible to account for those pseudo strains and subtract them to obtain true strain. Sutton et al. (2008) have demonstrated calculation of out-of-plane errors using the pinhole equation (see Equation 3.1). 


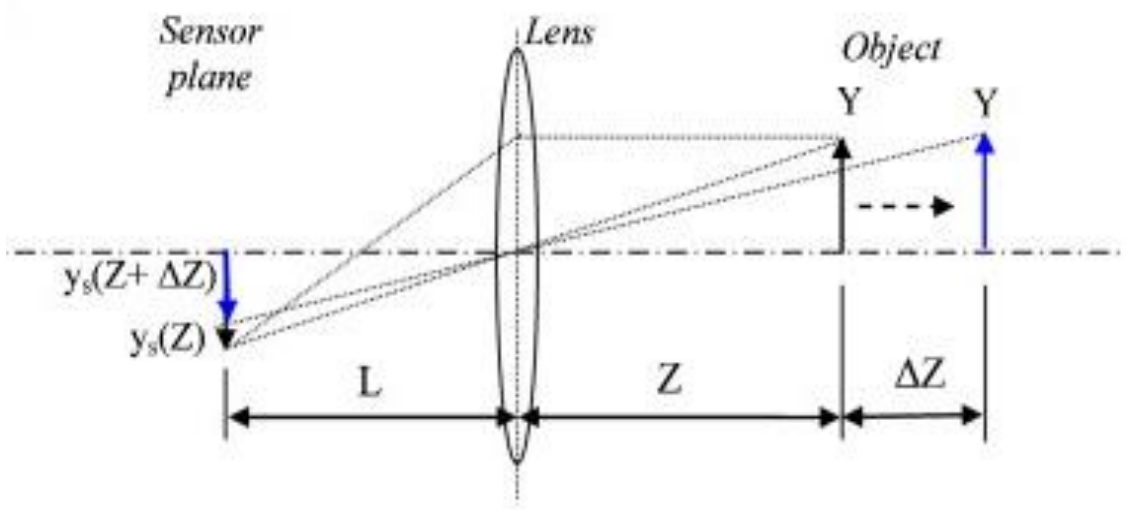

Figure 3.13 Out-of-Plane Translation of Image, (Michael et al ,2008).

Here, $\mathrm{Z}$ is the distance between object and lens, $\mathrm{L}$ is the distance between focal plane where image forms and lens and $\Delta \mathrm{Z}$ is the out of plane translation.

Now, if we consider $(\mathrm{X}, \mathrm{Y})$ as object dimensions and $\left(\mathrm{x}_{\mathrm{s}}(\mathrm{Z}), \mathrm{y}_{\mathrm{s}}(\mathrm{Z})\right)$ as inplane image dimensions, it can be obtained by implementing the lens formula as follows:

$$
\begin{aligned}
& x_{S}(Z)=-\frac{L}{Z} X=M_{T} X \\
& y_{s}(Z)=-\frac{L}{Z} Y=M_{T} Y
\end{aligned}
$$

Here, $M_{T}=-\frac{L}{Z}$ is the true magnification factor. But here the object has been translated out-of-plane by $\Delta \mathrm{Z}$ distance. Therefore, updated image distance can be calculated as:

$$
\begin{aligned}
& x_{S}(Z+\Delta Z)=-\frac{L}{Z+\Delta Z} X \approx-\frac{L}{Z} X\left(1-\frac{\Delta Z}{Z}\right) \\
& y_{S}(Z+\Delta Z)=-\frac{L}{Z+\Delta Z} Y \approx-\frac{L}{Z} Y\left(1-\frac{\Delta Z}{Z}\right)
\end{aligned}
$$


Now, out-of-plane displacements can be calculated by subtracting the original displacements from errored displacements as shown below:

$$
\begin{gathered}
U(\Delta Z)=x_{s}(Z+\Delta Z)-x_{s}(Z) \\
\approx-\frac{L}{Z} X\left(-\frac{\Delta Z}{Z}\right)=x_{s}\left(-\frac{\Delta Z}{Z}\right) \\
V(\Delta Z)=y_{s}(Z+\Delta Z)-y_{s}(Z) \\
\approx-\frac{L}{Z} Y\left(-\frac{\Delta Z}{Z}\right)=y_{s}\left(-\frac{\Delta Z}{Z}\right)
\end{gathered}
$$

Finally, based on displacements, strain due to out-of-plane translation can be obtained as follows:

$$
\begin{aligned}
& \Delta \varepsilon_{x x}=\frac{\partial U(\Delta Z)}{\partial x_{s}} \approx \frac{(\Delta Z)}{Z} \\
& \Delta \varepsilon_{y y}=\frac{\partial V(\Delta Z)}{\partial y_{s}} \approx \frac{(\Delta Z)}{Z}
\end{aligned}
$$

These changes in strain due to out-of-plane translation are subtracted from total strain to obtain the original strain.

\section{Table 3.1}

Test Matrix

\begin{tabular}{|l|l|l|}
\hline Run & $\begin{array}{l}\text { Layer thickness } \\
(\mathbf{m m})\end{array}$ & $\begin{array}{l}\text { Print } \\
\text { Temperature }\left({ }^{\circ} \mathbf{C}\right)\end{array}$ \\
\hline Run 1 & 0.15 & 185 \\
\hline Run 2 & 0.2 & 185 \\
\hline Run 3 & 0.25 & 185 \\
\hline Run 4 & 0.15 & 200 \\
\hline Run 5 & 0.2 & 200 \\
\hline Run 6 & 0.25 & 200 \\
\hline Run 7 & 0.15 & 215 \\
\hline Run 8 & 0.2 & 215 \\
\hline Run 9 & 0.25 & 215 \\
\hline
\end{tabular}


The above Test Matrix is created considering printer capacities and PLA

properties. For all the tests, print speed was set to $60 \mathrm{~mm} / \mathrm{s}$ and print bed temperature was fixed to $60^{\circ} \mathrm{C}$ as recommended by PLA manufacturer ( Enotepad®). 


\section{Experimental Results}

This section provides strain and temperature data obtained from real-time observation of 3D printing of thermoplastic rectangular samples. Data has been processed in MATLAB and MS Excel. Here sections for each layer are named as Section 11, Section 21, and so forth, where the first number represents layer, i.e., layer 1, layer 2, and layer 3, the second number represents each section respectively.

The beginning part of this section discusses the defects observed while printing and their ideal plots without defects. Next, the cure pattern for each specimen at varying temperatures and thickness has been discussed with strain contours. Followed by that temperature evolution using the infrared camera is presented. Finally, a comparison of strain evolution for a combination of three different print temperatures and three different layer thicknesses is reported.

\subsection{Detecting Print Defects Using DIC}

Warping is a commonly observed phenomenon in $3 \mathrm{D}$ printed parts due to the rapid cooling of material deposited on the platform, which causes the material to shrink and lift off from the print bed. There can be several reasons for warping, such as speed of the cooling fan, absence of raft, poor deposition of material on the print bed and, external factors like surrounding temperature and airflow. However, the prominent reason for warpage is insufficient print platform temperature settings.

In this case, the platform temperature was set to $60^{\circ} \mathrm{C}$ as required for PLA. But, since the location of setup is near to door which is frequently in use caused this defect in the section along the edge of the bed. 
Real-time monitoring of part enabled capturing this phenomenon in the final layer final section. Even though the defect is visible as it was on the final layer, it was possible to monitor when exactly the specimen started to warp using the in-situ approach.

Following Figure 4.1 reveals compressive strain observed in the plot of strain along the $\mathrm{x}$-direction for Section 31 with respect to time.

It is noticeable that all sections in all the three layers expand over time whereas in the final layer warping causes shrinkage of specimen in that area. A similar trend was observed for strain in the y-direction as well.

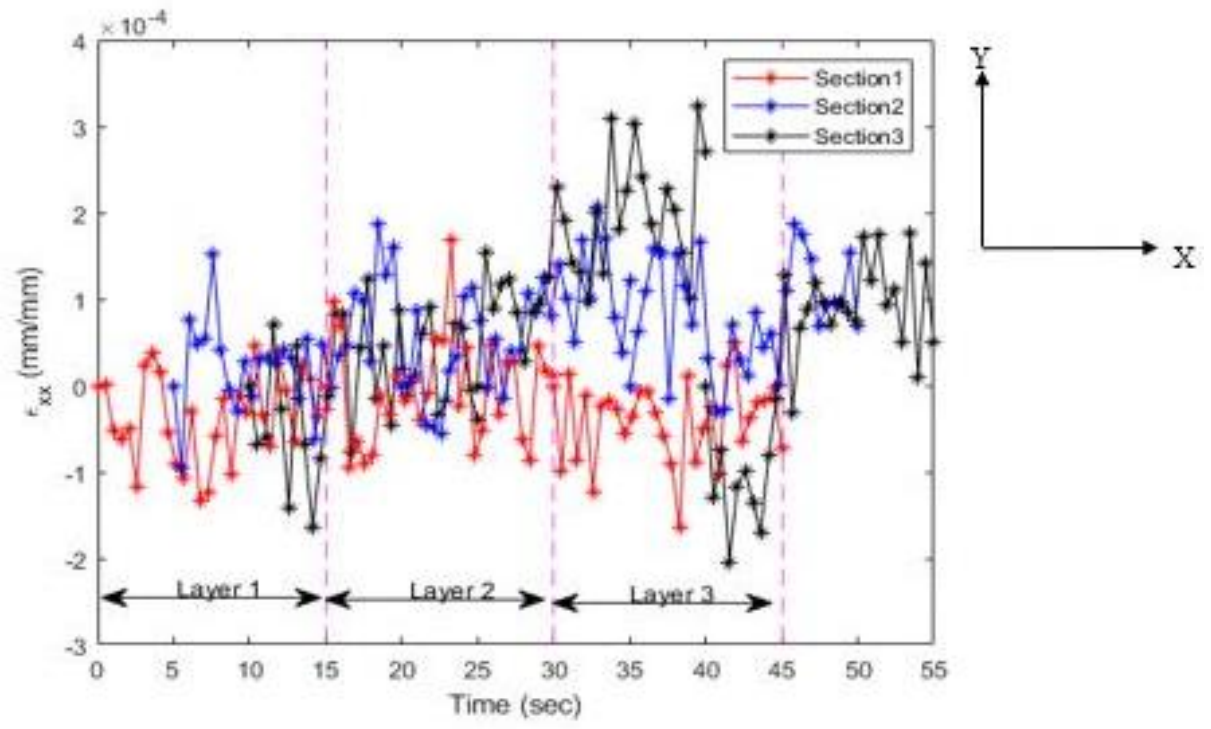

Figure 4.1 Compressive Strain in Section 31 along X- direction

Shrinkage in PLA specimen was observed in VIC-2D analysis also, as exhibited in following Figure 4.3 with compressed iso-lines and its corresponding image captured by DIC camera. In-situ and ex-situ methods have their individual benefits. It is difficult to 
account for minor warping in x-ray tomography of the specimen, but a real-time observation made it possible to capture it.

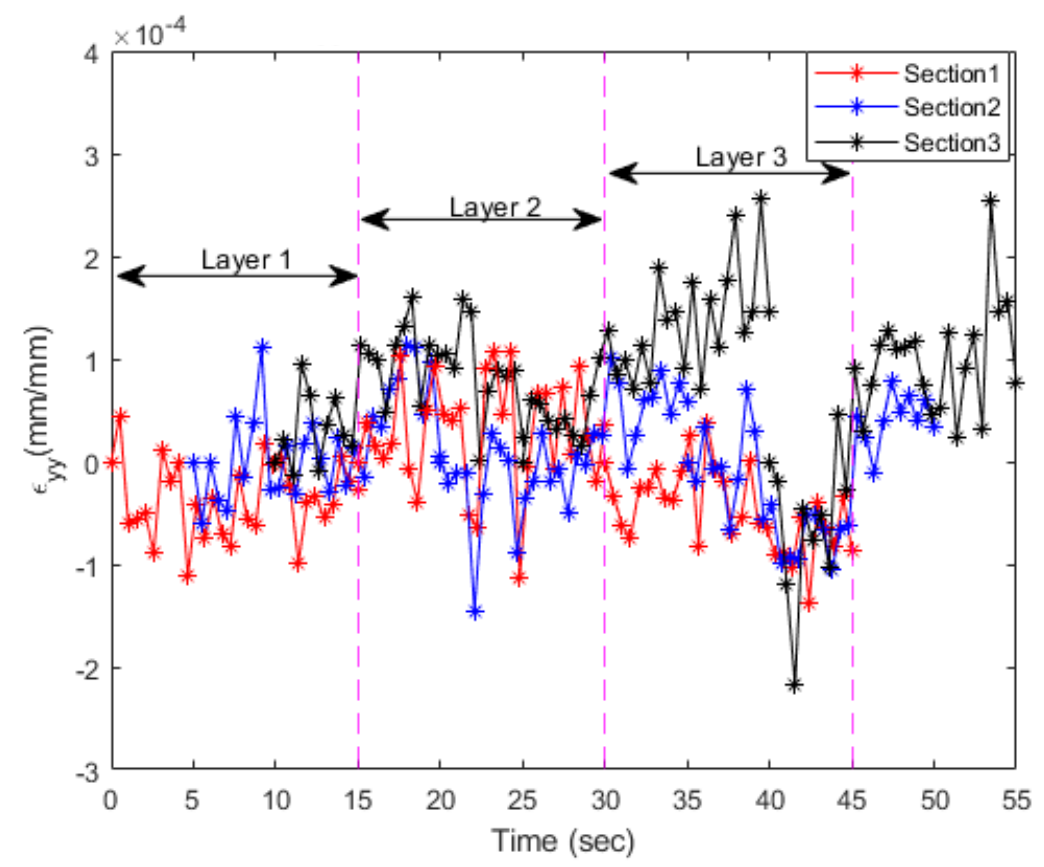

Figure 4.2 Compressive Strain in Section 31 along Y-direction

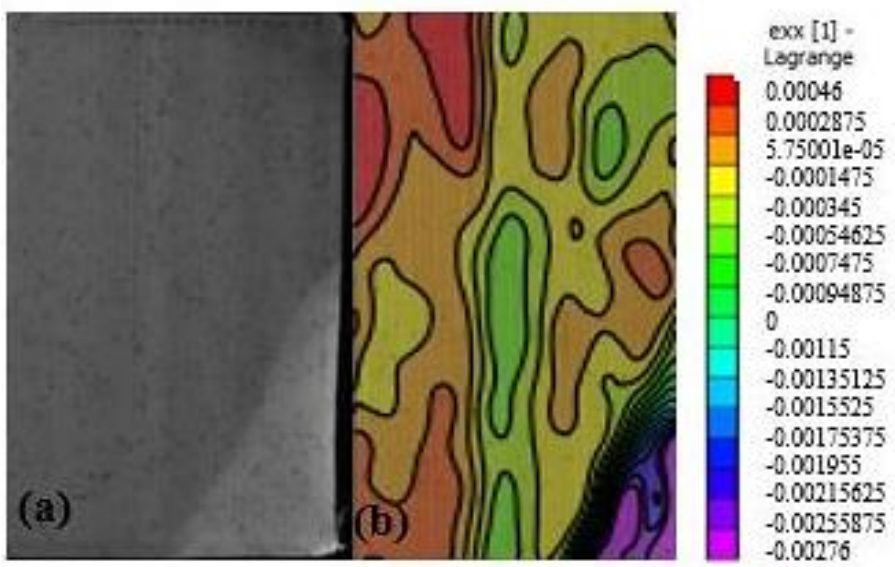

Figure 4.3 (a) Warping Captured by DIC (b) Compressive X-strains through Analysis 
Additionally, under-extrusion was observed in the middle section of one of the specimens printed at $200^{\circ} \mathrm{C}$ with $0.15 \mathrm{~mm}$ layer resolution. Missing material can occur due to a clogged nozzle, a high print speed that gives less deposition time, improper print temperatures, incorrect $\mathrm{z}$-axis compensation, and so forth.

In this case, this defect was observed in the middle section for layer 2 and layer 3. The reason for this defect could be a change in the change in nozzle leveling as this defect was not observed in the other two repeated tests but was only observed for one test.

The material tends to shrink along the area where there was under extrusion. As shown in the following strain vs time plot for $\mathrm{x}$-direction strain, compressive strains are visible for layer 2 and layer 3 . An interesting observation here was that even though the defect was present, strain along y-direction remained unaffected by this defect which could be credited to the printing direction of the specimen which is always vertical.

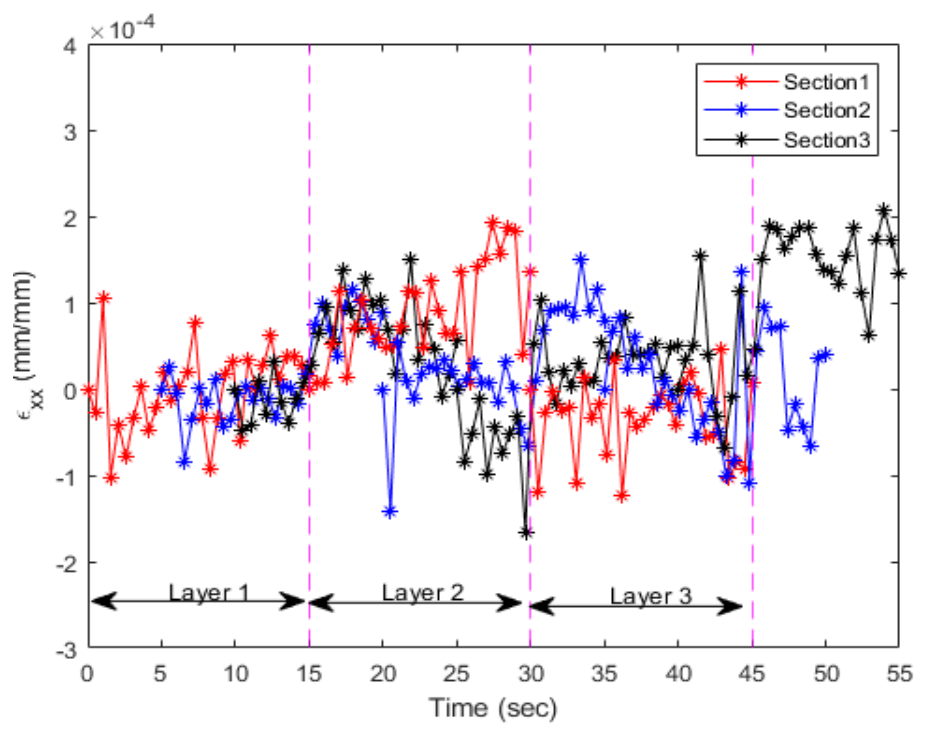

Figure 4.4(a) Strain along X-Direction 
Figure 4.5 shows missing material along y-direction (vertical print direction) and its corresponding compressive strain contour in that whole region. Figure 4.6 shows the XRay tomography obtained for the same section and exhibits reflection of radiation in the region where the material has not been extruded.

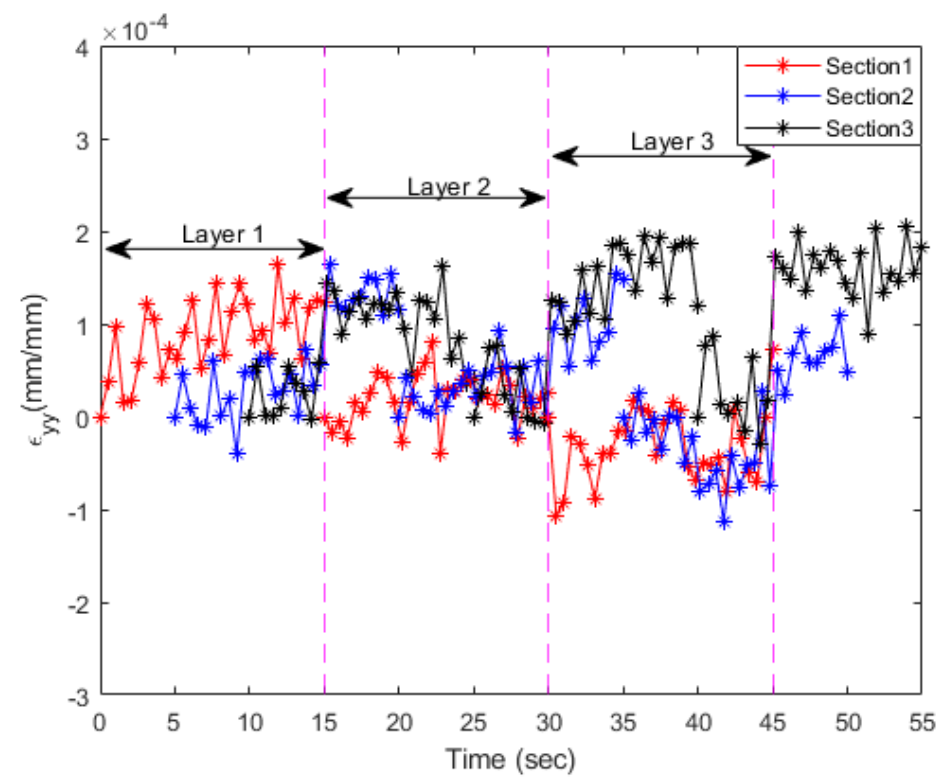

Figure 4.4 (b) Strain along Y-direction
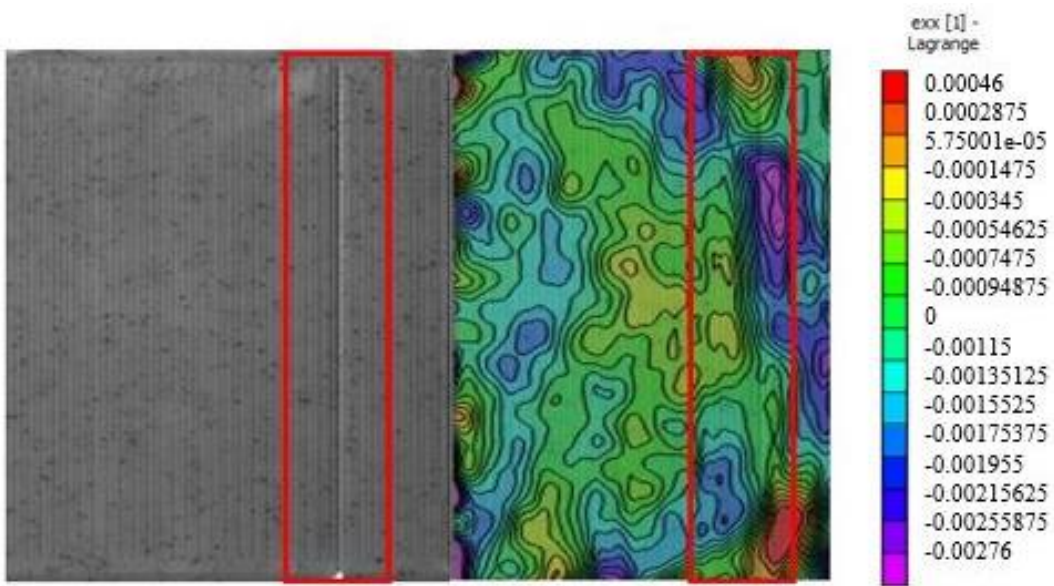

(a)

(b)

Figure 4.5(a) Under-Extrusion in Section 2 through DIC Camera $(b)$ Under-Extrusion in Section 2 through Analysis. 


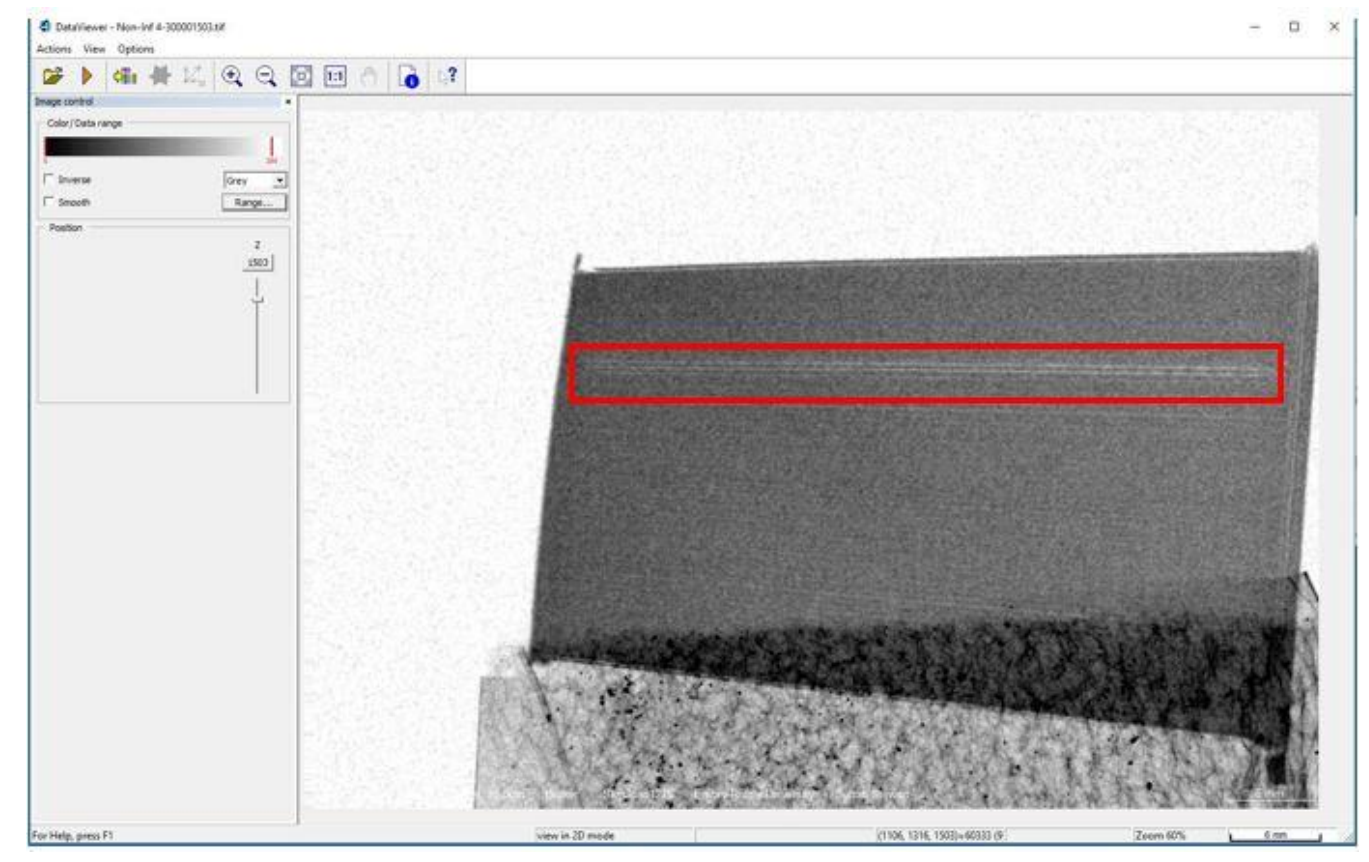

Figure 4.6 X-Ray image for under-extruded section placed horizontally

\subsection{Investigation of In-Situ Deformations}

This section presents the cure pattern of the PLA sample in terms of deformation and strain. Uneven cooling of polylactic acid depends on printing conditions. In this case total of nine different combinations have been selected as per the test matrix. Each test has been repeated three-time and an average result of all the tests has been presented here.

In order to clearly observe the strain evolution over time, each layer has been divided into three sections. Plots presented here depict strain evolution for each section up to three layers for all the 27 observed specimens. Error bars have not been included in this case to clearly represent data along the $\mathrm{x}$ and $\mathrm{y}$ direction for nine different sections in a single plot. Figure 4.6 schematically shows the different sections for subsequent analysis. Stain plots for each thickness at $185^{\circ} \mathrm{C}$ are discussed in detail. Other similar plots are reported in Appendix. 


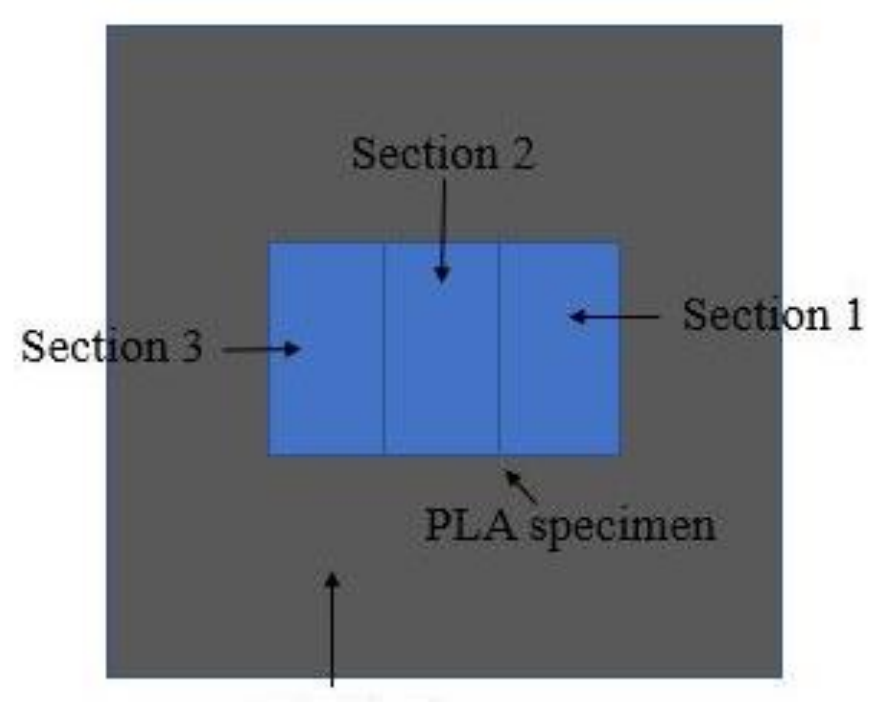

Print bed

Figure 4.7 Location of Each Printed Section

\subsubsection{Deformations in the Specimen with $0.15 \mathrm{~mm}$ Thickness}

Specimen with $0.15 \mathrm{~mm}$ thickness was monitored for strain development along $\mathrm{x}$ and y directions. Section 1 which is plotted with a red marker, has an increasing strain in a positive direction for each layer. Compared to the previous layer, the subsequent layer exhibited higher strain.

For Sections 2 and 3 represented in blue and black ink, changes in deformations again exhibited a similar increasing trend. The strain was observed over layers for each respective section, which increased in layer 2 but dropped down a little in the final layer as shown in Figure 4.8.

Next, observing the strain evolution in y-direction for the same specimen, it was seen that strain is expanding over time for all the three sections in the first two layers. In case of Y-direction strains, as the next layer gets added to each section, strain in the new layer 
begins from lower strains as compared to the previous layer and goes to a higher limit than in the previous layer.

Also, it was found that strain along y-direction ranges from -0.0002172 to 0.0002555 , and for $\mathrm{x}$-direction, it ranges from -0.0002044 to 0.0003242 , which means strain range along the $\mathrm{x}$-direction is $21 \%$ higher than along $\mathrm{y}$-direction, which is because the specimen is printed along the $\mathrm{y}$-direction. A larger strain in the $\mathrm{x}$-direction can be related to more expansion of specimen in the $\mathrm{x}$-direction to nucleate with adjacent sections. Increment in y strain can be related to the tendency to nucleate with the boundary which is printed before each layer.

Strain contours can help to understand higher and lower strain distributed across the area of interest, due to thermal cooling as shown in Figure 4.8 and Figure 4.9.

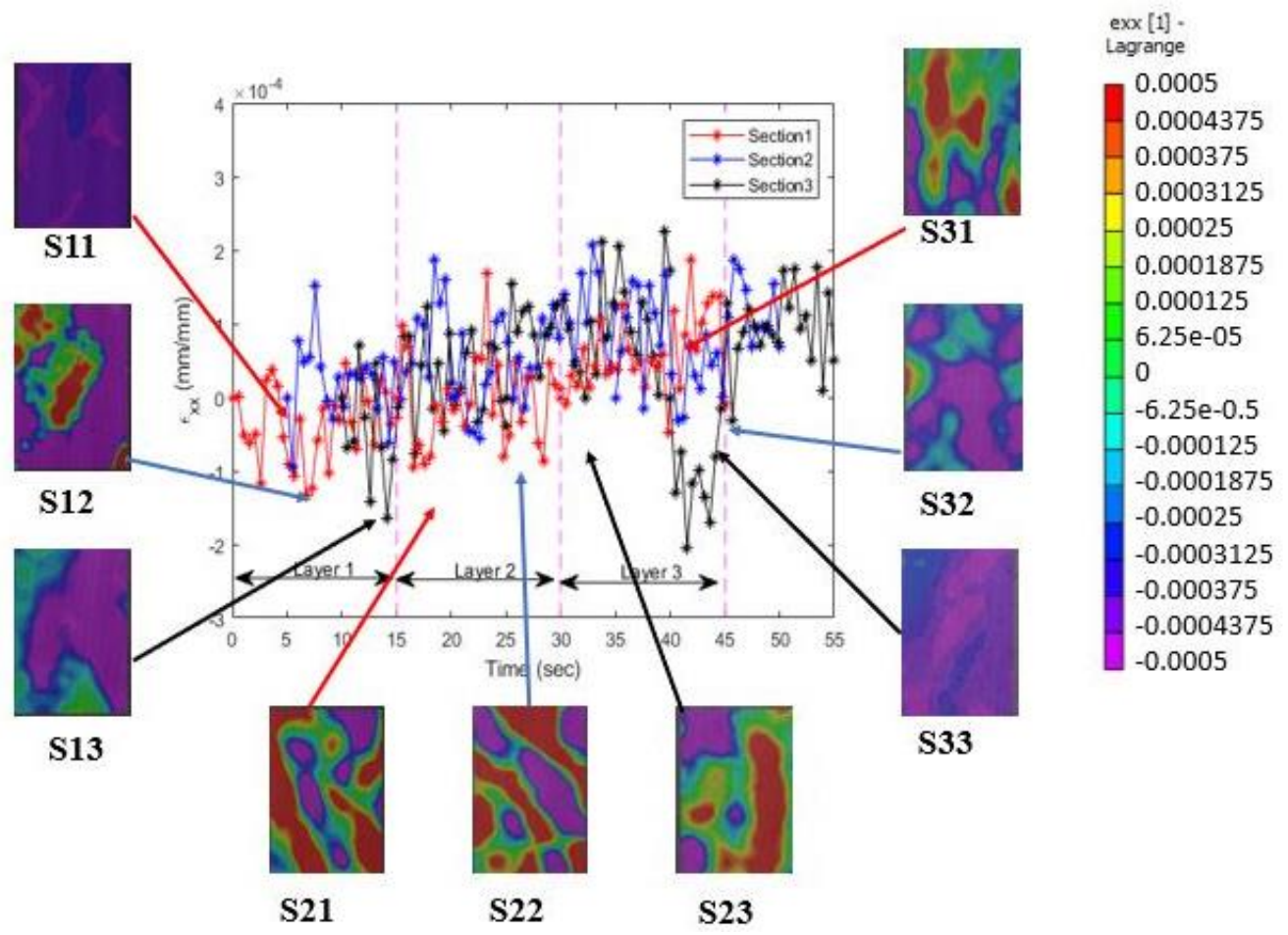

Figure 4.8 Strain Contours along the X-Direction. 

previous layer.

Strain evolution for the specimen with a layer resolution of $0.15 \mathrm{~mm}$ at $200{ }^{\circ} \mathrm{C}$ was observed. For each section at every layer, the strain was increasing with respect to time along $\mathrm{x}$ and $\mathrm{y}$-directions. In the case of $\mathrm{x}$ strains for Section 1, the final layer strain dropped down. In Section 2 and Section 3 strain for added layer begins from the average value of the previous layer stain and goes a little beyond the maximum strain of the

Likewise, strain along the y-direction for specimen with $0.15 \mathrm{~mm}$ layer height at $200^{\circ} \mathrm{C}$ also revealed increment with time. For Section $1, \epsilon_{y y}$ reduced in magnitude over the addition of layer. Whereas, Section 2 and Section 3 strains did not change much, adding layers. Also, strain magnitude for Section 2 and Section 3 was similar.

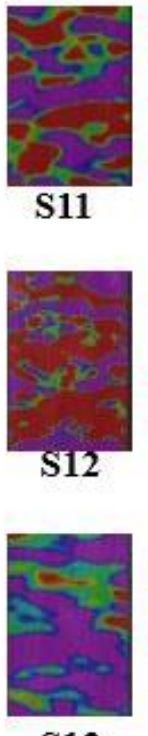

S11
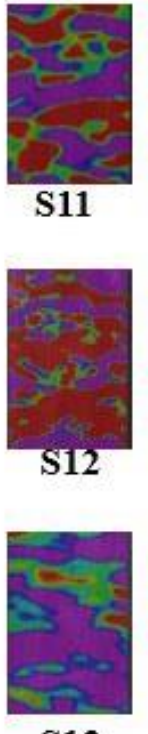

S13
S21
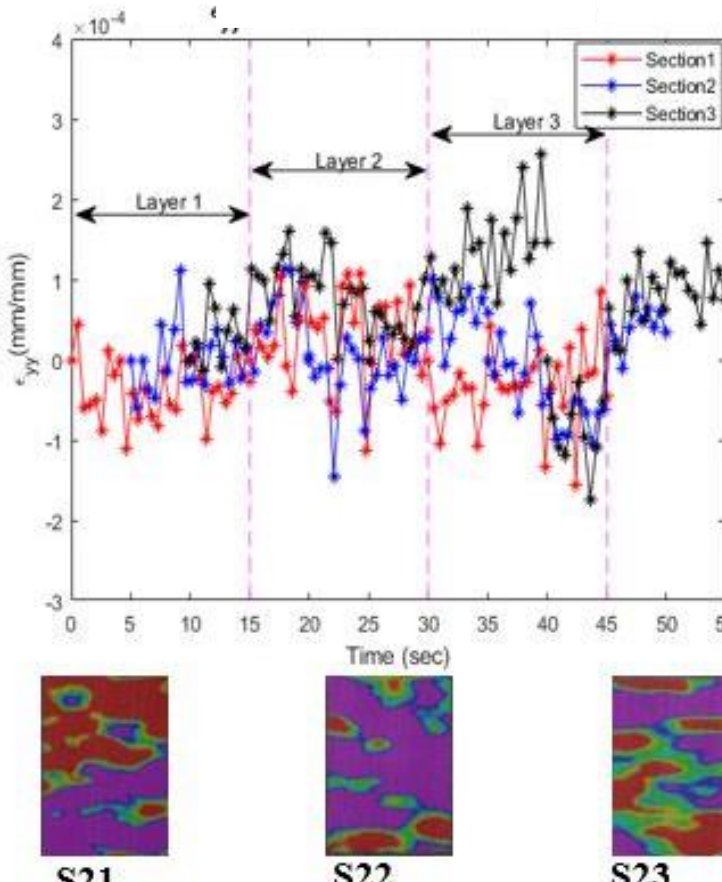
(1)
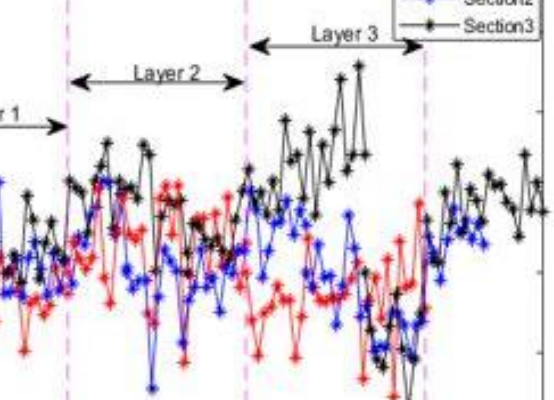

Figure 4.9 Strain Contours along the Y-Direction. eyy [1] -

Lagrange

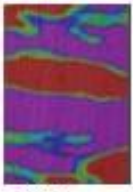

S31

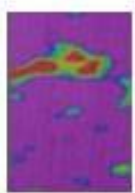

S32
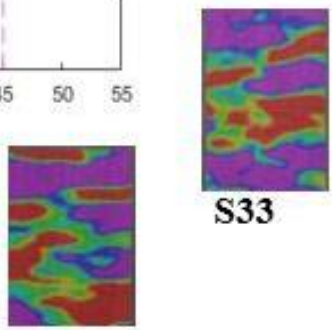

S33
0.00025

0.00021875

0.00015625

0.000125

9.375e-05

6.25e-05

3.125e-05

6.25e-05

0

$-3.125 e-05$

$-6.25 e-05$

$-9.375 e-05$

$-0.000125$

$-0.00015625$

$-0.0001875$

$-0.00021875$

$-0.00025$ 
Finally, the cure pattern was observed for the same specimen with $215^{\circ} \mathrm{C}$ print temperature. In this case, strain along the $\mathrm{x}$ and $\mathrm{y}$ direction in both the sections was increasing over time. But, for Section 3 compression in strain was observed in $\epsilon_{x x}$ and $\epsilon_{y y}$.

To summarize all the strains observed at temperatures $185^{\circ} \mathrm{C}, 200^{\circ} \mathrm{C}$, and $215^{\circ} \mathrm{C}$ were increasing for the specimen with the lowest thickness. The reason for expansion can be the lateral print direction and the influence of temperature on the thinner part. Strains in most cases for the final layer drop down because the final layer is not in direct contact with the hot platform, and the bottom layers would already start solidifying by the time the third layer is printed.

\subsubsection{Deformations in the Specimen with $0.20 \mathrm{~mm}$ Thickness}

Strain evolution for specimens with $0.20 \mathrm{~m}$ layer height was observed at three different temperatures. Strains are expanding for all sections and all layers for 0.20-layer height at $185^{\circ} \mathrm{C}$. The magnitude of strain along x-direction was higher in the bottommost layer for all three sections. For middle layer strain for all three sections was almost in a similar range and were not expanding with higher fluctuation like layer 1 . In the final layer strain for all the three sections dropped considerably as revealed in Figure 10.

Strain along the $\mathrm{y}$-direction is again smaller in magnitude as compared to the $\mathrm{x}$ direction strain and they exhibit an increasing trend. As observed in X-direction strains, for the bottommost layer strain magnitude was highest in all the respective sections which were reduced for upper layers. On the contrary, strain fluctuations decreased, and the magnitude of strain was almost consistent for all the sections in the next two layers. 
Strain evolution for the same specimen with a $15^{\circ}$ higher temperature was observed. Strain in the $\mathrm{x}$ and $\mathrm{y}$ direction exhibited increment in the initial stage but on the addition of layers, strain did not change significantly in a positive or negative direction. In comparison, it can be said that higher strain fluctuations were observed in $\mathrm{x}$-direction as compared to y-direction strain patterns in all layers.

For specimen at $215^{\circ} \mathrm{C}$ strain was much higher in magnitude for both $\mathrm{x}$ and $\mathrm{y}-$ direction. For the bottom-most layer at this maximum temperature, strain tends to be reducing overtime. In the middle layer, the strain was fluctuating but there was no significant increment or decrement and in the final layer again strain was tending towards increment.

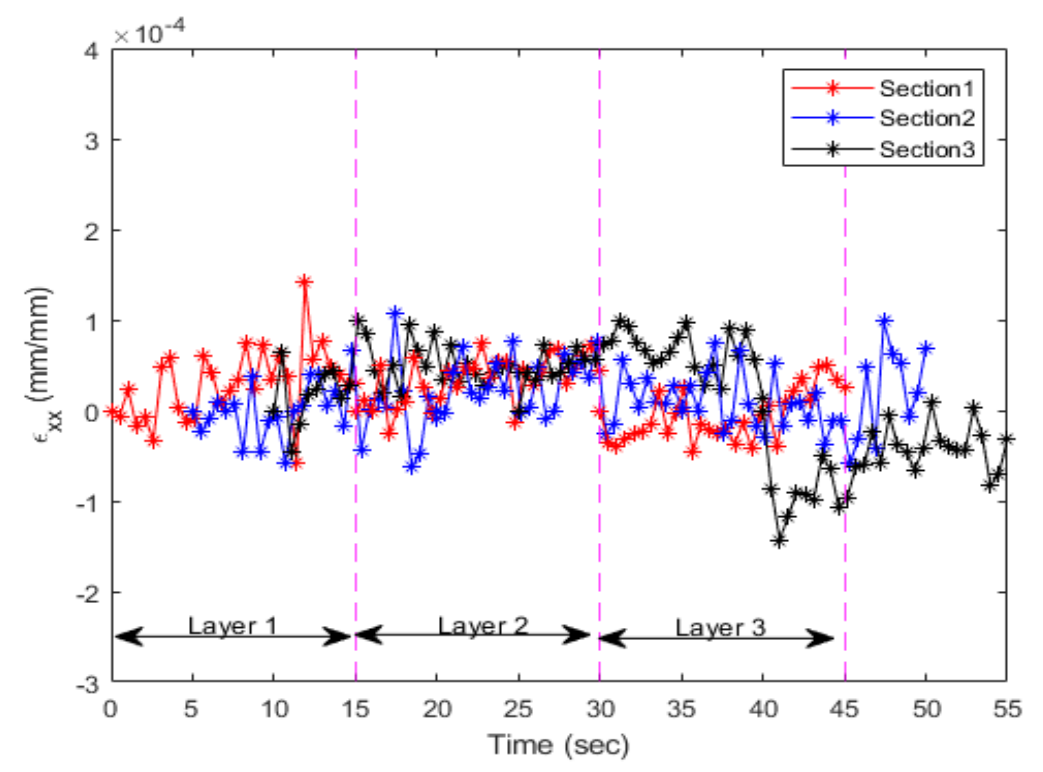

Figure 4.10 Strain Evolution for $0.20 \mathrm{~mm}$ Specimen in X -direction

Comparing all three temperatures for the same specimen height, it can be said that at $185^{\circ} \mathrm{C}$ and $200^{\circ} \mathrm{C}$, the specimen does not have much influence of temperature as observed 
in both $\mathrm{X}$ and $\mathrm{Y}$ strains, whereas for $215^{\circ} \mathrm{C}$ strain the magnitude was much higher and strain fluctuations were also more. However, one common observation for the tests for this specimen was a higher strain in the bottom layer.

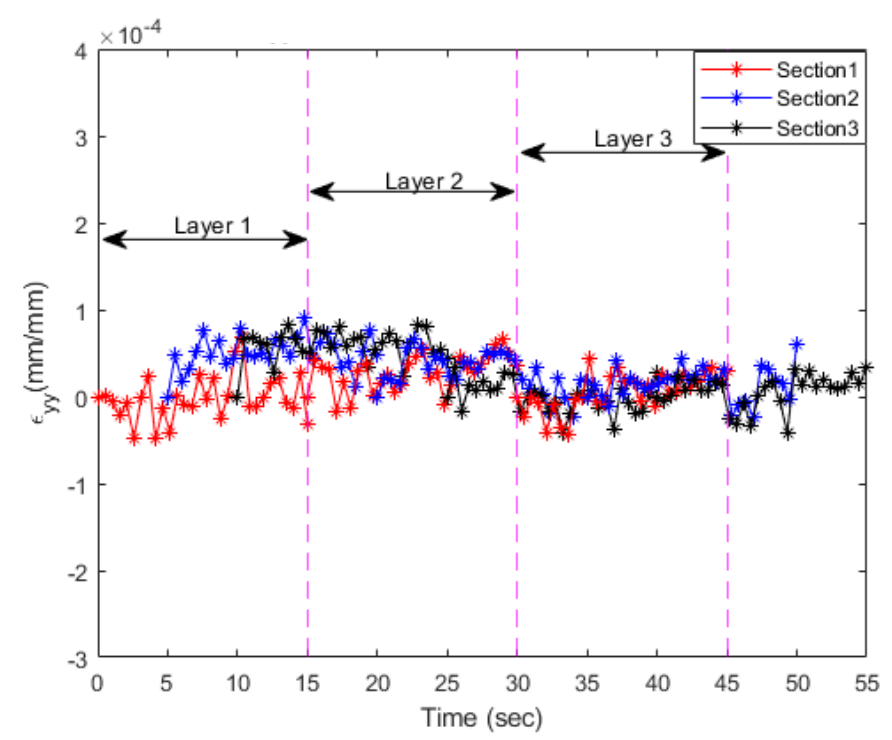

Figure 4.11 Strain Evolution for $0.20 \mathrm{~mm}$ Specimen along Y-direction

To summarize, it can be said that thickness $0.20 \mathrm{~mm}$ is a better choice for printing as compared to the thinner specimen to avoid more thermal fluctuations except for $215^{\circ} \mathrm{C}$. At the same time, a bottom-most layer is having more influence on temperature than top layers.

\subsubsection{Deformations for Specimens with $0.25 \mathrm{~mm}$ Thickness}

Strain data for $0.25 \mathrm{~mm}$ layer height exhibited the opposite behavior as compared to strain in the previous two thicknesses. For Section 1, Section 2, and Section 3, strain in the $\mathrm{x}$-direction is reducing and moving towards the negative side, which signifies the shrinking of the specimen. Moreover, adding a layer to each section doesn't significantly 
affect the strain except for the final layer where strain has reduced in all sections as shown in Figure 4.12.

Now for the y-direction strain, strain tends to expand with respect to time for all the sections. But, for each layer strain reduces as compared to strain from the previous layer as shown in Figure 4.13. As we increase the print temperature for the same specimen, the magnitude of strain increases. But, for each section and each layer strain in the $\mathrm{x}$ and $\mathrm{y}$ direction, respectively is again decreasing, indicating the solidification of the sample.

However, there is one interesting observation that for Section 1 strain remains in the same range, whereas, for Section 2 and Section 3 magnitude of strain increases as the layer changes. This means strain for Section 22 is higher than strain in Section 12 and likewise strain in Section 23 is higher than Section 22.

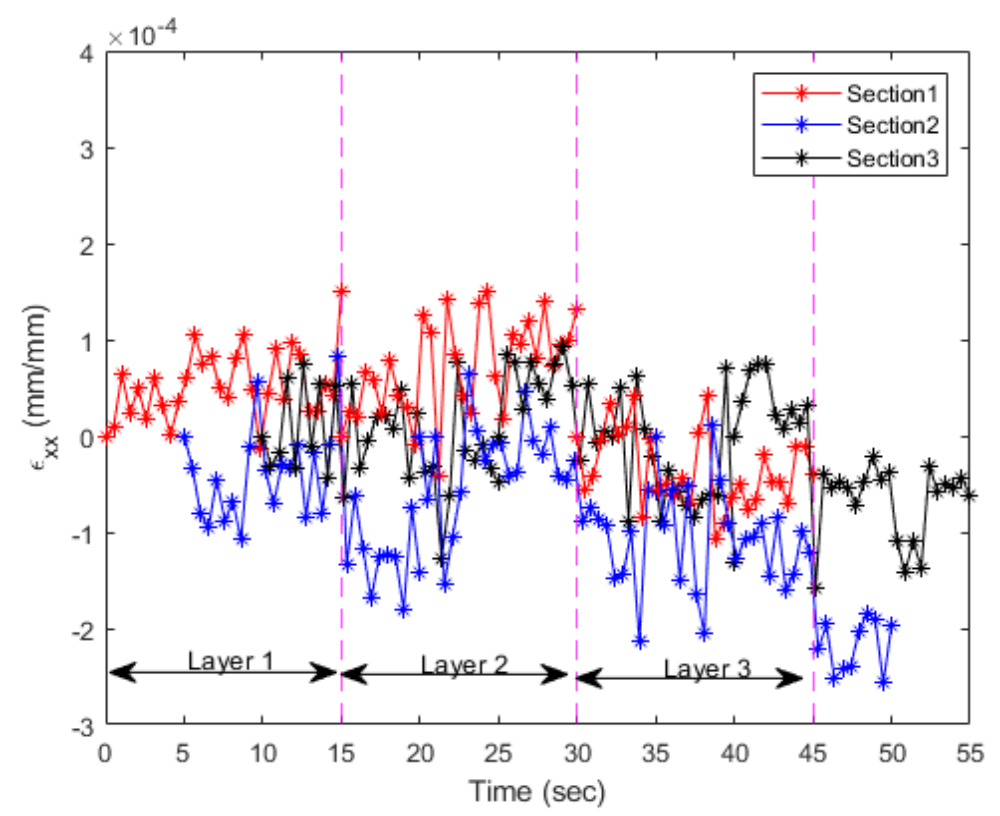

Figure 4.12 Strain for $0.25 \mathrm{~mm}$ Specimen along X-direction 
Finally, for the specimen with $0.25 \mathrm{~mm}$ thickness, at $215^{\circ} \mathrm{C}$, strain along the $\mathrm{x}$ and $\mathrm{y}$ direction was compressive overtime for all the sections. Compression was not significant over layer in Section 1 but for Section 2 and Section 3 it was decreasing considerably.

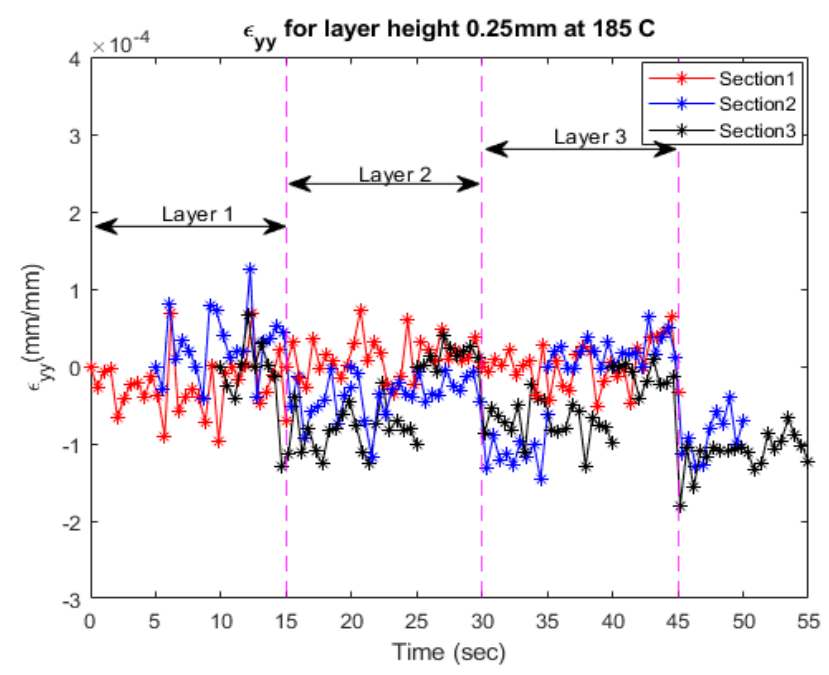

Figure 4.13 Strain for $0.25 \mathrm{~mm}$ Specimen along Y-direction.

To summarize, it was observed that for the thickest specimen, solidification quickly begins and does specimen does not expand as in case of sample with $0.15 \mathrm{~mm}$ layer height. Moreover, as temperature increases, the magnitude of strain increases for the specimen along $\mathrm{x}$ and y directions. Additionally, magnitude of strain is higher in case of X-direction strains as compared to y-direction strains.

\subsection{Infrared Camera Analysis}

An infrared camera can capture the temperature contours of the specimen in realtime. Therefore, a similar algorithm of printing section by section was implemented but this time to measure temperature evolution with time for all the tests listed in the test 
matrix. MATLAB was used to process image files derived from Research IR software and temperature along the $\mathrm{x}$-direction was obtained selecting various lines along one section.

Figure 4.14 depicts thermal gradients for each printed section. It is noticeable that white colored region corresponds to highest temperature observed where as temperature of regions which were already printed reveals orange, yellow colors. First image corresponds to temperature distribution in Section 1, second image corresponds to thermal gradients for Section 1 and Section 2 both and final image shows temperature for whole layer.

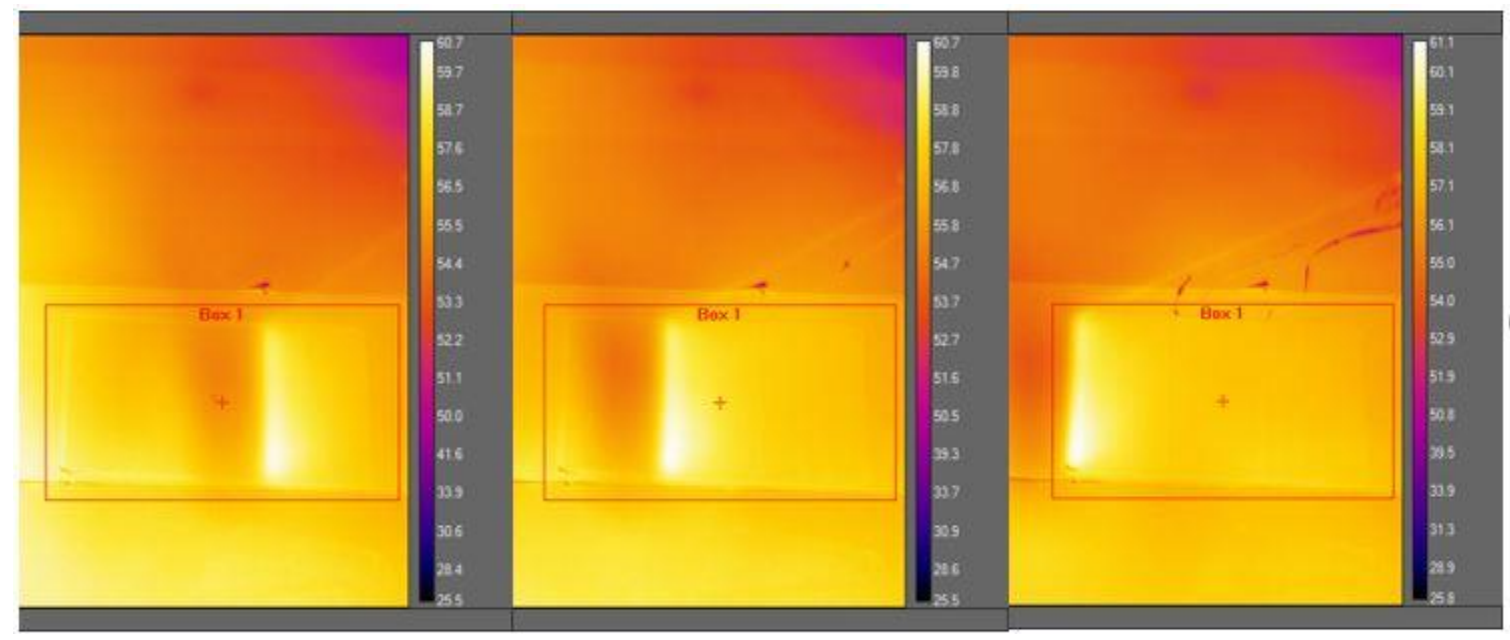

Figure 4.14 Temperature of Each Section in Real-Time using FLIR A655 SC

In the following plots, the blue line indicates temperature for Section1, the orange line indicates temperature for Section 1 and Section 2 and finally, the gray line indicates the temperature for the whole layer (with all sections printed). Circular patterned lines indicate layer 1 and triangular patterned lines reflect second layer temperature data. 


\subsubsection{Temperature Evolution for Specimen with $0.15 \mathrm{~mm}$ Thickness at $185^{\circ} \mathrm{C}$}

The plots depict temperature distribution across the length of the specimen. An infrared camera captured the real-time contours for the PLA specimen every 2.5 minutes for two layers. It is noticeable that, as we move towards the freshly laid filament temperature of almost increases by 2 degrees for each part captured after 2.5 minutes. The temperature of the next added layer is a little higher than the previously printed layer. Total temperature varies by 4 degrees considering both layers with a maximum temperature of $59.63{ }^{\circ} \mathrm{C}$ and a minimum of $55.72^{\circ} \mathrm{C}$.

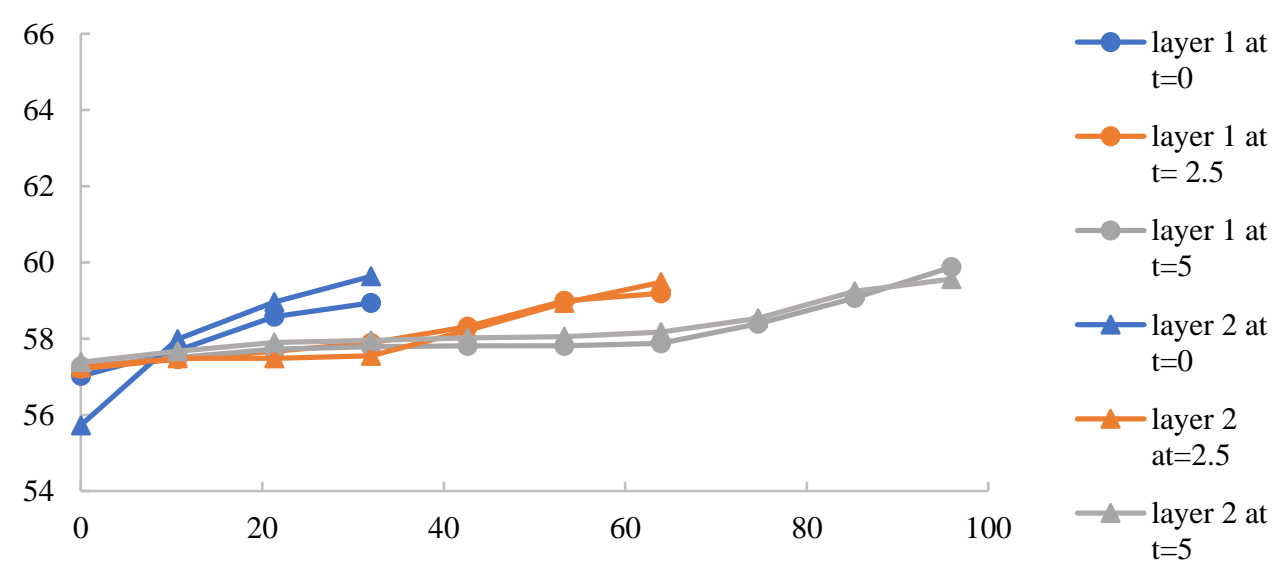

Figure 4.15 Temperature in Thin Sample at $185^{\circ} \mathrm{C}$

\subsubsection{Temperature Evolution for Specimen with $0.15 \mathrm{~mm}$ Layer Height at $200{ }^{\circ} \mathrm{C}$}

Specimen with $0.20 \mathrm{~mm}$ layer thickness with print temperature $200^{\circ} \mathrm{C}$ was observed. In this case, also temperature for the already printed section drops down by $1^{\circ}$ or $2^{\circ}$ when its neighboring region is getting printed. But in this case temperature of a newly printed 
layer is considerably higher than the temperature range of the first layer as visible through a larger gap in between same-colored lines.

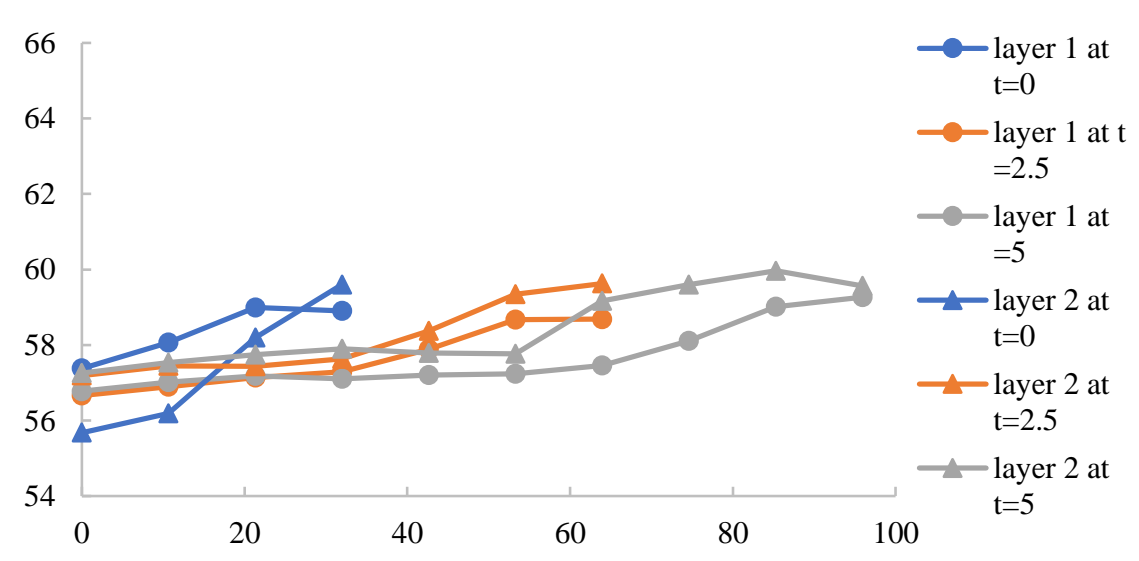

Figure 4.16 Temperature in Thin Sample at $200{ }^{\circ} \mathrm{C}$

\subsubsection{Temperature Evolution for Specimen with $0.15 \mathrm{~mm}$ Layer Height at $215{ }^{\circ} \mathrm{C}$}

This plot represents temperature over the whole length of the specimen for the thickness of $0.15 \mathrm{~mm}$ at print temperature $215^{\circ} \mathrm{C}$. In this case, there is a total $6^{\circ}$ temperature drop between layers. Interestingly, temperatures for different regions of the already printed layer are higher than layer that was freshly printed as shown by top circular patterned lines in all the regions represented by different colors.

Gap between temperature for each layer when compared sectionwise reduces as we move to fully printed layer. Here we can see that gray lines with circular plotter and triangular plotter do not have significant temperature gap as observed for the regions printed before because by the time whole layer gets printed sample cools down 
significantly, as observed in prvios plots, that already printed sample cools down by almost two degrees when its neigboring section is getting printed.

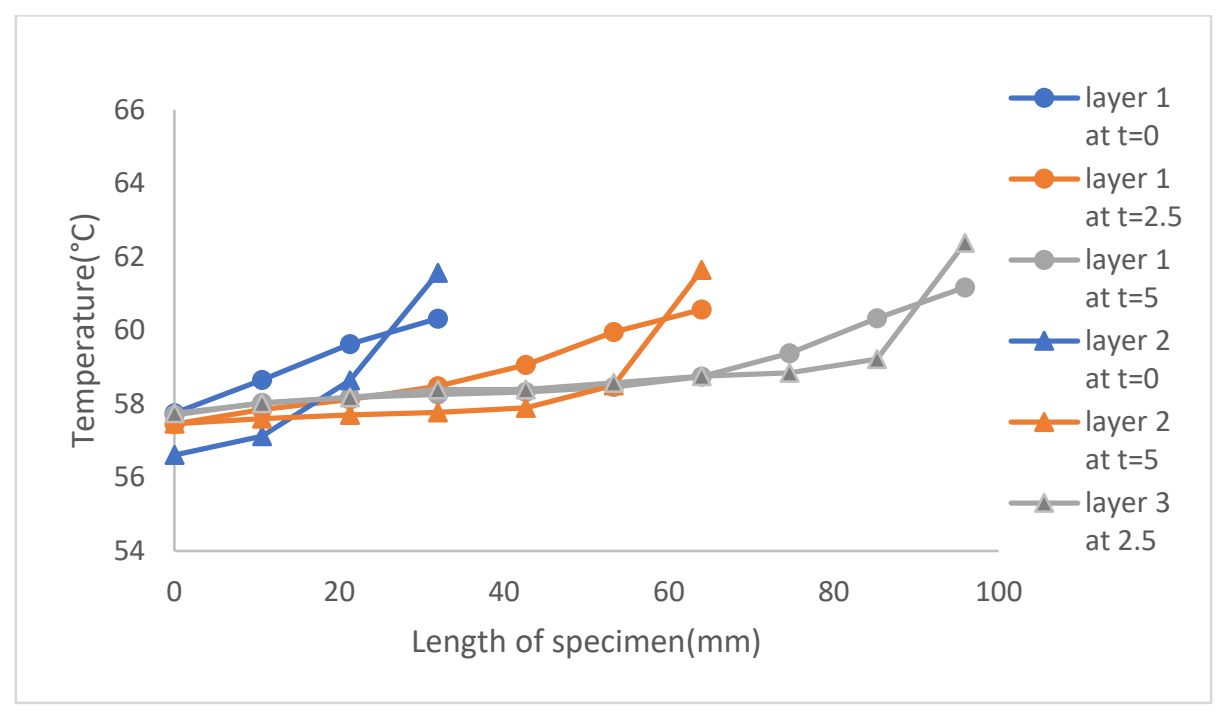

Figure 4.17 Temperature inThin Sample at $215^{\circ} \mathrm{C}$

\subsubsection{Temperature Evolution of Specimen with $0.20 \mathrm{~mm}$ Layer Height at $185{ }^{\circ} \mathrm{C}$}

For a sample with $0.20 \mathrm{~mm}$ thickness printed at $185^{\circ} \mathrm{C}$, the temperature followed a similar trend of reducing over time while the next sections are printed. In this case, also, temperature for the newly printed layer was lower by a degree or two as compared to the temperature of the initial layers as reveaved in Figure 4.18.

However, the temperature difference between each layer of each printed section is not too high, similar to the case of the specimen with $0.15 \mathrm{~mm}$ thickness at $185^{\circ} \mathrm{C}$. This is due to the fact that for initial two layer with average print thickness effect of platfrom temperature and set print temperature is similar but as they layers get added top layer 
temperature drops down quickly due to direct exposure to ambient temperature and indirect contact with print bed thermal envelope.

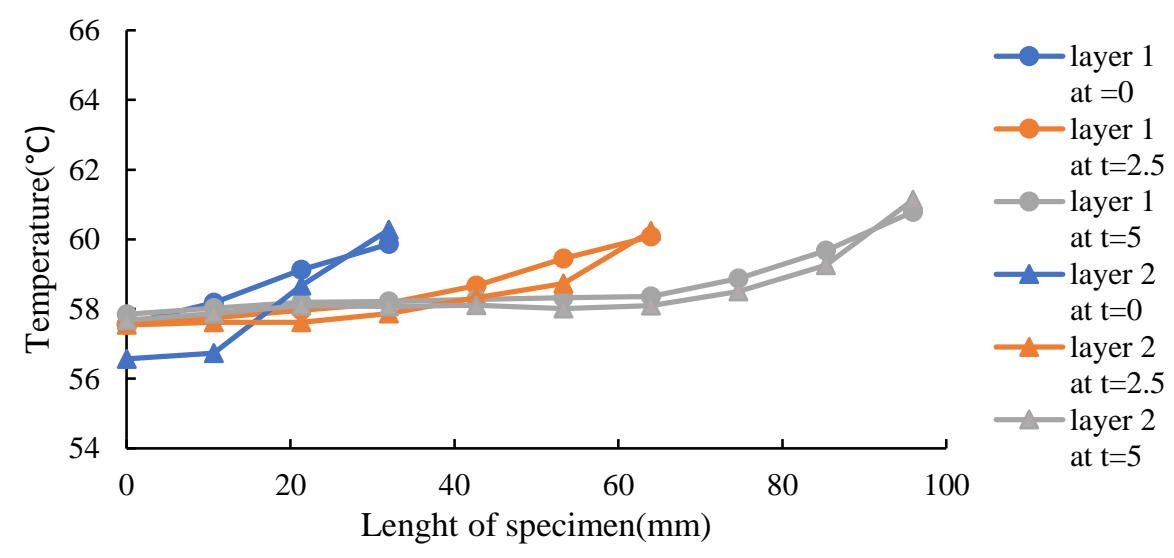

Figure 4.18 Temperature in Average Sample at $185{ }^{\circ} \mathrm{C}$

\subsubsection{Temperature Evolution for Specimen with $0.20 \mathrm{~mm}$ Layer Height at $200{ }^{\circ} \mathrm{C}$}

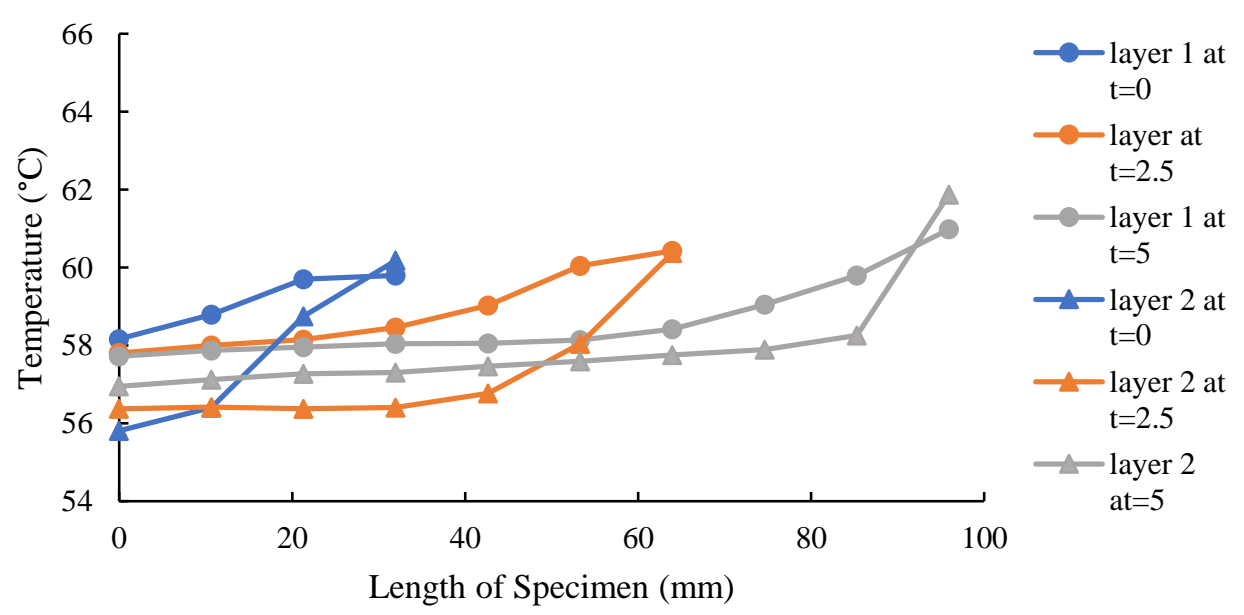

Figure 4.19 Temperature in Average Sample at $200{ }^{\circ} \mathrm{C}$

For thickness $0.20 \mathrm{~mm}$ layer height there is a higher temperature drop, approximately 2.5 degrees was observed between layer 1 and layer 2 . In this as well temperature for the 
top layer is lower as compared to the temperature of the initial later. As the next region across the length gets printed temperature drop in the previously printed specimen is about 1.5 degrees.

\subsubsection{Temperature Evolution for Specimen with $0.20 \mathrm{~mm}$ Layer Height at $215{ }^{\circ} \mathrm{C}$}

For specimen printed with $0.20 \mathrm{~mm}$ layer height at maximum print temperature, it was observed there was almost 6 degrees temperature difference between already printed and newly printed regions. It is noticeable that for layer 2 temperatures were lower by 1 or 2 degrees as compared to temperature captured for all the regions in the first layer.

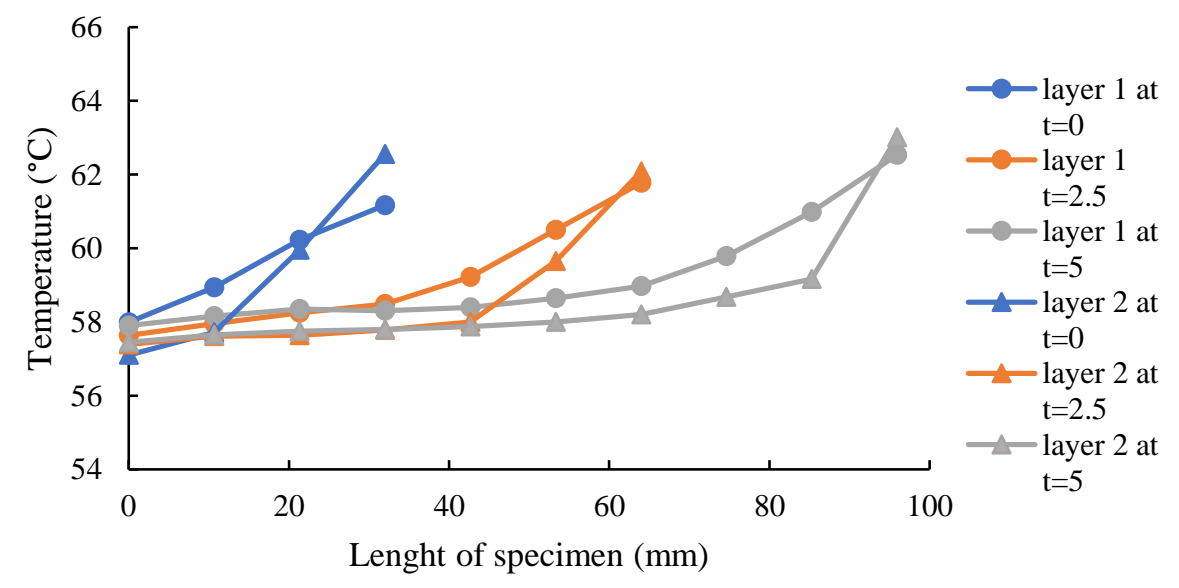

Figure 4.20 Temperature in Average Sample at $215^{\circ} \mathrm{C}$

\subsubsection{Temperature Evolution for Specimen with $0.25 \mathrm{~mm}$ Layer Height at $185{ }^{\circ} \mathrm{C}$}

In case specimen with $0.25 \mathrm{~mm}$ layer resolution at $185^{\circ} \mathrm{C}$, the bottom layer exhibited higher temperature while the top layer had lower temperatures for all the regions. Like every specimen, the temperature goes down within the layer as its neighboring regions 
get printed. There is considerable temperature gap between thermal evolution for layer 1 and layer 2 duc to thicker layer of the sample.

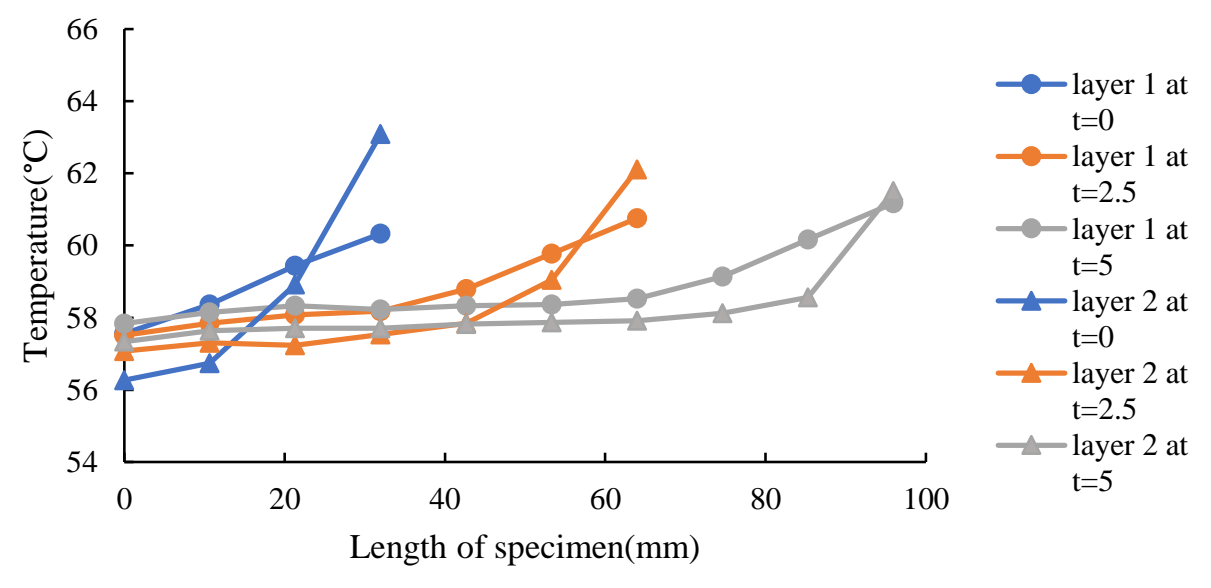

Figure 4.21 Temperature in Thick Sample at $185^{\circ} \mathrm{C}$

\subsubsection{Temperature Evolution for Specimen with $0.25 \mathrm{~mm}$ Layer Height at $200{ }^{\circ} \mathrm{C}$}

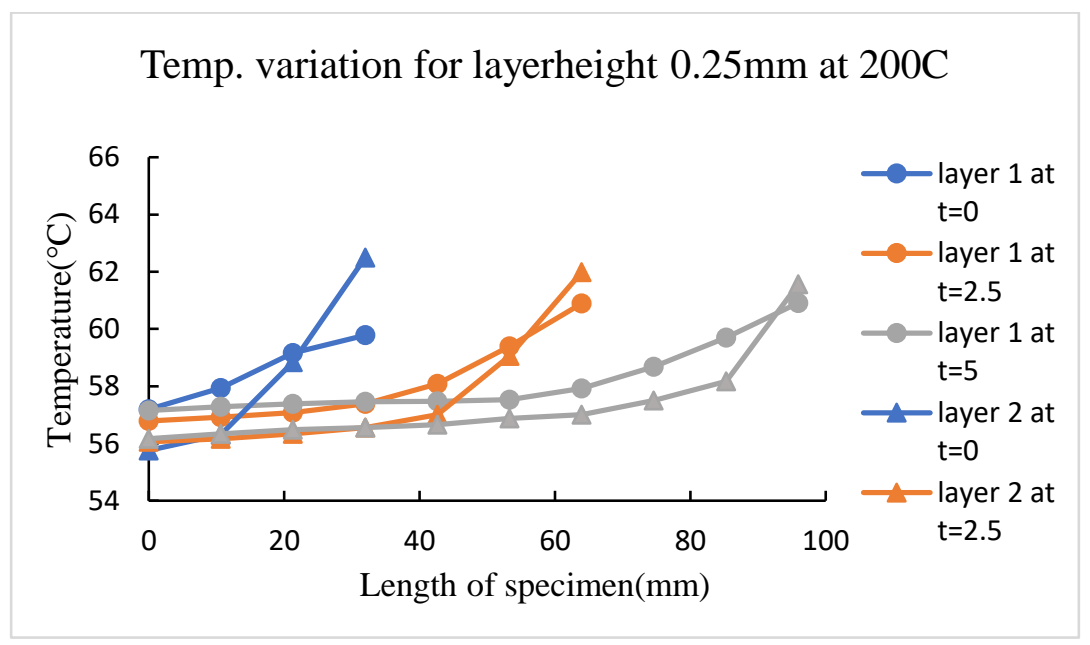

Figure 4.22 Temperature in Thick Sample at $200{ }^{\circ} \mathrm{C}$ 
Similarly, at temperature $200{ }^{\circ} \mathrm{C}$, the temperature of the newly added layer is reduced as compared to the bottom layer and temoerature for each section after time period of one section print dropped down by two degrees.

\subsubsection{Temperature Evolution for Specimen with $0.25 \mathrm{~mm}$ Layer Height at $215{ }^{\circ} \mathrm{C}$}

Similarly, at temperature $215^{\circ} \mathrm{C}$ also, the added layer has reduced temperature. From the temperature plots, it can be observed that when temperatures for Section 1 are captured for another layer over it there is a higher drop as compared to a temperature between the first and second layer of the other two printed sections. The temperature for this specimen was a little higher than other specimens.

To summarize for all the temperature plots, it was found that a lower temperature gap was observed for a minimum temperature of $185^{\circ} \mathrm{C}$ as compared to $200^{\circ} \mathrm{C}$ and $215^{\circ} \mathrm{C}$. Another interesting thing to note is that for higher thickness top layer temperatures were a little lower as compared to bottom layer temperature.

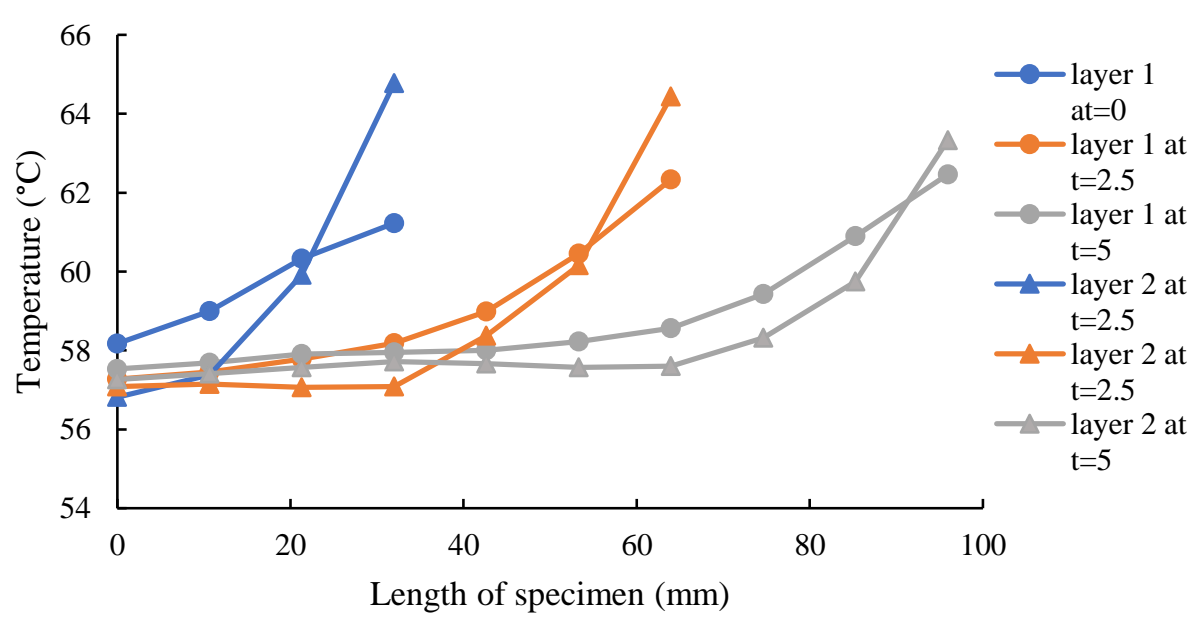

Figure 4.23 Temperature in Thick Sample at $215^{\circ} \mathrm{C}$ 
It can be due to the fact that the thinnest specimen has more influence on the print bed and print temperature whereas as the thickness increases, we can say that barrier between maintained platform temperature and added layer increased which is why top layers cool down faster in case of increase layer thickness.

Another common observation was maximum temperature gap was observed between layers of Section 1, whereas when the whole layer's temperature is compared between layers, there is minimal temperature variation because while the whole layer gets printed temperature would settle down significantly. Finally, the temperature for Section 1 in the second layer always begins with a lower temperature than Section 1 layer 1 and rises more than layer 1 temperature.

\subsection{Parametric Analysis of Thickness Variation}

The analysis presented here, is the strain evolution over time for three different layer thicknesses $0.15 \mathrm{~mm}, 0.20 \mathrm{~mm}$, and $0.25 \mathrm{~mm}$ respectively, at a print temperature of $185^{\circ} \mathrm{C}$. Strain in each section has been compared for each $\mathrm{x}$ and $\mathrm{y}$-direction. It is found that when Section 1 was compared for all the three layers in specimen with the same dimensional parameters at different layer resolution, overall strain for thinnest specimen were least while for the average thickness and maximum thickness strains were higher in Section 1 as shown in Figure 4.24.

Now considering the influence of thickness in Section 2, the compressive strain was observed for $0.25 \mathrm{~mm}$ thickness specimen while the strain was expanding and highest in magnitude for lower thickness specimen. This could be because Section 2 is right in the middle of the print platform where the temperature remains consistent as compared to the 
edges where it rapidly cools down. For the thinner part temperature effects on the deformation can be more, while for the thicker layer temperature has a lower influence.

For Section 3 it was observed that strains are compressive for maximum thickness and are least while for thinnest layer height strain are highest and for $0.20 \mathrm{~mm}$ layer height strain are average as shown in Figure 4.26.

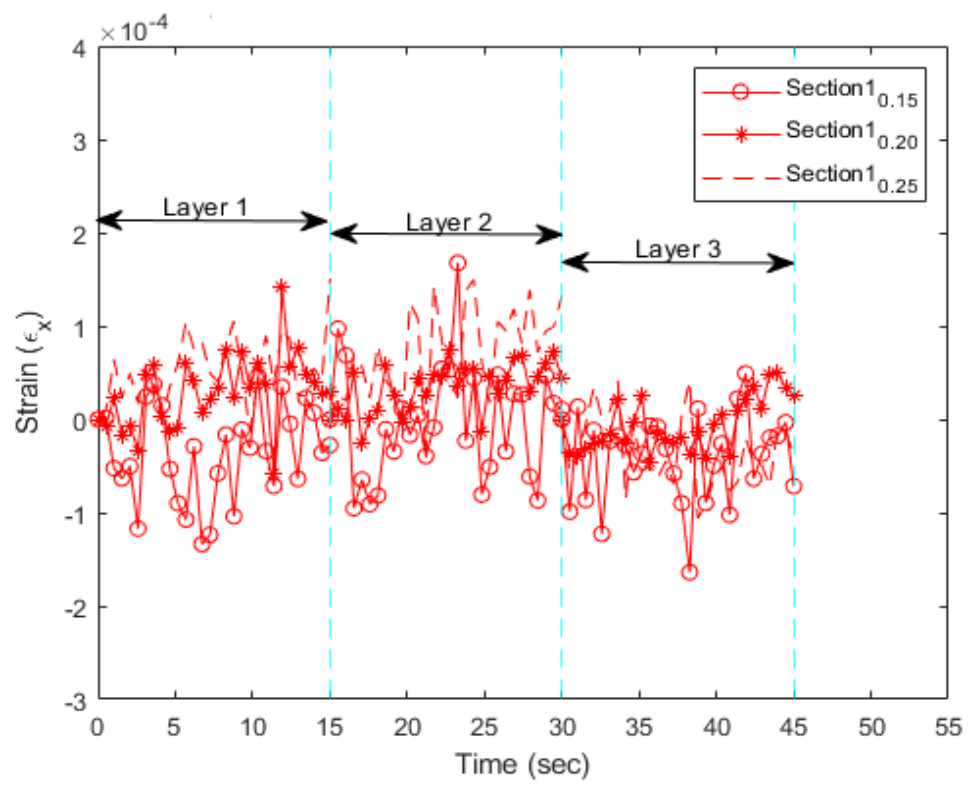

Figure 4.24 Strain along X-Direction in Section 1 for Different Thicknesses

Strain along the y-direction for all the layer thicknesses are coinciding with each other and do not have much influence on layer height. For Section 2, strain in the ydirection has the influence of temperature for least thickness, strains were observed to be the highest while for either two thicknesses strain range were close to each other. For Section 3 strain along the y-direction are again observed to be highest for a minimum resolution of the layer as compared to average and maximum layer height. Strain along Y 
direction for minimum thickness was higher as compared to maximum thickness. Strain comparison for different thicknesses at $215^{\circ} \mathrm{C}$.

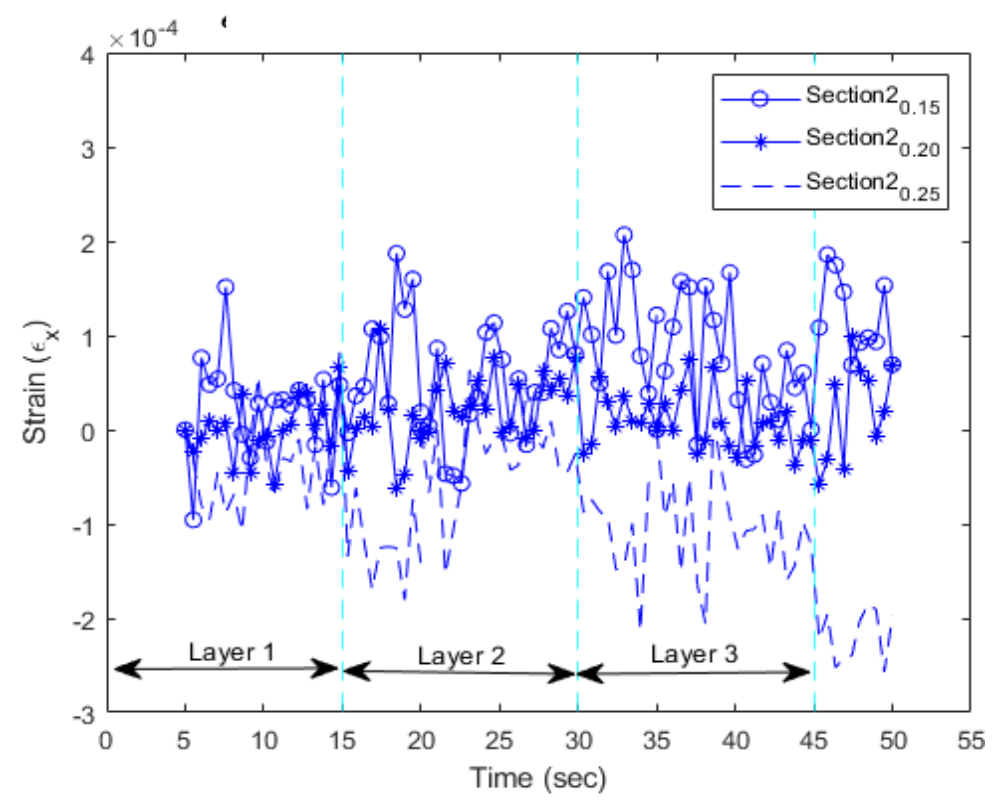

Figure 4.25 Strain along X- Direction for Section 2 for Different Thicknesses

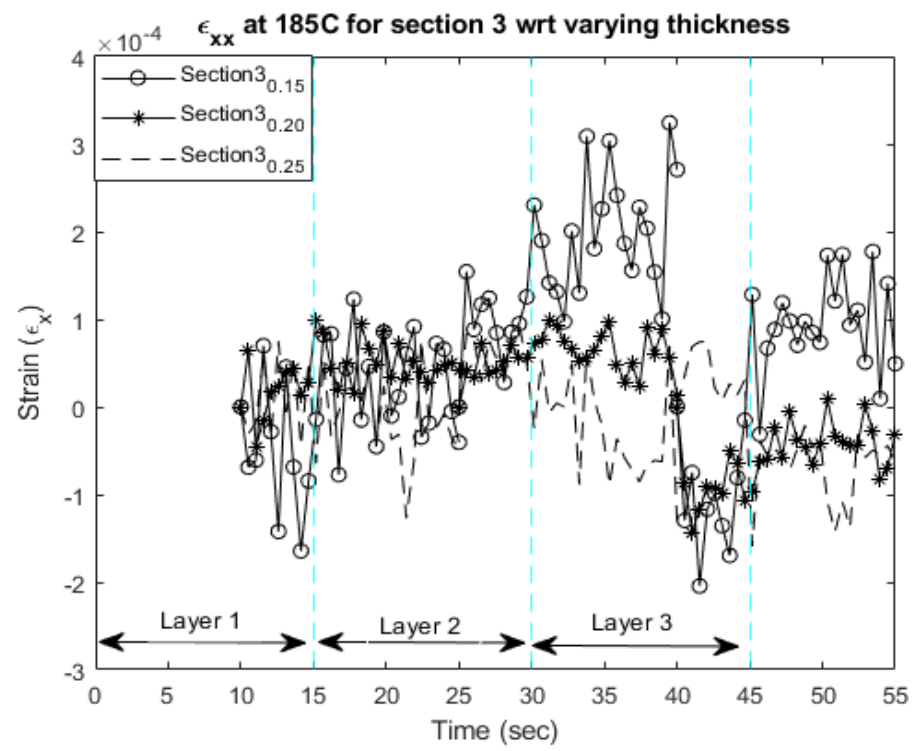

Figure 4.26 Strain along X- Direction for Section 3 for Different Thicknesses 


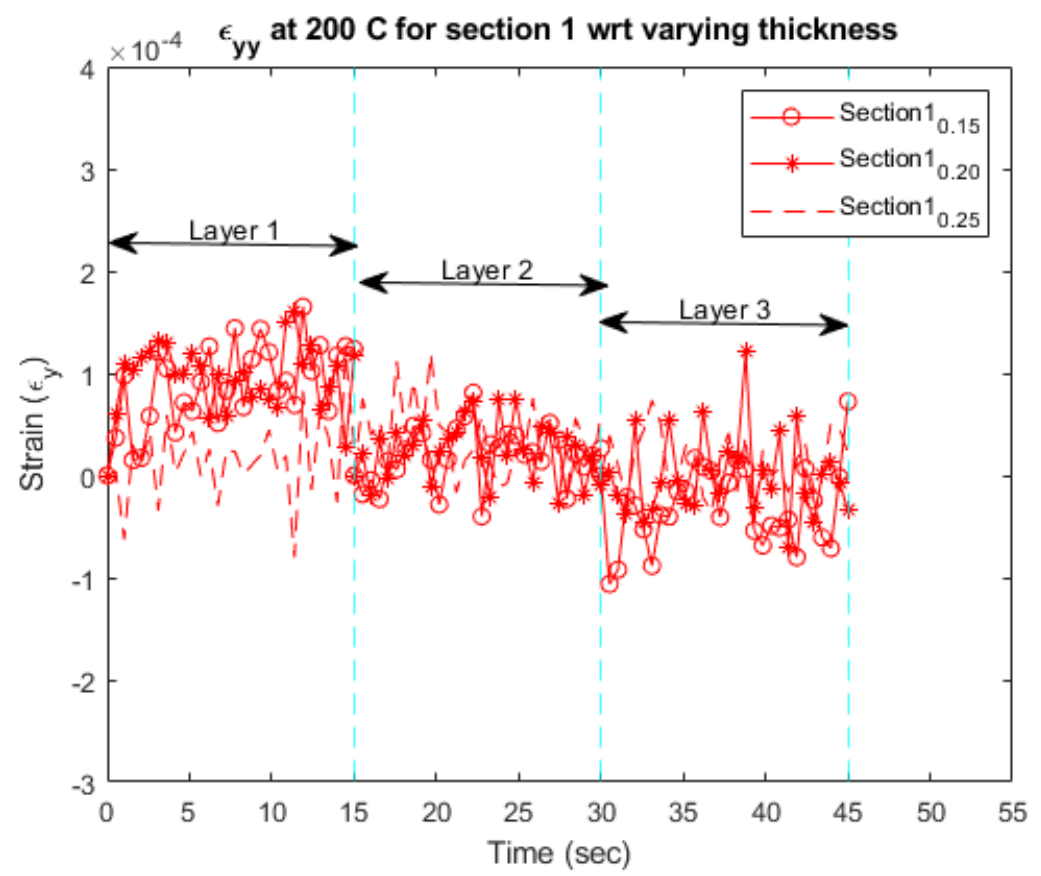

Figure 4.27 Strain along Y-Direction for Section 1

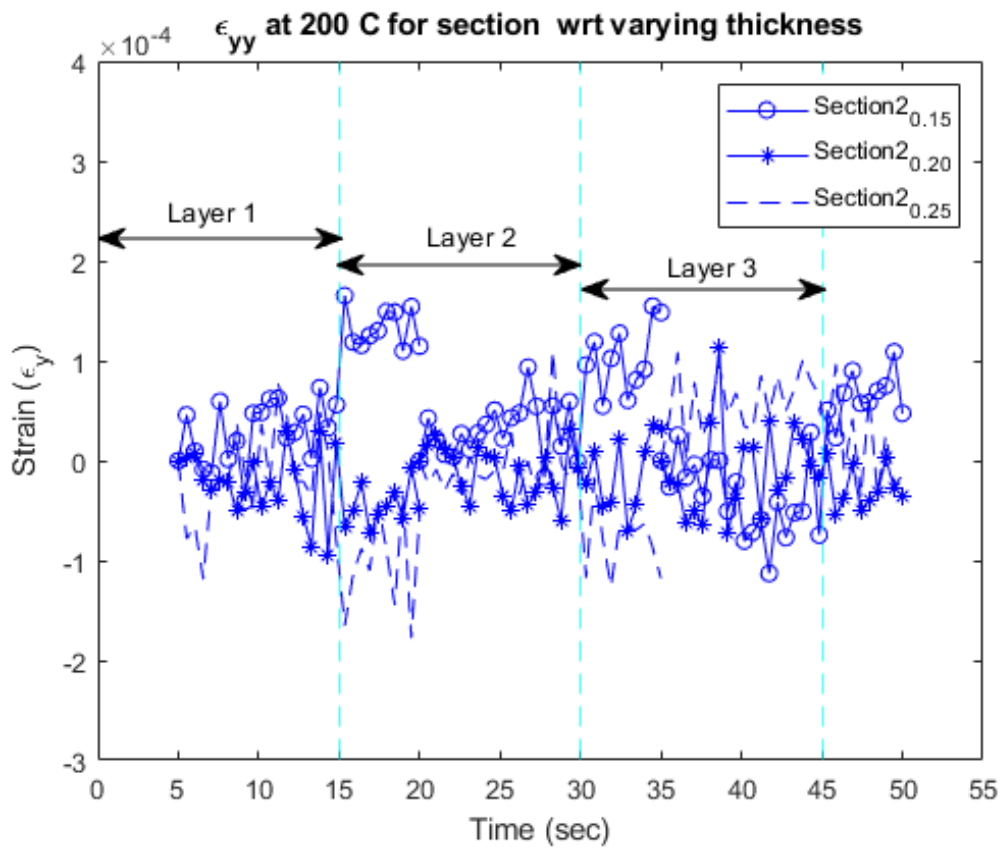

Figure 4.28 Strain along Y-Direction for Section 2 


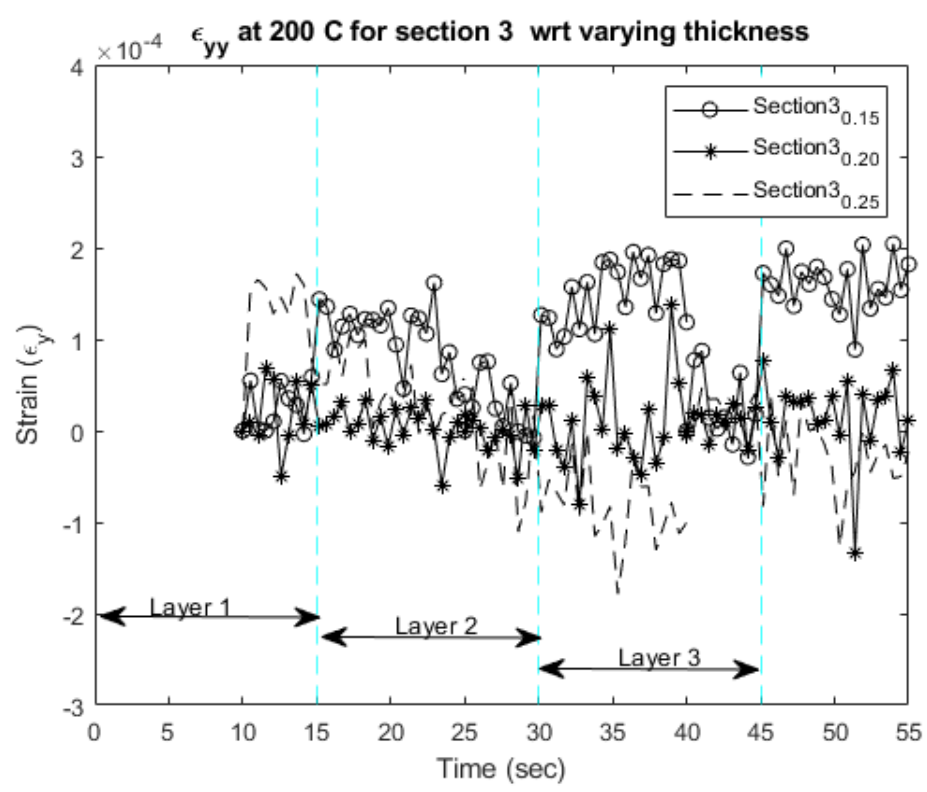

Figure 4.29 Strain along Y-Direction for Section 3

This parametric comparison has been done for first three layers of the specimen with different layer resolutions. However, if the specimen height is fixed and specimens are printed with three different layer heights, total number of layer will vary in each sample which can reveal how the layers are binding based on layer thickness and other defect formation like porosity and warping takes place.

\subsection{Parametric Analysis of Temperature Variation}

Strain evolution for specimens with the lowest layer resolution of $0.15 \mathrm{~mm}$ was selected and was observed for three different print temperatures, $185^{\circ} \mathrm{C}, 200^{\circ} \mathrm{C}$, and $215^{\circ} \mathrm{C}$ respectively. Following strain plots provide, deformation characteristics up to here layers for all the sections.

Strain progression for specimens with the same geometric parameter at the lowest set temperature was minimum while for the highest temperature magnitude of strain was highest in Section 1 as revealed in Figure 4.29. When Section 2 was observed for layer 
height $0.15 \mathrm{~mm}$ with respect to temperature it was found that the least strains were observed for the lowest temperature while the highest strain was observed at $215^{\circ} \mathrm{C}$, followed by $200^{\circ} \mathrm{C}$.

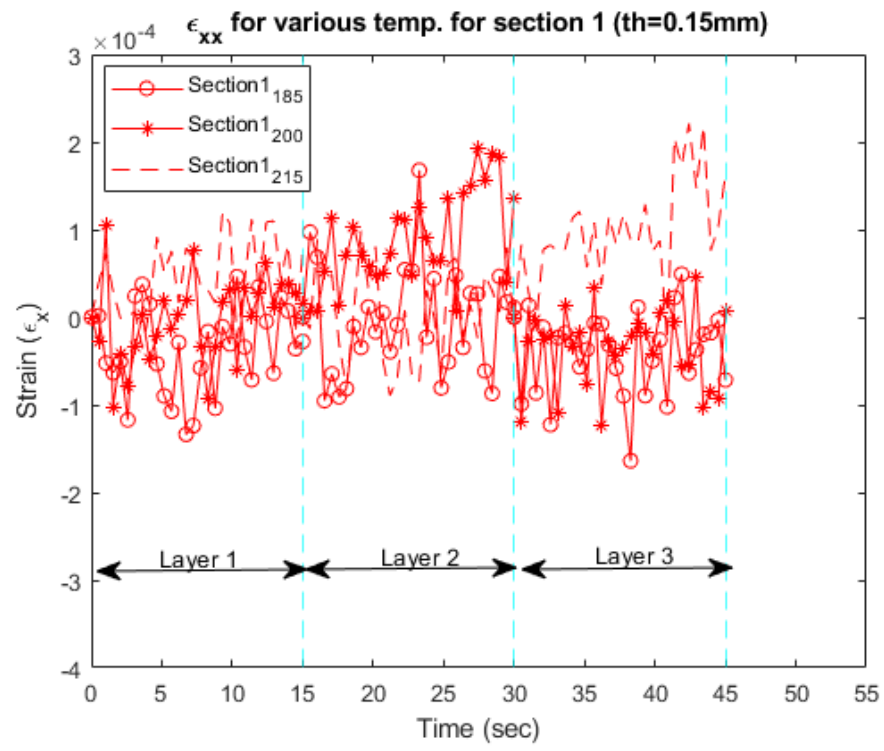

Figure 4.30 Strain along X-Direction for Section 1 for $0.15 \mathrm{~mm}$ Thickness

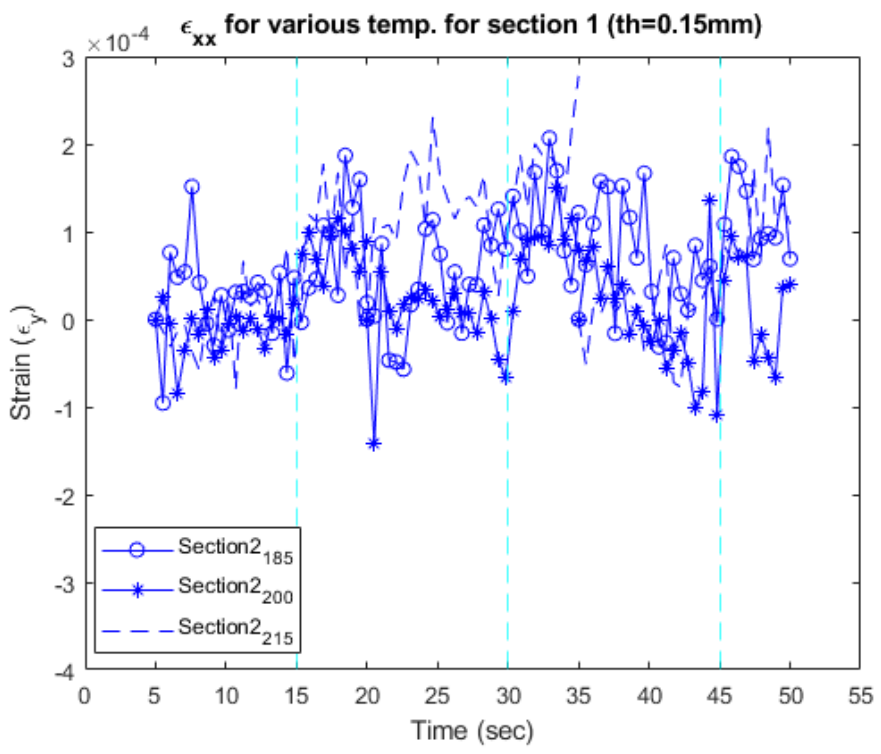

Figure 4.31 Strain along X-Direction for Section 2 for $0.15 \mathrm{~mm}$ Thickness 
The influence of temperature on Section 3 exhibited variation in trend. For the first and third layers, maximum strains were observed at $200^{\circ} \mathrm{C}$ whereas for the middle layer higher magnitude strains were observed at $185^{\circ} \mathrm{C}$. The temperature has an influence on the specimen, at $185^{\circ} \mathrm{C}$ strain magnitude is least for $0.15 \mathrm{~mm}$ PLA specimen as compared to strain at $215^{\circ} \mathrm{C}$. However, depending on the position strain can vary.

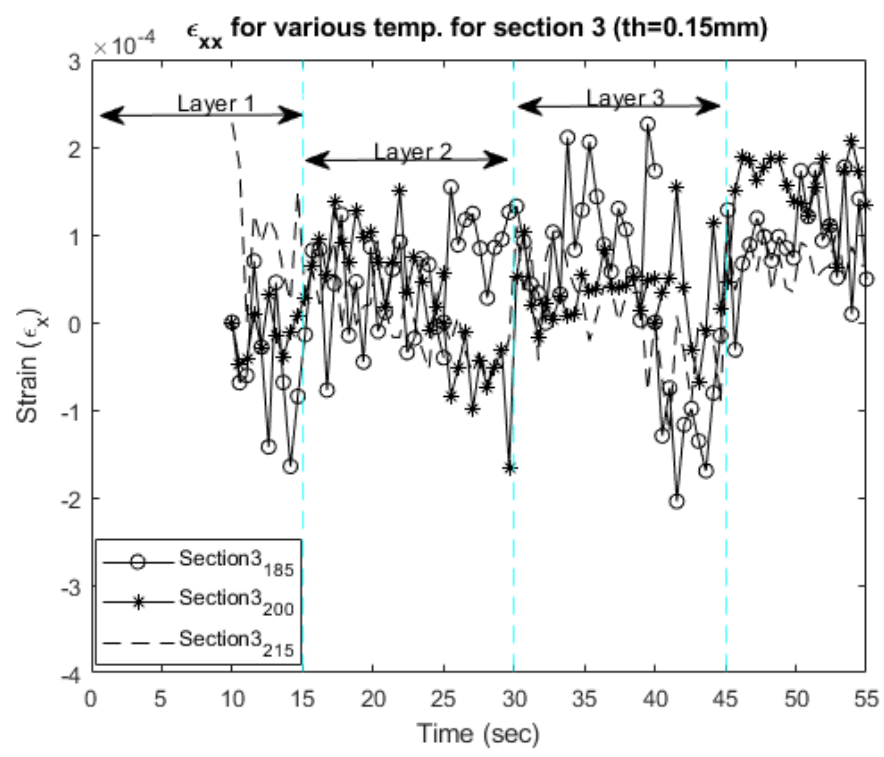

Figure 4.32 Strain along Y- Direction for Section 3 for $0.15 \mathrm{~mm}$ Thickness

Likewise, Strain along y-direction has been compared for the different print temperatures at $0.15 \mathrm{~mm}$ layer thickness. For Section 1, layer 2 and layer 3 remained unaffected by temperature. But, for layer 1 strain demonstrated at $200^{\circ} \mathrm{C}$ was maximum followed by $215^{\circ} \mathrm{C}$ and $185^{\circ} \mathrm{C}$. In Section 2 , strain along Y direction was observed to have maximum magnitude at $185^{\circ} \mathrm{C}$ and $215^{\circ} \mathrm{C}$. On the contrary, strains were smaller and compressive at $200{ }^{\circ} \mathrm{C}$. 
Strain along y-direction in the case of Section 3 does not have much influence on temperature as they all lie within a defined range. Strain along Y-direction also has lower strains at $185^{\circ} \mathrm{C}$ print temperature and higher strains at maximum print temperature.

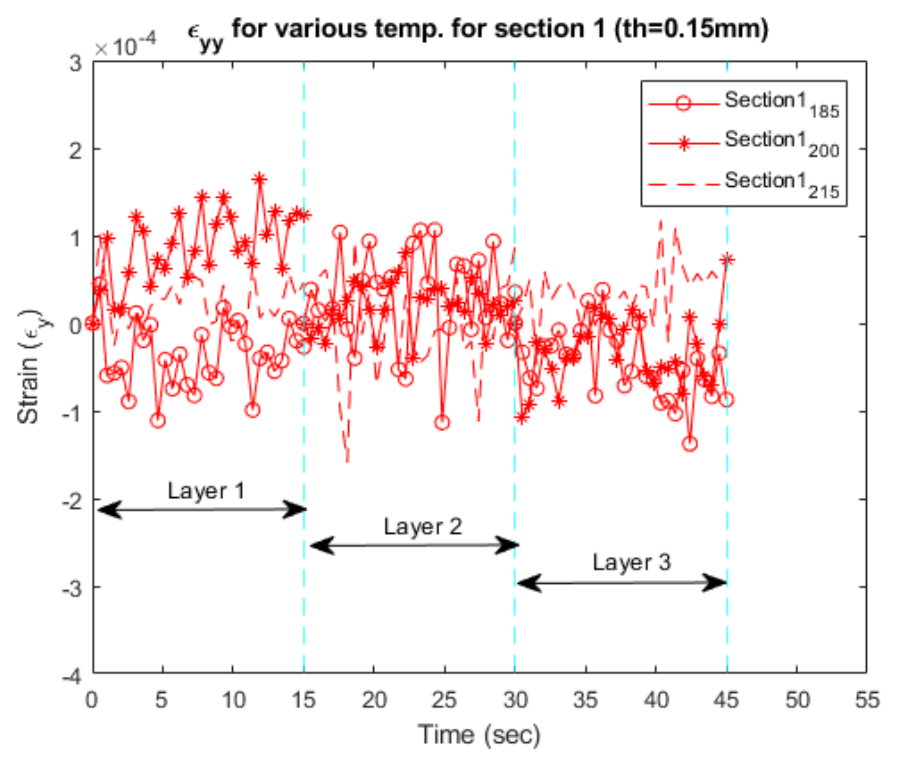

Figure 4.33 Strain along Y- Direction for section 1 for $0.15 \mathrm{~mm}$ Thickness

Figure 4.36 shows temperature evolution for the first layer across the length of the specimen for three different print temperatures for the sample with a thickness of $0.15 \mathrm{~mm}$. Similar to previous temperature plots, the blue line indicates the temperature of the first printed section, orange and gray line indicates, temperature for two printed sections and temperature for full payer respectively. Here, minimum temperature has been represented with a solid line, average with a dashed line, and maximum with a dotted line. 


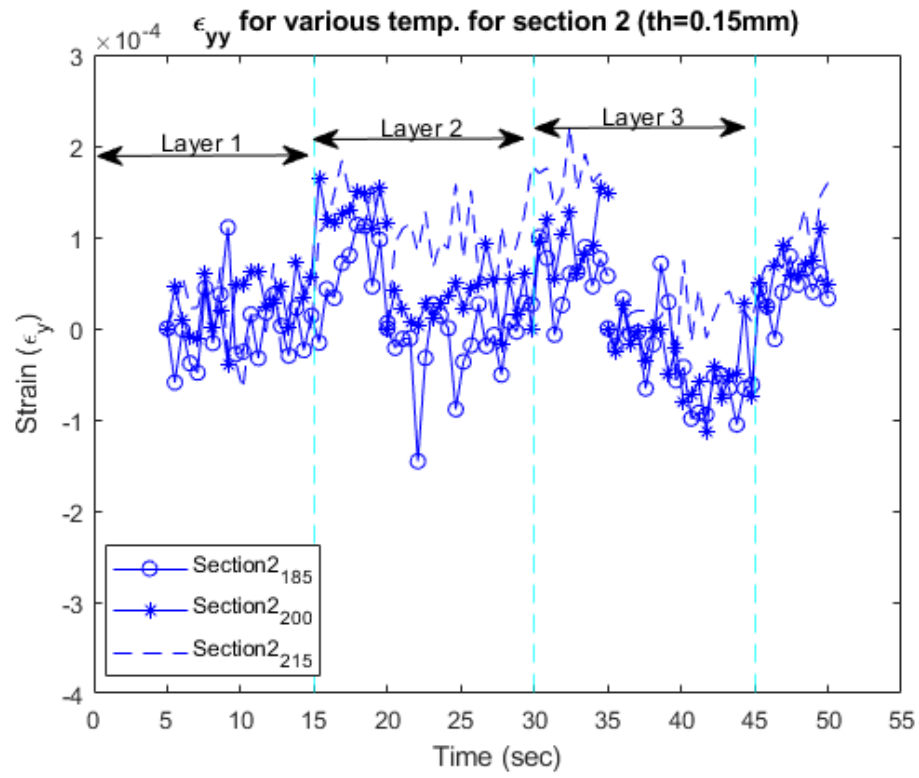

Figure 4.34 Strain along Y-Direction for Section 2 for $0.15 \mathrm{~mm}$ Thickness

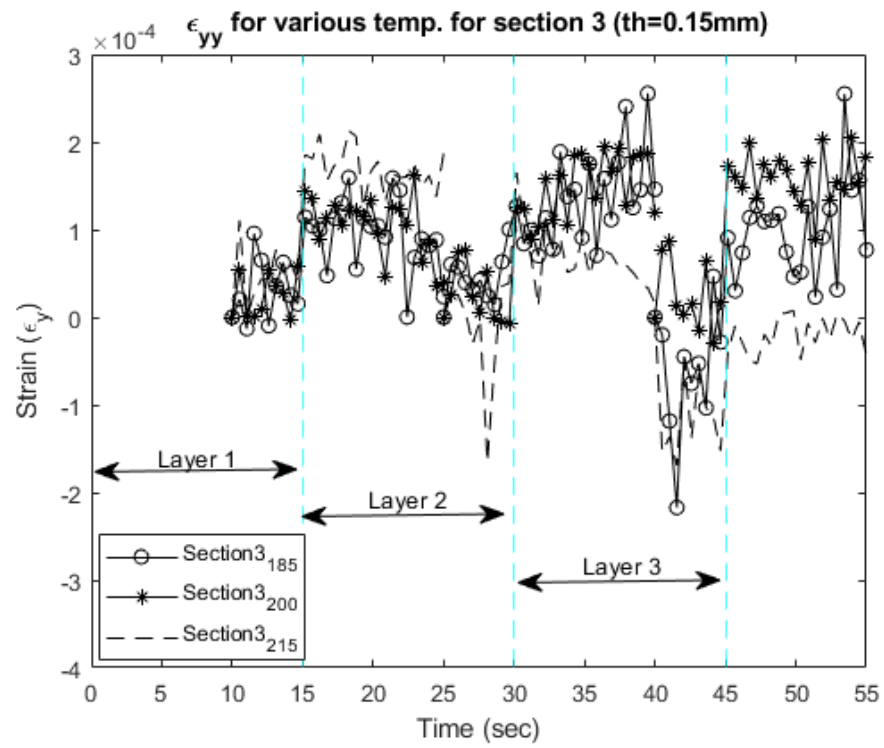

Figure 4.35 Strain along Y- Direction for Section 3 for $0.15 \mathrm{~mm}$ Thickness

It can be noticed that for each section, across the length which is along X-direction, overall specimen temperatures for a sample at $215^{\circ} \mathrm{C}$ overshadow temperature 
distribution for the other two specimens. The thermal energy distribution difference for a plate at $185^{\circ} \mathrm{C}$ and $200^{\circ} \mathrm{C}$ is smaller as compared to the highest temperature.

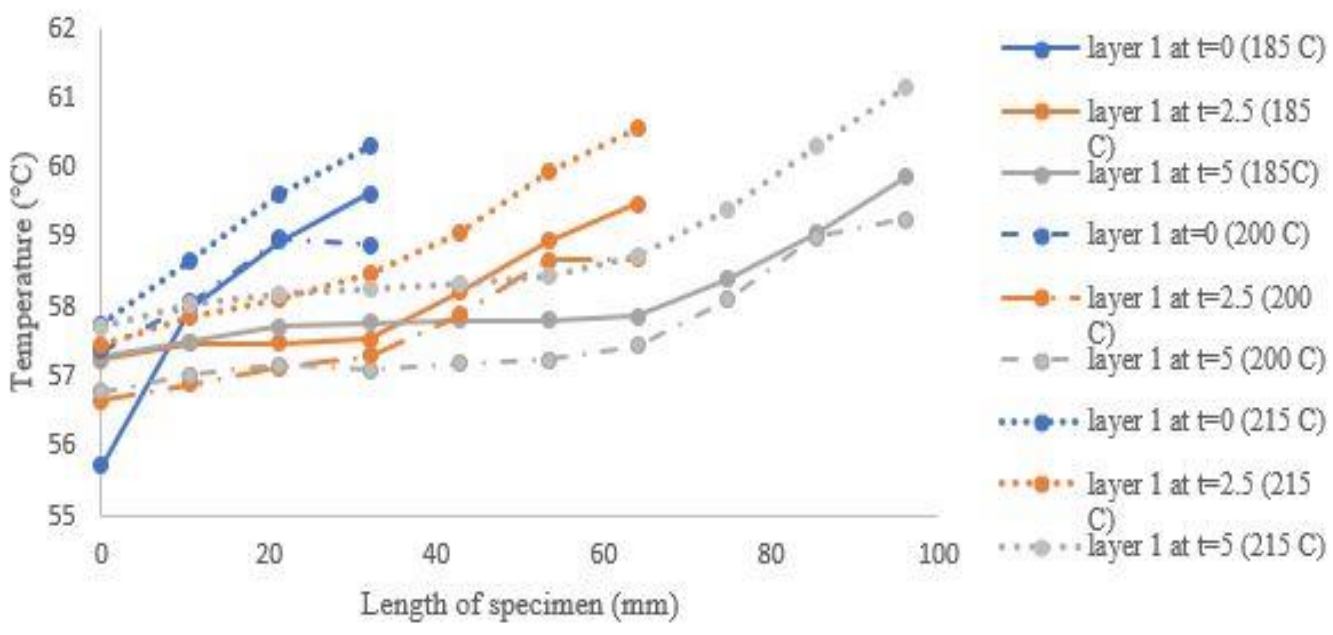

Figure 4.36 Temperature Evolution for Various Print Temperature 


\section{Conclusions and Future Work}

In this research, in-situ monitoring of PLA 3D printing was achieved using DIC and thermal camera. The primary conclusions of this thesis are as follows.

1. It was observed that specimens with the smallest layer height easily demonstrate strain expansion with temperature. Therefore, it can be said that at a higher temperature such specimen will have lower dimensional stability.

2. Specimen with an average thickness of $0.20 \mathrm{~mm}$ demonstrates the least influence of temperature and lower strains. Therefore, $0.20 \mathrm{~mm}$ layer height gives a better quality part with fewer chances of defects.

3. Specimen with maximum layer thickness revealed higher strains fluctuation as compared to the other two thicknesses as it has more mass to volume ratio for the same amount of cooling time. Based on higher fluctuations, it can be said that cooling is highly uneven for a thick specimen which can induce more thermal stresses.

4. Results obtained in this research work are subjected to several factors like platform leveling, DIC camera calibration, the effect of day and night light on DIC camera aperture, the effect of ambient temperature on cooling rate.

Therefore, more tests can be performed to achieve accurate results.

Overall, the objective of this thesis, to observe the additive manufacturing process in real-time for each layer has been accomplished. It was also possible to observe the impact of thermal gradients on strain evolution. The influence of process parameters on each section and each layer has been demonstrated. Finally, this similar concept is applicable for composite printing which is a popular application in the aerospace engineering field. 


\subsection{Future work}

This research work can work as a foundation for various future aspects related to additive manufacturing, First and foremost, the motivation for this thesis, defects in the additively manufactured composite. As composite printing also utilizes fused deposition modeling technique, the algorithm and the process developed here can be implemented for composite printing to catch defect generation instantaneously.

Metal additive manufacturing is popularly used for printing aerospace parts like a nozzle. Therefore, observation of metal 3D printing can be useful in obtaining defect-free and accurate parts.

This thesis work accounted for strain evolution and defects using a single DIC camera. Comparison of strain evolution and impact of process parameters using 2D-DI and 3D-DIC can be another interesting application. As digital image correlation accounts for the strain developed due to thermal changes, residual stress on the printed part can also be computed for the 3D printed specimen. Finally, the evolution of thermal stresses can be verified using a finite element model or molecular dynamics simulation. 


\section{References}

Abeykoon, C., Sri-Amphorn, P., \& Fernando, A. (2020). Optimization of fused deposition modeling parameters for improved PLA and ABS 3D printed structures. International Journal of Lightweight Materials and Manufacture, 3(3), 284-297.doi: 10.1016/j.ijlmm.2020.03.003

Altıparmak, S. C., Yardley, V. A., Shi, Z., \& Lin, J. (2021). Challenges in additive manufacturing of high-strength aluminium alloys and current developments in hybrid additive manufacturing. International Journal of Lightweight Materials and Manufacture, 4(2), 246-261. doi: 10.1016/j.ijlmm.2020.12.004

Bean, Q. A., Cooper, K. G., Edmunson, J. E., Johnston, M. M., \& Werkheiser, M. J. (2015, June). International space station (iss) 3d printer performance and material characterization methodology. In 62nd JANNAF Propulsion Meeting

Belloni, V., Ravanelli, R., Nascetti, A., Di Rita, M., Mattei, D., \& Crespi, M. (2019). py2DIC: A new free and open source software for displacement and strain measurements in the field of experimental mechanics. Sensors, 19(18), 3832.doi: $10.3390 / \mathrm{s} 19183832$

Bermudo Gamboa, C., Martín-Béjar, S., Trujillo Vilches, F. J., Castillo López, G., \& Sevilla Hurtado, L. (2019). 2D-3D Digital Image Correlation Comparative Analysis for Indentation Process. Materials, 12(24), 4156. doi:10.3390/ma12244156

Bilkar, D., Keshavamurthy, R., \& Tambrallimath, V. (2021). Influence of carbon nanofiber reinforcement on mechanical properties of polymer composites developed by FDM. Materials Today: Proceedings, 46, 4559-4562.doi: 10.1016/j.matpr.2020.09.707

Blok, L. G., Longana, M. L., Yu, H., \& Woods, B. K. (2018). An investigation into 3D printing of fibre reinforced thermoplastic composites. Additive Manufacturing, 22, 176-186.doi: 10.1016/j.addma.2018.04.039

Bouapao, L., Tsuji, H., Tashiro, K., Zhang, J., \& Hanesaka, M. (2009). Crystallization, spherulite growth, and structure of blends of crystalline and amorphous poly (lactide) s. Polymer, 50(16), 4007-4017.Lord, N. M. (2010). Digital Image Correlation. Materials Today, 52-54. doi: 10.1016/j.polymer.2009.06.040

Chacón, J. M., Caminero, M. A., García-Plaza, E., \& Núnez, P. J. (2017). Additive manufacturing of PLA structures using fused deposition modelling: Effect of process parameters on mechanical properties and their optimal selection. Materials \& Design, 124, 143-157.doi: 10.1016/j.matdes.2017.03.065

Chacón, J. M., Caminero, M. A., Núñez, P. J., García-Plaza, E., García-Moreno, I., \& Reverte, J. M. (2019). Additive manufacturing of continuous fibre reinforced 
thermoplastic composites using fused deposition modelling: Effect of process parameters on mechanical properties. Composites science and technology, 181, 107688

Chava, S., \& Namilae, S. (2021). Continuous evolution of processing induced residual stresses in composites: An in-situ approach. Composites Part A: Applied Science and Manufacturing, 145, 10636. doi: 10.1016/j.compositesa.2021.106368

Chen, F., Chen, X., Xie, X., Feng, X., \& Yang, L. (2013). Full-field 3D measurement using multi-camera digital image correlation system. Optics and Lasers in Engineering, 51(9), 1044-1052.doi: 10.1016/j.optlaseng.2013.03.001

Cooper, Kenneth. Rapid prototyping technology: selection and application. CRC press, 2001.doi:10.1201/9780203910795

Craeghs, T., Clijsters, S., Kruth, J. P., Bechmann, F., \& Ebert, M. C. (2012). Detection of process failures in layerwise laser melting with optical process monitoring. Physics Procedia, 39, 753-759.doi: 10.1016/j.phpro.2012.10.097

Cunha, F. G., Santos, T. G., \& Xavier, J. (2021). In Situ Monitoring of Additive Manufacturing Using Digital Image Correlation: A Review. Materials, 14(6), 1511.doi: $10.3390 / \mathrm{ma} 14061511$

Despeisse, M., \& Ford, S. (2015, September). The role of additive manufacturing in improving resource efficiency and sustainability. In IFIP International Conference on Advances in Production Management Systems (pp. 129-136). Springer, Cham.doi: 10.1007/978-3-319-22759-7_15

Farah, S., Anderson, D. G., \& Langer, R. (2016). Physical and mechanical properties of PLA, and their functions in widespread applications-A comprehensive review. Advanced drug delivery reviews, 107, 367-392.Sudhir, S. P. (2018). Integration of 3D printing with dosage forms: A new perspective for modern healthcare . Biomed Pharmacother, 146-154. doi: 10.1016/j.addr.2016.06.012

Fayazbakhsh, K., Movahedi, M., \& Kalman, J. (2019). The impact of defects on tensile properties of 3D printed parts manufactured by fused filament fabrication. Materials Today Communications, 18, 140-148.doi: 10.1016/j.mtcomm.2018.12.003

Ford, S. L. (2014). Additive manufacturing technology: potential implications for US manufacturing competitiveness. J. Int'l Com. \& Econ., 6, 40.

Ford, S., \& Despeisse, M. (2016). Additive manufacturing and sustainability: an exploratory study of the advantages and challenges. Journal of cleaner Production, 137, 1573-1587.doi: 10.1016/j.jclepro.2016.04.150

Gornet, T. W. (2014). History of additive manufacturing. Wohlers Report. 
Górszczyk, J., Malicki, K., \& Zych, T. (2019). Application of digital image correlation (DIC) method for road material testing. Materials, 12(15), 2349.doi: 10.3390/ma12152349

Haq, R. H. A., Marwah, O. M. F., Rahman, M. N. A., Haw, H. F., Abdullah, H., \& Ahmad, S. (2019, August). 3D Printer parameters analysis for PCL/PLA filament wire using Design of Experiment (DOE). In IOP Conference Series: Materials Science and Engineering (Vol. 607, No. 1, p. 012001). IOP Publishing.

Holzmond, O., \& Li, X. (2017). In situ real time defect detection of 3D printed parts. Additive Manufacturing, 17, 135-142. doi: 10.1016/j.addma.2017.08.003

Hu, J. (2017, August). Study on STL-based slicing process for 3D printing. In Proceedings of the 28th Annual International, Solid Freeform Fabrication Symposium-An Additive Manufacturing Conference. Austin TX, August (pp. 7-9).

Hubs, 3. (2021, April 28). Additive manufacturing trend report 2021. Industry today.

Hull, C. W. (1986). U.S. Patent No. 4,575,330. Washington, DC: U.S. Patent and Trademark Office.

International, A. (2012). Standard terminology for additive manufacturing technologies : designation F2792-12a. West Conshohocken, PA : ASTM International.

Kahn-Jetter, Z. L., \& Chu, T. C. (1990). Three-dimensional displacement measurements using digital image correlation and photogrammic analysis. Experimental Mechanics, 30(1), 10-16.doi: 10.1007/BF02322695

Kalender, M., Kılıç, S. E., Ersoy, S., Bozkurt, Y., \& Salman, S. (2019, June). Additive manufacturing and 3D printer technology in aerospace industry. In 2019 9th International Conference on Recent Advances in Space Technologies (RAST) (pp. 689-694). IEEE.doi:10.1109/RAST.2019.8767881.

Kousiatza, C., \& Karalekas, D. (2016). In-situ monitoring of strain and temperature distributions during fused deposition modeling process. Materials \& Design, 97, 400-406.doi: 10.1016/j.matdes.2016.02.099

Kousiatza, C., \& Karalekas, D. (2016). In-situ monitoring of strain and temperature distributions during fused deposition modeling process. Materials \& Design, 97, 400-406.doi: 10.1016/j.matdes.2016.02.099

Kumar, K. P. A., \& Pumera, M. (2021). 3D-Printing to Mitigate COVID-19

Pandemic. Advanced Functional Materials, 31(22), 2100450.:doi

10.1002/adfm.202100450

Lasprilla, A. J., Martinez, G. A., Lunelli, B. H., Jardini, A. L., \& Maciel Filho, R. (2012). Poly-lactic acid synthesis for application in biomedical devices-A review. Biotechnology advances, 30(1), 321-328. doi:10.1016/j.biotechadv.2011.06.019 
Mangalgiri, P. D. (1999). Composite materials for aerospace applications. Bulletin of Materials Science, 22(3), 657-664.

Masuo, H., Tanaka, Y., Morokoshi, S., Yagura, H., Uchida, T., Yamamoto, Y., \& Murakami, Y. (2018). Influence of defects, surface roughness and HIP on the fatigue strength of Ti-6Al-4V manufactured by additive manufacturing. International Journal of Fatigue, 117, 163-179. doi:10.1016/j.ijfatigue.2018.07.020

Mehta, R., Kumar, V., Bhunia, H., \& Upadhyay, S. N. (2005). Synthesis of poly (lactic acid): a review. Journal of Macromolecular Science, Part C: Polymer Reviews, 45(4), 325-349 doi: 10.1080/15321790500304148

Murienne, B. J., \& Nguyen, T. D. (2016). A comparison of 2D and 3D digital image correlation for a membrane under inflation. Optics and lasers in engineering, 77, 92-99.doi: 10.1016/j.optlaseng.2015.07.013

Murr, L. E. (2016). Frontiers of 3D printing/additive manufacturing: from human organs to aircraft fabrication. Journal of Materials Science \& Technology, 32(10), 987-995. doi: 10.1016/j.jmst.2016.08.011

Mwema, F. M., \& Akinlabi, E. T. (2020). Basics of fused deposition modelling (FDM). In Fused Deposition Modeling (pp. 1-15). Springer, Cham.

Naveed, N. (2021). Investigate the effects of process parameters on material properties and microstructural changes of 3D-printed specimens using fused deposition modelling (FDM). Materials Technology, 36(5), 317-330. doi: $10.1080 / 10667857.2020 .1758475$

Pan, B., Yu, L., \& Wu, D. (2013). High-accuracy 2D digital image correlation measurements with bilateral telecentric lenses: error analysis and experimental verification. Experimental Mechanics, 53(9), 1719-1733. doi: 10.1007/s11340-0139774

Peters, W. H., \& Ranson, W. F. (1982). Digital imaging techniques in experimental stress analysis. Optical engineering, 21(3), 213427. doi: 10.1117/12.7972925

Shahrubudin, N., Lee, T. C., \& Ramlan, R. (2019). An overview on 3D printing technology: Technological, materials, and applications. Procedia Manufacturing, 35, 1286-1296.doi: 10.1016/j.promfg.2019.06.089

Shapiro, A. A., Borgonia, J. P., Chen, Q. N., Dillon, R. P., McEnerney, B., Polit-Casillas, R., \& Soloway, L. (2016). Additive manufacturing for aerospace flight applications. Journal of Spacecraft and Rockets, 952-959. doi:10.2514/1.A33544

Sirichakwal, I., \& Conner, B. (2016). Implications of additive manufacturing for spare parts inventory. 3D printing and Additive Manufacturing, 3(1), 56-63.doi: $10.1089 / 3 \mathrm{dp} .2015 .0035$ 
Sun, Q., Rizvi, G. M., Bellehumeur, C. T., \& Gu, P. (2008). Effect of processing conditions on the bonding quality of FDM polymer filaments. Rapid prototyping journal.

Sutton, M. A., Yan, J. H., Tiwari, V., Schreier, H. W., \& Orteu, J. J. (2008). The effect of out-of-plane motion on 2D and 3D digital image correlation measurements. Optics and Lasers in Engineering, 46(10), 746-757.doi: 10.1016/j.optlaseng.2008.05.005

Tay, C. J., Quan, C., Huang, Y. H., \& Fu, Y. (2005). Digital image correlation for whole field out-of-plane displacement measurement using a single camera. Optics Communications, 251(1-3), 23-36. doi:10.1016/j.optcom.2005.02.070

Uhlmann, E., Kersting, R., Klein, T. B., Cruz, M. F., \& Borille, A. V. (2015). Additive manufacturing of titanium alloy for aircraft components. Procedia Cirp, 35, 55-60. doi: 10.1016/j.procir.2015.08.061

Van Der Klift, F., Koga, Y., Todoroki, A., Ueda, M., Hirano, Y., \& Matsuzaki, R. (2016). 3D printing of continuous carbon fibre reinforced thermo-plastic (CFRTP) tensile test specimens. Open Journal of Composite Materials, 6(01), 18.doi: 10.4236/ojcm.2016.61003

Vanaei, H. R., Shirinbayan, M., Costa, S. F., Duarte, F. M., Covas, J. A., Deligant, M., ... $\&$ Tcharkhtchi, A. (2021). Experimental study of PLA thermal behavior during fused filament fabrication. Journal of Applied Polymer Science, 138(4), 49747. doi: 10.1002/app.49747

Wang, Y. H., Jiang, J. H., Wanintrudal, C., Du, C. H. A. N. G. Q. I. N. G., Zhou, D. A. J. U. N., Smith, L. M., \& Yang, L. X. (2010). Whole field sheet-metal tensile test using digital image correlation. Experimental Techniques, 34(2), 54-59.

Wickramasinghe, S., Do, T., \& Tran, P. (2020). FDM-based 3D printing of polymer and associated composite: A review on mechanical properties, defects and treatments. Polymers, 12(7), 1529. doi:10.3390/polym12071529

Wittevrongel, L., Badaloni, M., Balcaen, R., Lava, P., \& Debruyne, D. (2015). Evaluation of methodologies for compensation of out of plane motions in a $2 \mathrm{D}$ digital image correlation setup. Strain, 51(5), 357-369.doi: 10.1111/str.12146

Wohlers, T. (2021). Wohlers Report 2021. Colorado: Wohlers Associates.

Wong, K. V., \& Hernandez, A. (2012). A review of additive manufacturing. International scholarly research notices, 2012. doi:10.5402/2012/208760

Yan, Q., Dong, H., Su, J., Han, J., Song, B., Wei, Q., \& Shi, Y. (2018). A review of 3D printing technology for medical applications. Engineering, 4(5), 729-742. doi: 10.1016/j.eng.2018.07.021 
Yasa, E., \& Ersoy, K. (2019). Dimensional accuracy and mechanical properties of chopped carbon reinforced polymers produced by material extrusion additive manufacturing. Materials, 12(23), 3885.doi: 10.3390/ma12233885

Yoneyama, S., \& Murasawa, G. (2009). Digital image correlation. Experimental mechanics, 207.

Zhu, F., Bai, P., Zhang, J., Lei, D., \& He, X. (2015). Measurement of true stress-strain curves and evolution of plastic zone of low carbon steel under uniaxial tension using digital image correlation. Optics and Lasers in Engineering, 65, 81-88.doi: 10.1016/j.optlaseng.2014.06.013 


\section{Appendix A}

Plots presented here exhibits strain evolution along $\mathrm{x}$ and $\mathrm{y}$ direction for thickness $0.15 \mathrm{~mm}, 0.20 \mathrm{~mm}$ and $0.25 \mathrm{~mm}$ at $200^{\circ} \mathrm{C}$ and $215^{\circ} \mathrm{C}$ respectively which have been discussed in section 4.2 in detail.

\section{Strain data for specimen with 0.15 layer height at $200^{\circ} \mathrm{C}$}

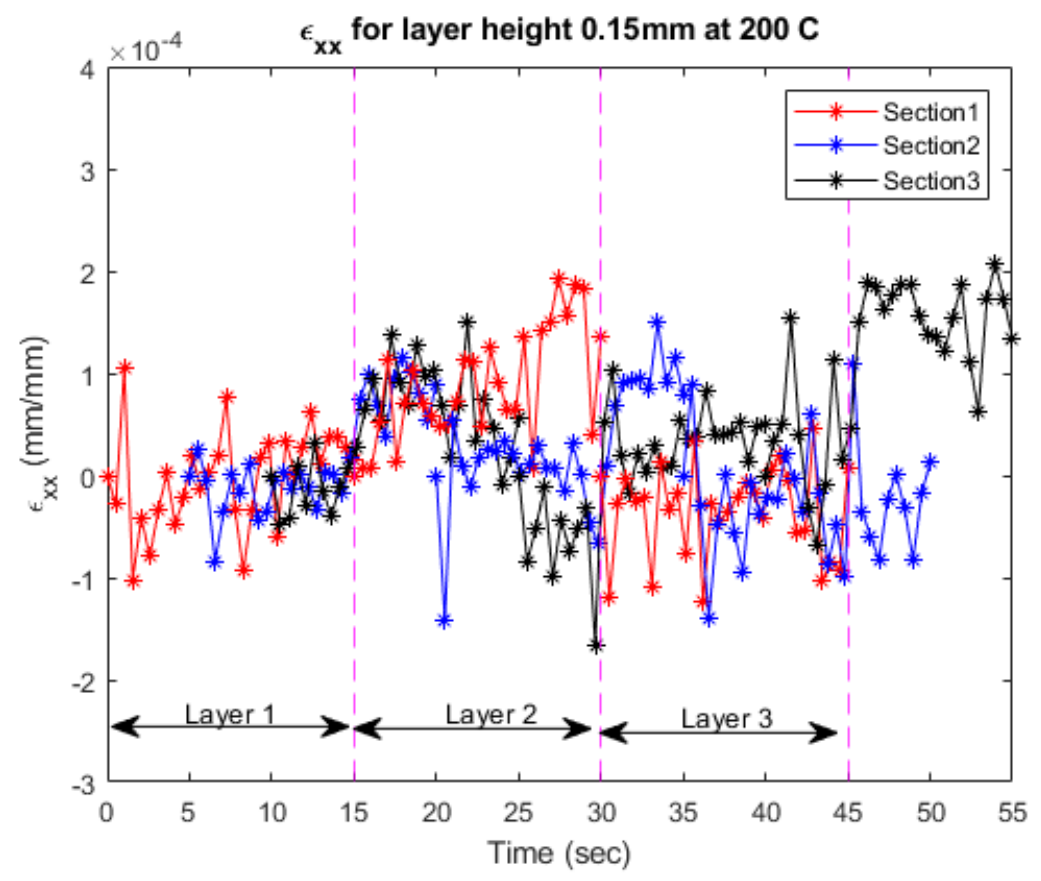




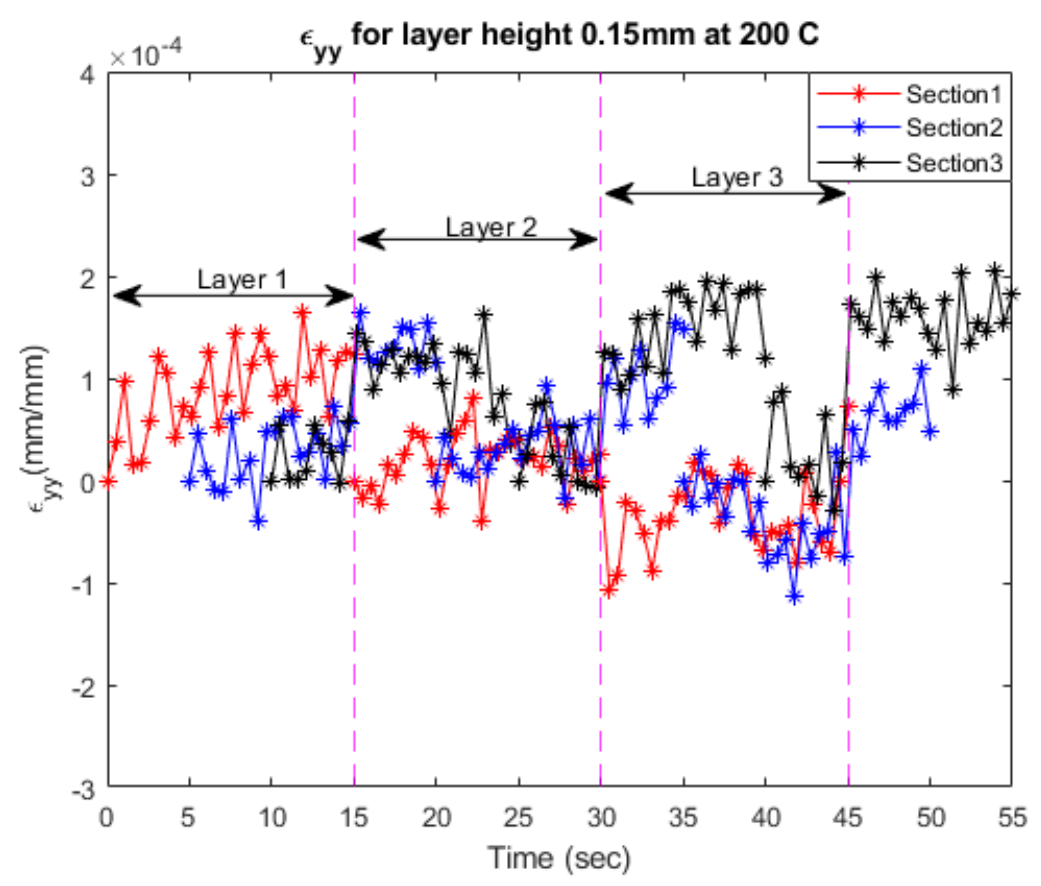

Strain data for specimen with 0.15 layer height at $215^{\circ} \mathrm{C}$

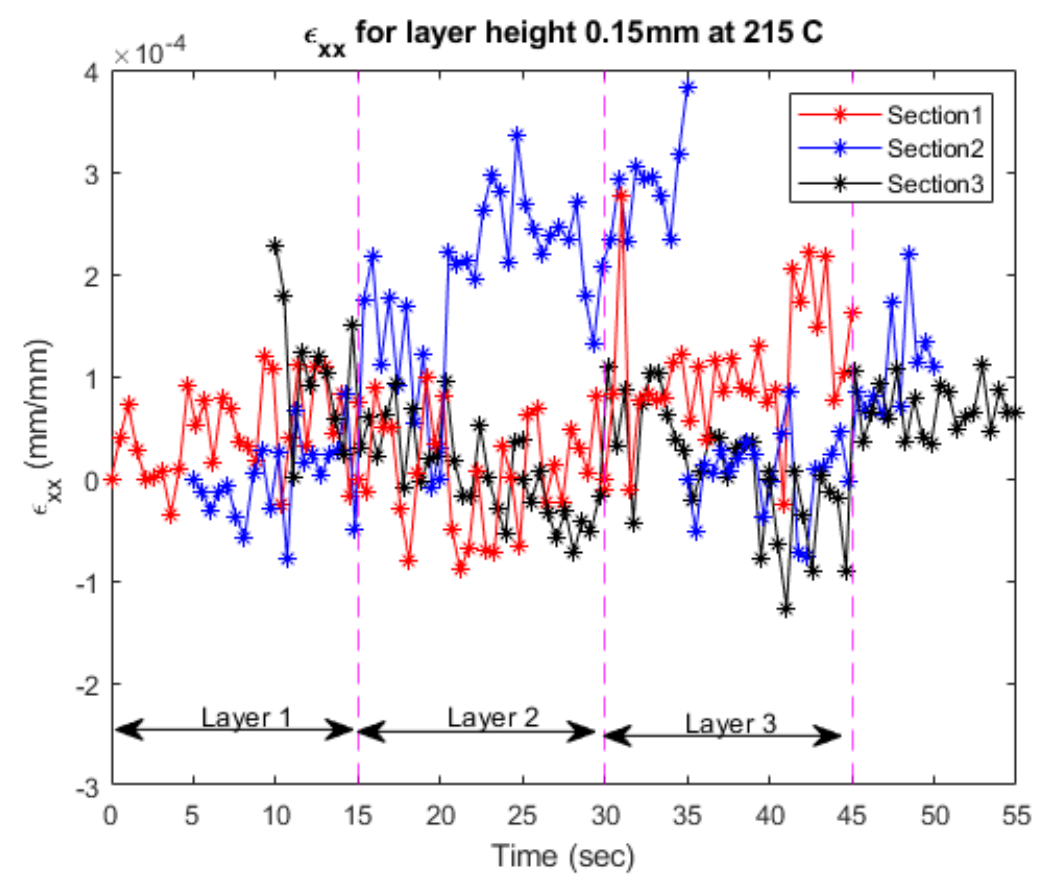




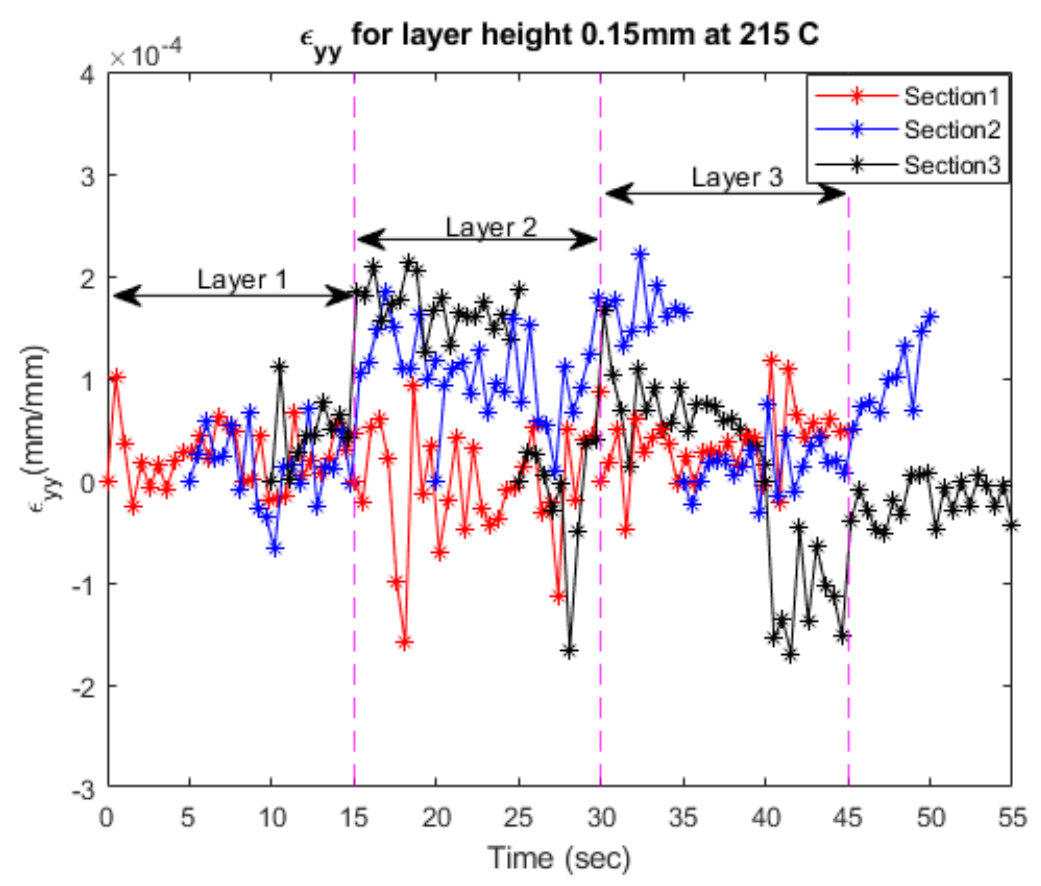

Strain data for specimen with 0.20 layer height at $200^{\circ} \mathrm{C}$

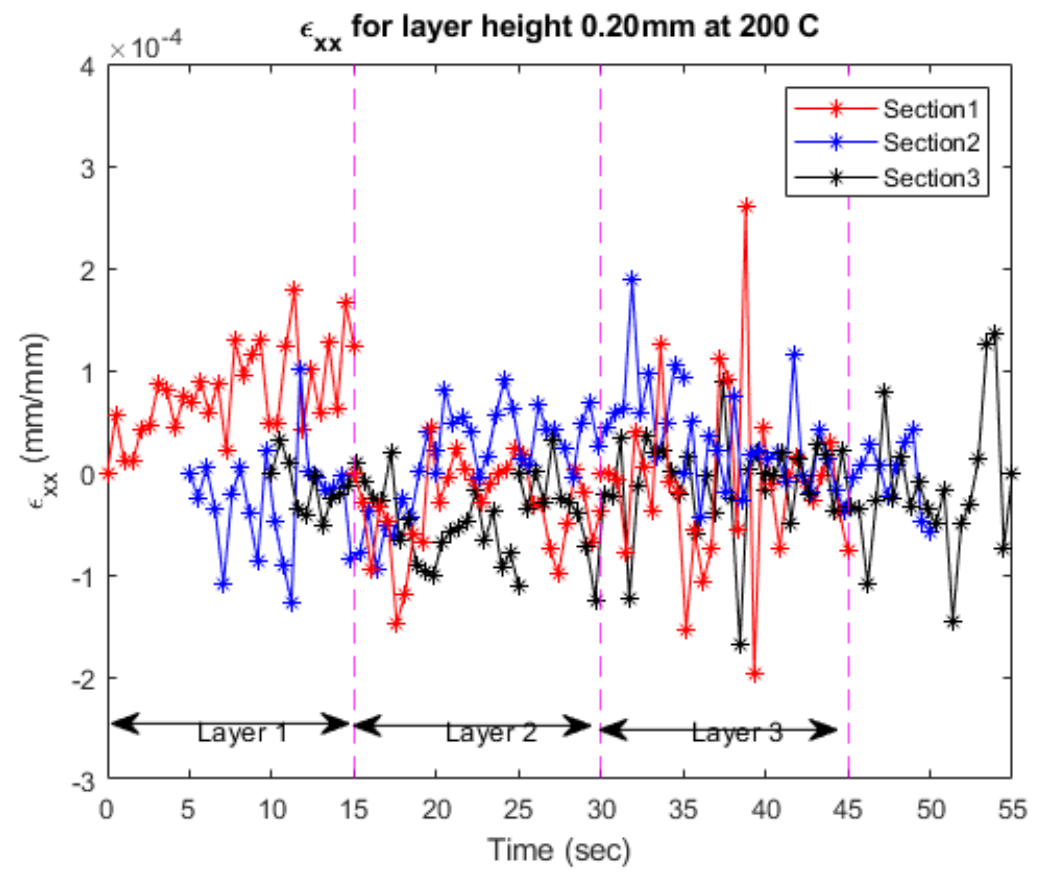




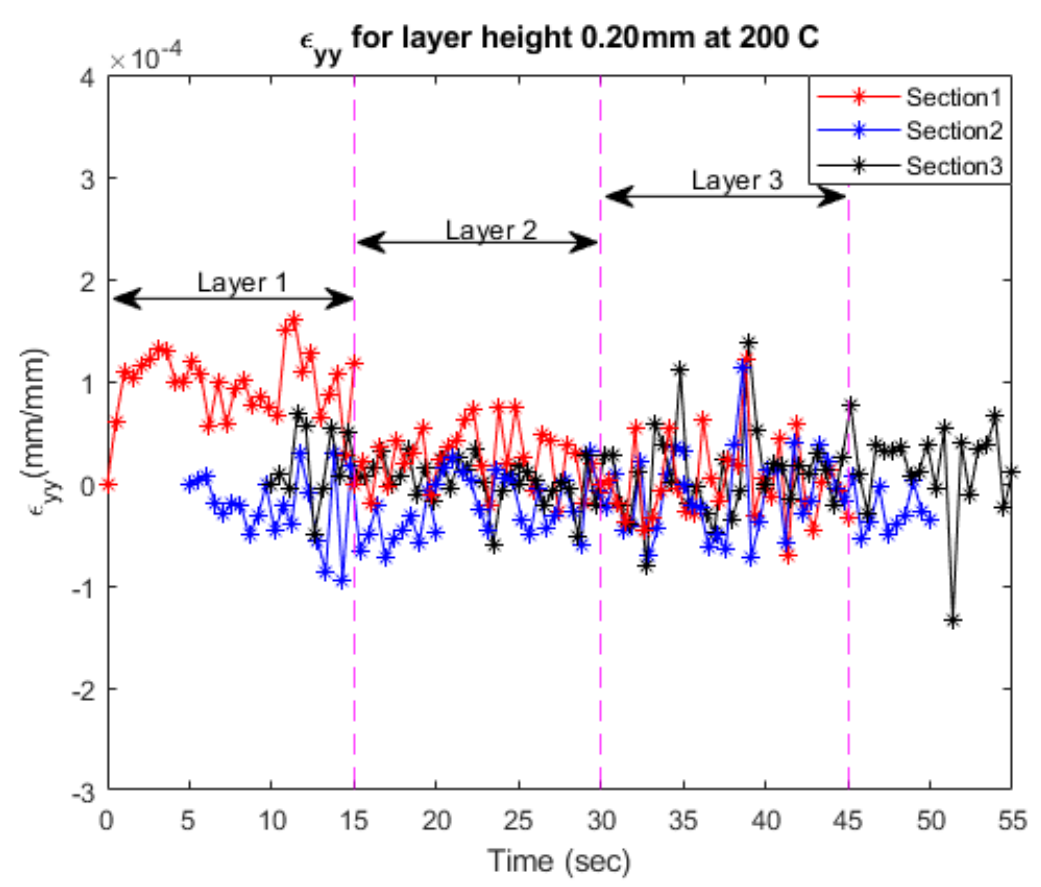

Strain data for specimen with 0.20 layer height at $215^{\circ} \mathrm{C}$

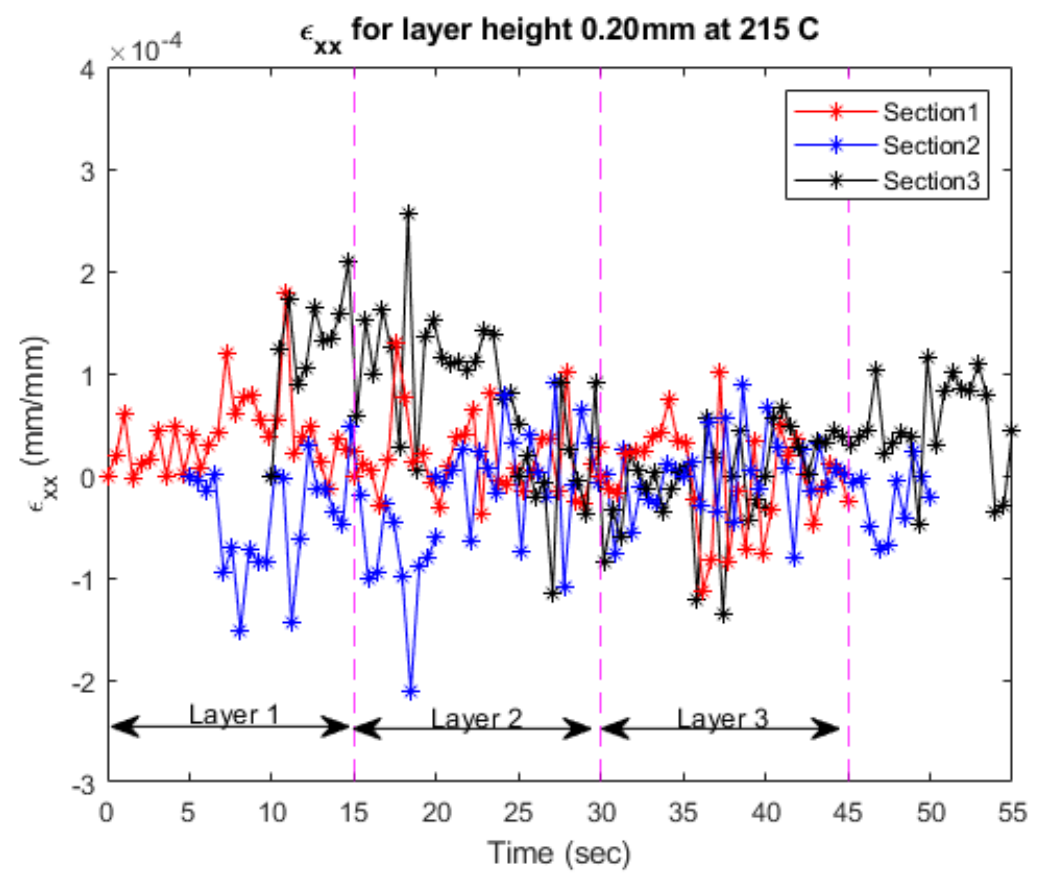




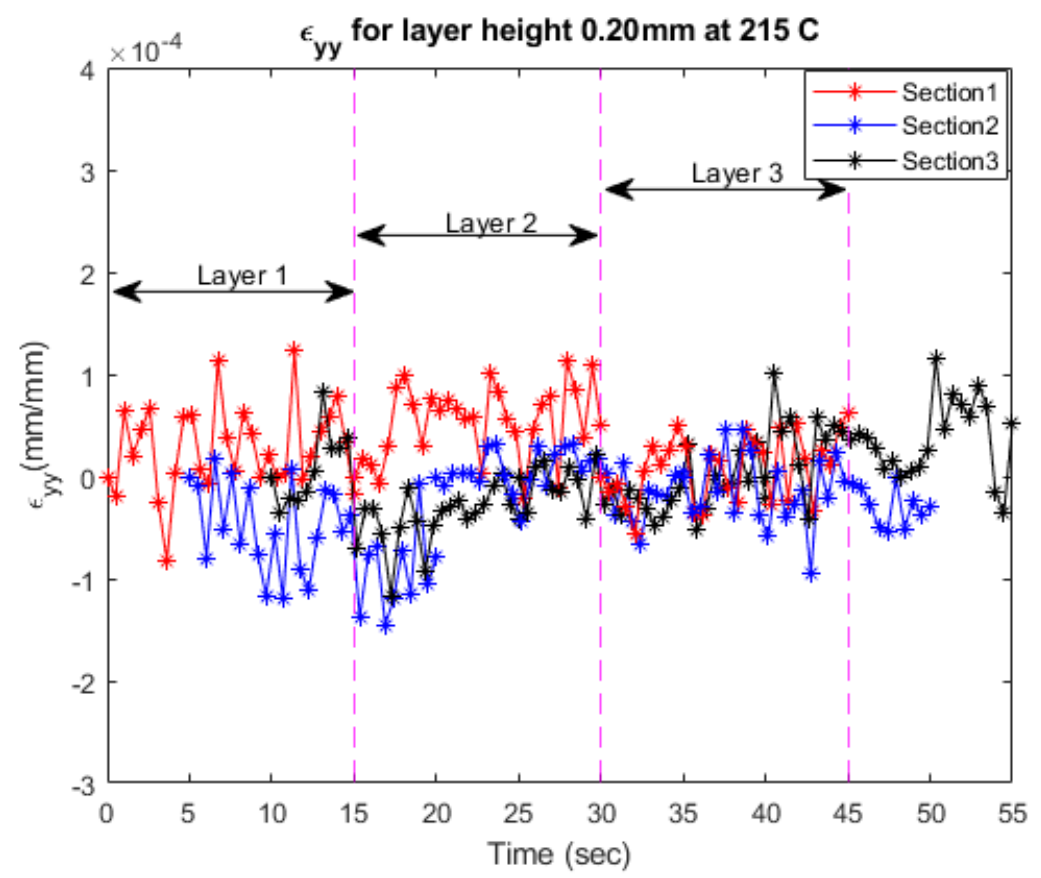

Strain data for specimen with 0.25 layer height at $200^{\circ} \mathrm{C}$

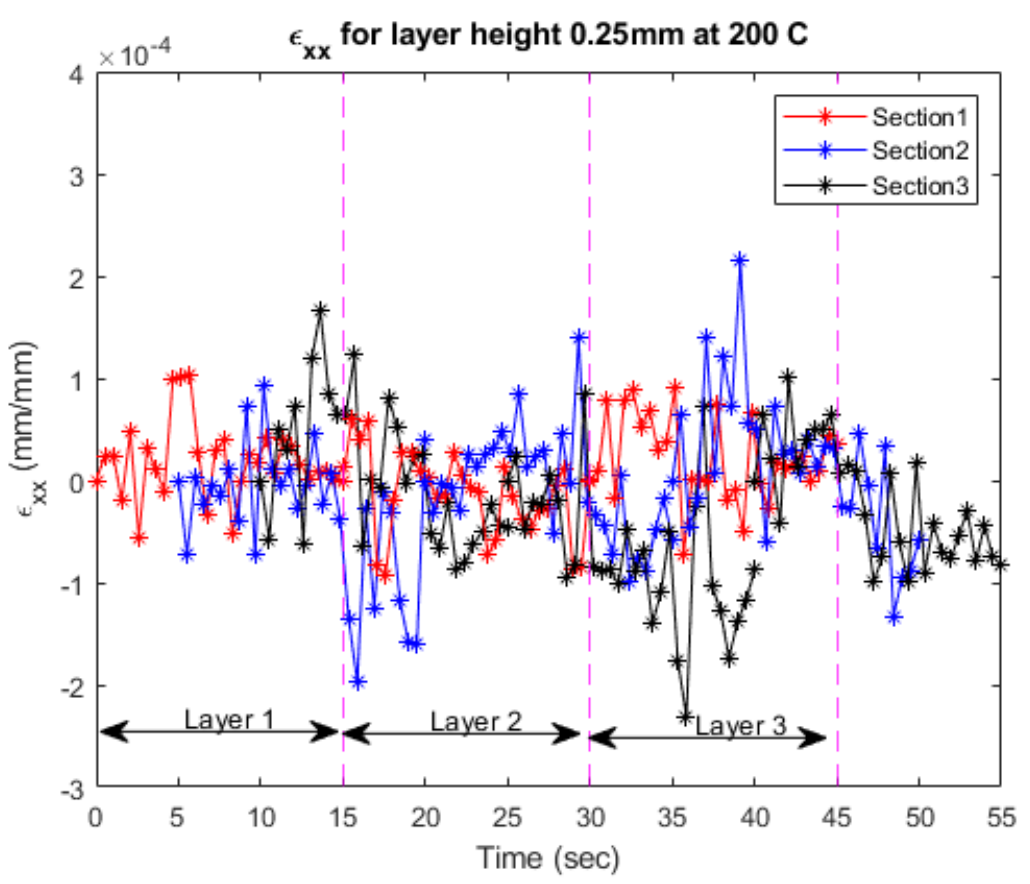




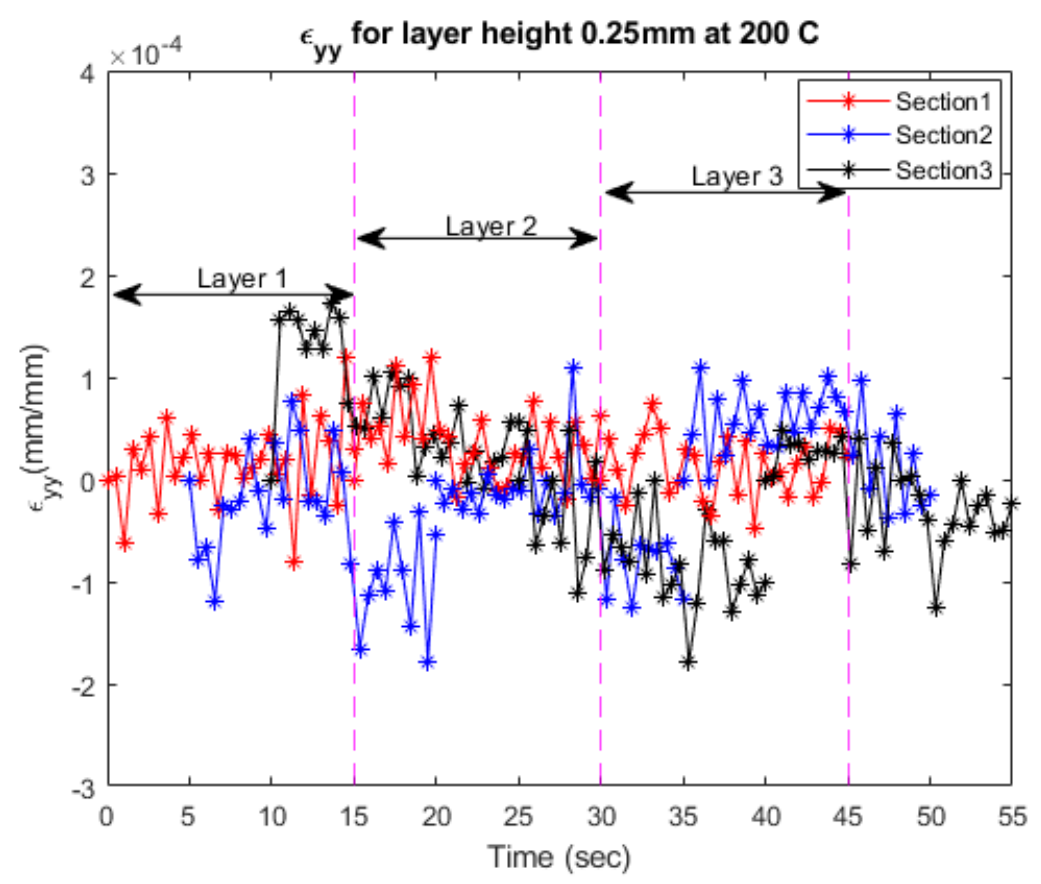

Strain data for specimen with 0.25 layer height at $215^{\circ} \mathrm{C}$

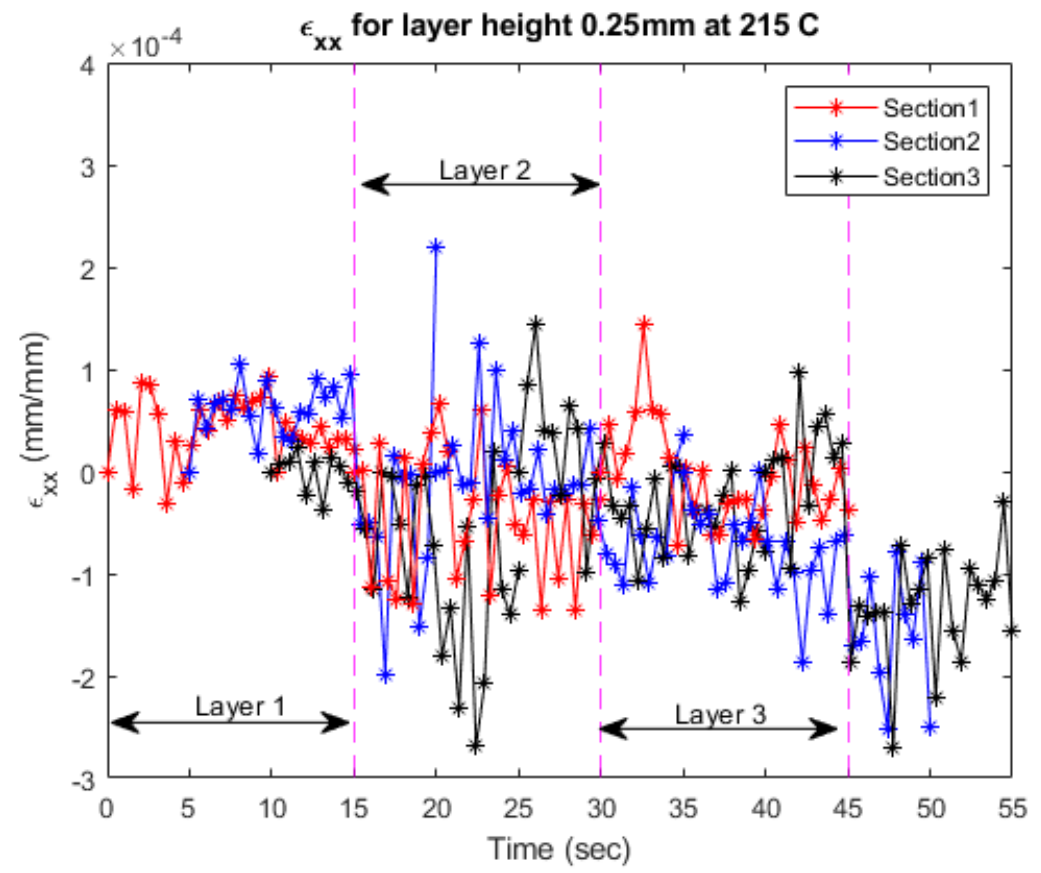




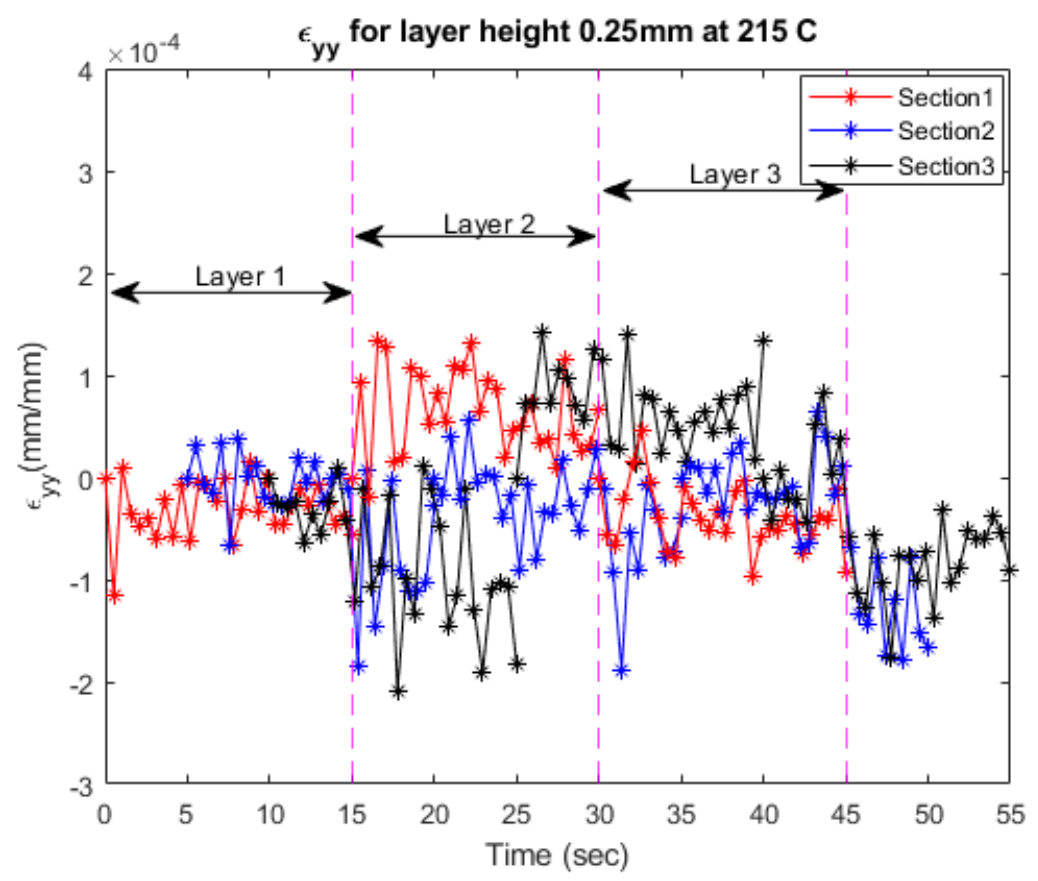




\section{Appendix B}

Following code has been used to plot strain data for all the nine tests given in test matrix. Improfile commands enalbes temperature reading from the images captured through IR camera and saved in .mat format.

\section{Script for Strain plot}

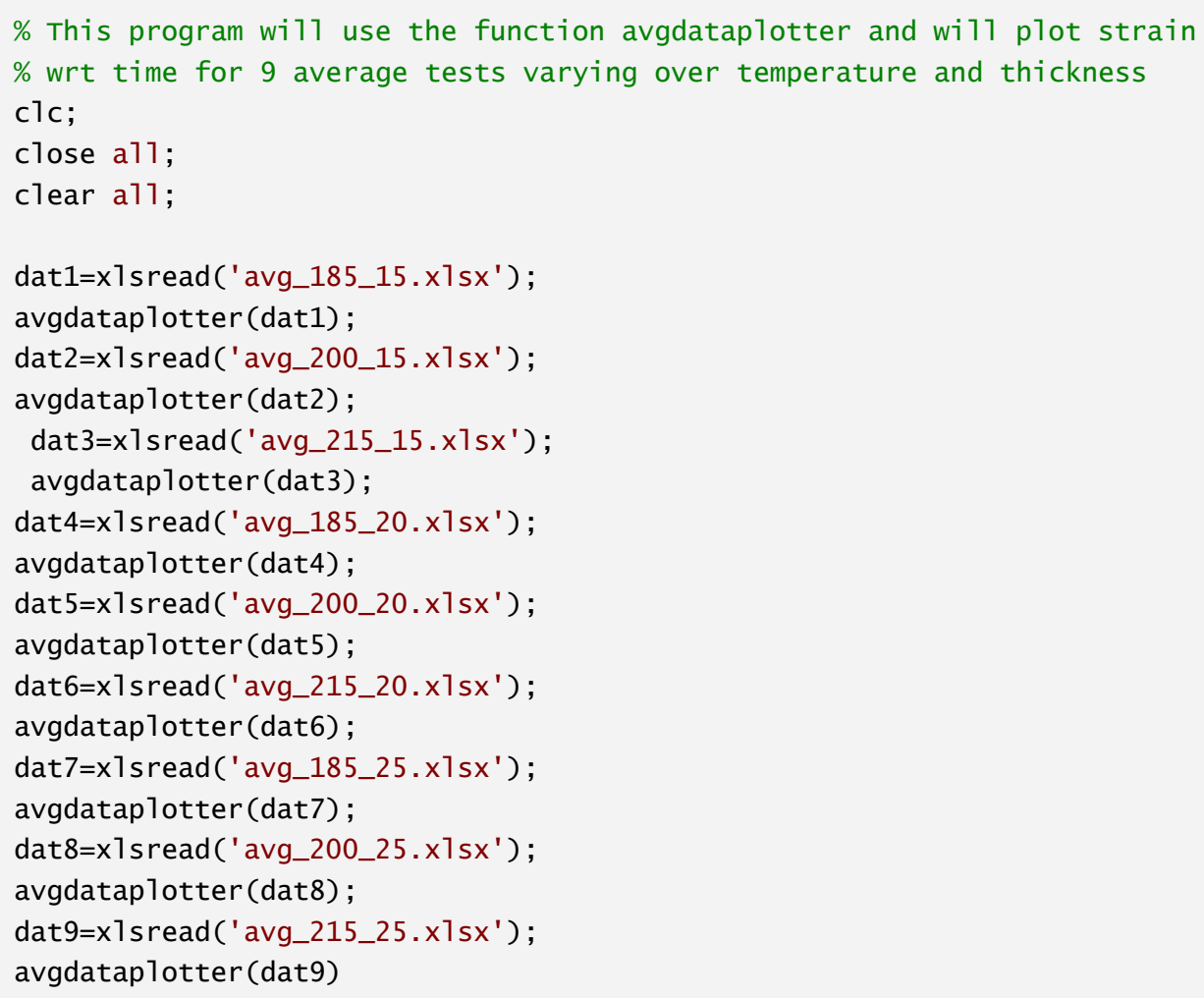

\section{Published with MATLAB® R2019b}

\section{function avgdataplotter(x1sxsheet)}

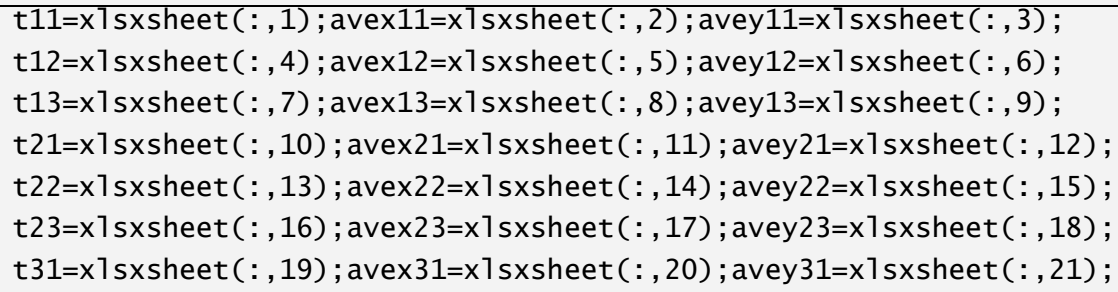




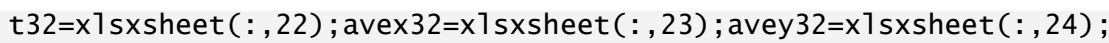

$\mathrm{t} 33=x 1$ sxsheet $(:, 25) ; \operatorname{avex} 33=x 1 \operatorname{sxsheet}(:, 26) ; \operatorname{avey} 33=x 1 \operatorname{sxsheet}(:, 27)$;

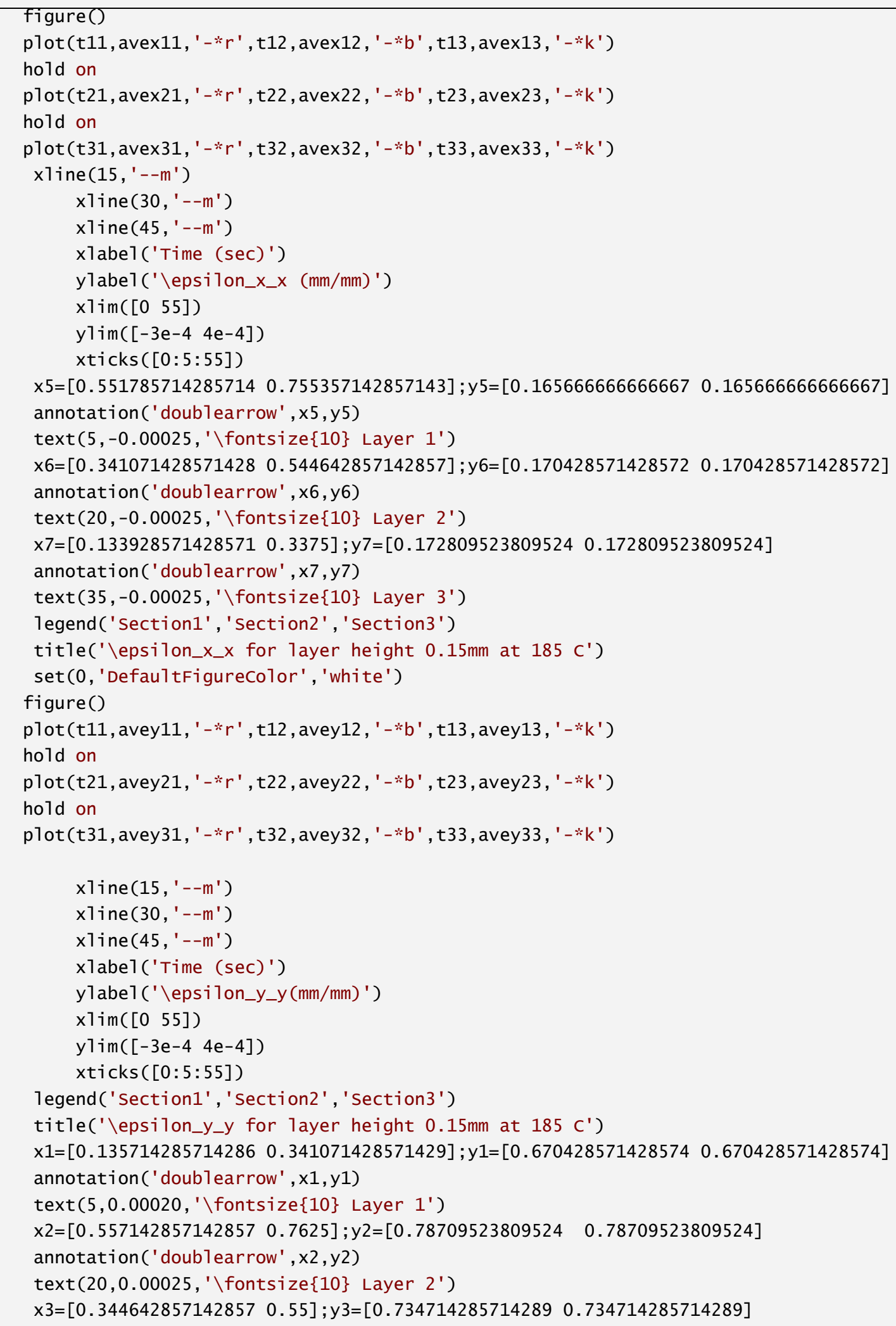


annotation ('doublearrow' , $\mathrm{x} 3, \mathrm{y} 3$ )

text $\left(35,0.00030, ' \backslash\right.$ fontsize $\{10\}$ Layer $\left.3^{\prime}\right)$

set (0, 'Defaultfigurecolor' , 'white')

end

Published with MATLAB® R2019b

\section{Script for Temperature plot}

Following script give temperature reading at different pixels across the length of the specimen.

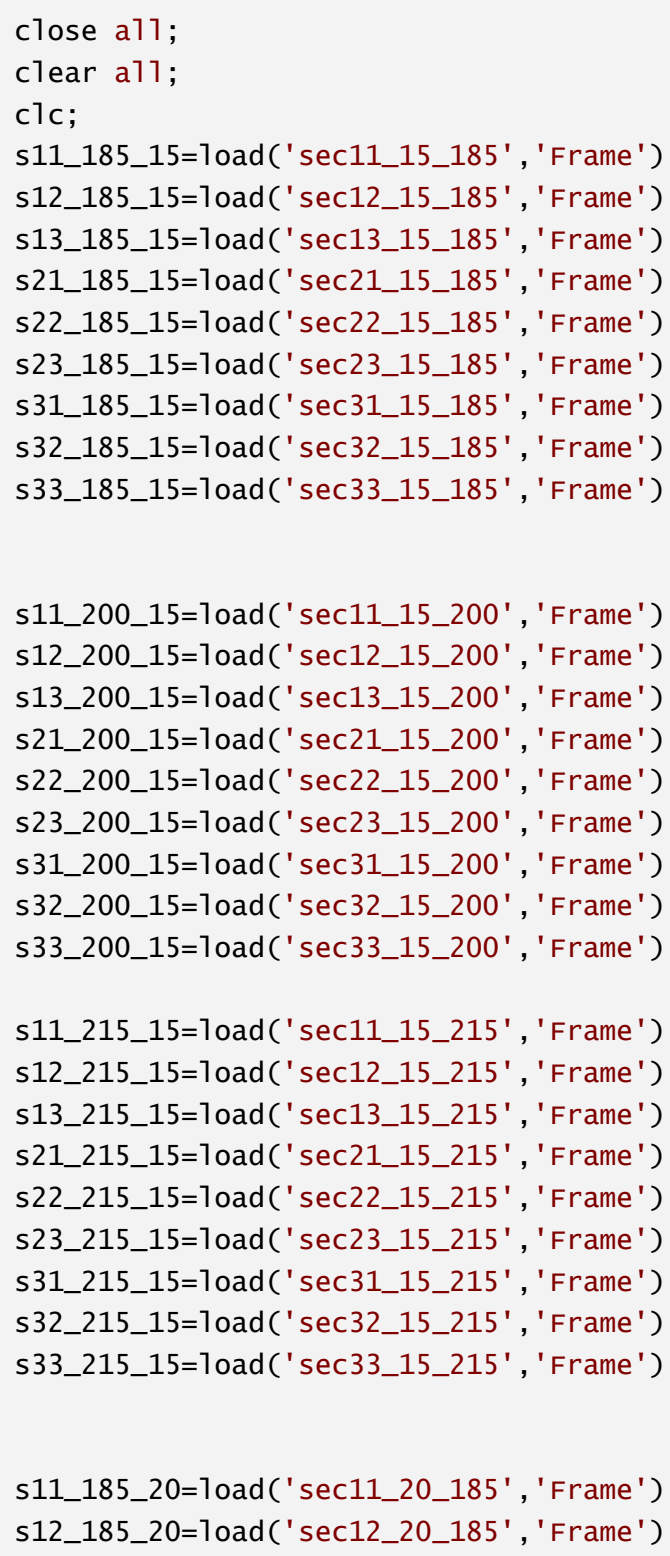




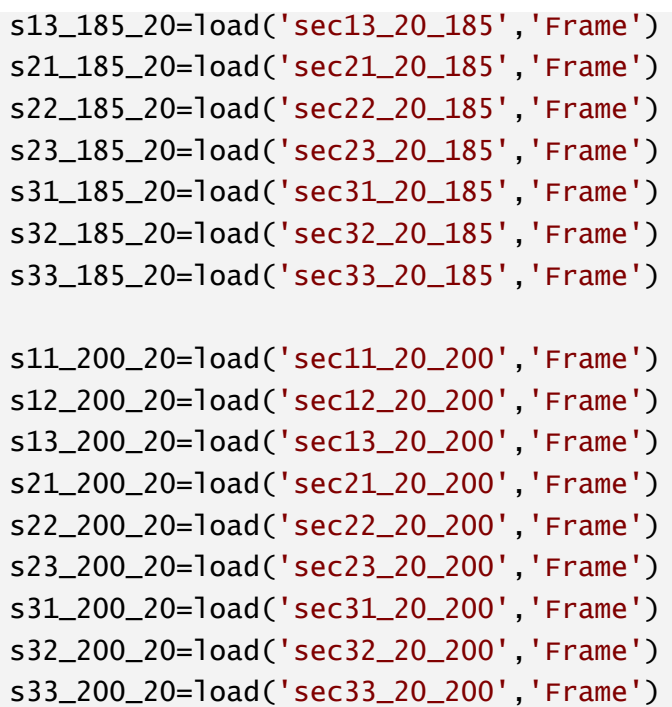

s11_215_20=1oad('sec11_20_215 ' , 'Frame ') ; s12_215_20=1oad(' sec12_20_215 ', 'Frame ') ; s13_215_20=1oad ('sec13_20_215 ' , 'Frame ') ; s21_215_20=1oad('sec21_20_215 ' , 'Frame ') ; s22_215_20=1oad ('sec22_20_215 ' , 'Frame ') ; s23_215_20=1oad('sec23_20_215 ' , 'Frame'); s31_215_20=1oad('sec31_20_215 ' , 'Frame') ; s32_215_20=1oad('sec32_20_215 ' , 'Frame ') ; s33_215_20=1oad('sec33_20_215 ' , 'Frame') ;

s11_185_25=1oad('sec11_25_185' , 'Frame') s12_185_25=1oad('sec12_25_185 ' , 'Frame') s13_185_25=1oad('sec13_25_185 ' , 'Frame') s21_185_25=1oad('sec21_25_185 ' , 'Frame') s22_185_25=1oad('sec22_25_185 ' , 'Frame') s23_185_25=1oad('sec23_25_185 ' , 'Frame') s31_185_25=1oad('sec31_25_185 ', 'Frame') s32_185_25=1oad('sec32_25_185 ' , 'Frame ') ; s33_185_25=1oad('sec33_25_185 ', 'Frame ') ;

s11_200_25=1oad('sec11_25_200' , 'Frame') s12_200_25=1oad('sec12_25_200' , 'Frame') s13_200_25=1oad('sec13_25_200' , 'Frame') s21_200_25=1oad('sec21_25_200', 'Frame') s22_200_25=1oad('sec22_25_200' , 'Frame') s23_200_25=1oad('sec23_25_200', 'Frame') s31_200_25=1oad('sec31_25_200' , 'Frame') s32_200_25=1oad(' sec32_25_200', 'Frame ') ; s33_200_25=1oad('sec33_25_200', 'Frame')

s11_215_25=1oad('sec11_25_215 ' , 'Frame ') ; s12_215_25=1oad('sec12_25_215 ' , 'Frame') ; s13_215_25=1oad('sec13_25_215 ', 'Frame '); s21_215_25=1oad('sec21_25_215 ', 'Frame ') ; 


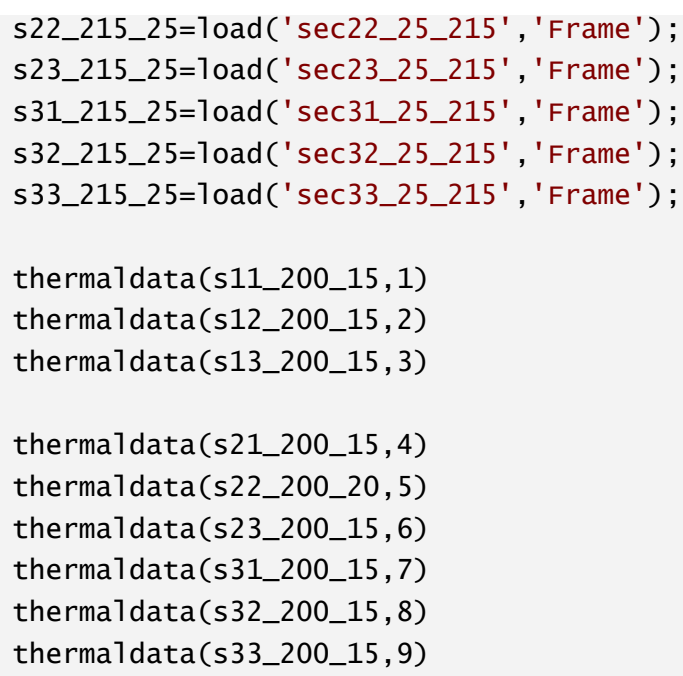

\section{Published with MATLAB® R2019b}

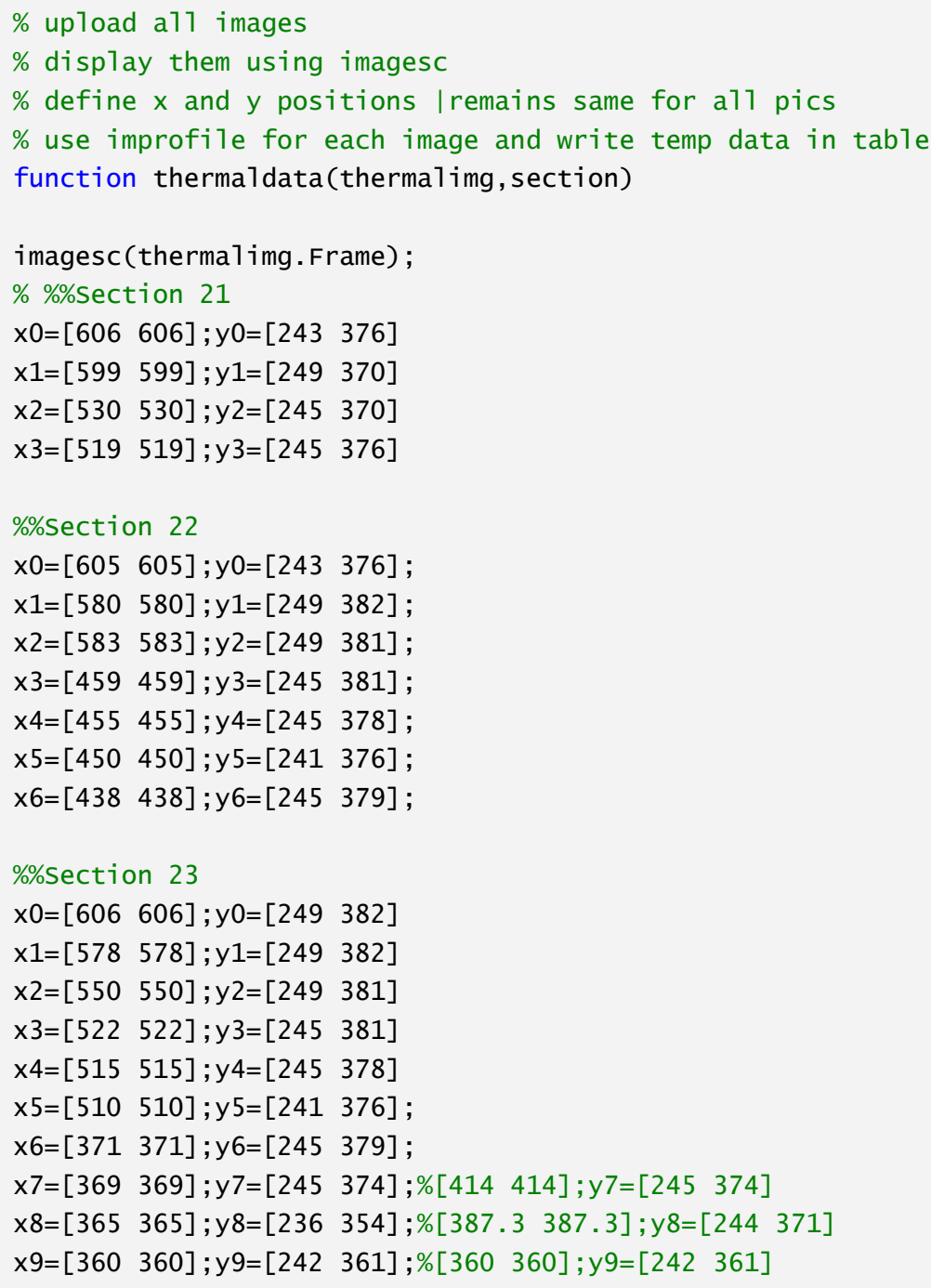




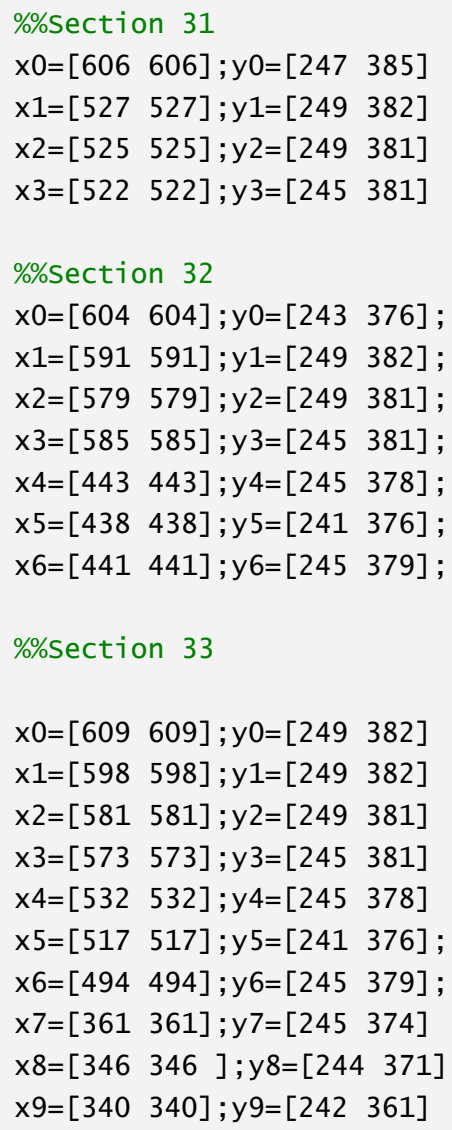


if section $==3$

$\mathrm{X} 13 \mathrm{~L} 1=$ improfi $1 \mathrm{e}$ (thermalimg. Frame, $\mathrm{x} 0$, y0) ; $\mathrm{X} 13 \mathrm{~L} 2=$ improfi1e (thermalimg. Frame, $\mathrm{x} 1, \mathrm{y} 1$ ) ; X13L3=improfi 1e (thermalimg. Frame, $x 2$, y2) ; $\mathrm{X} 13 \mathrm{~L} 4=$ improfi1e (thermalimg. Frame, $\mathrm{x} 3, \mathrm{y} 3$ ); X13L5=improfi le (thermalimg. Frame, $x 4, y 4$ ); X13L6=improfile (thermalimg. Frame, x5 , y5); $\mathrm{X} 13 \mathrm{~L} 7=$ improfi $1 \mathrm{e}$ (therma1 img. Frame, $\mathrm{x} 6$, y6) ; $\mathrm{X} 13 \mathrm{~L} 8=$ improfi 1 e (thermalimg. Frame, $x 7, y 7$ ); $\mathrm{X} 13 \mathrm{~L} 9=$ improfi1e (thermalimg. Frame, $\mathrm{x} 8, \mathrm{y} 8$ ) ; $x 13 L 10=i m p r o f i 1 e$ (therma1img. Frame, x9, y9); $\mathrm{t} 13 \mathrm{~L} 1=\operatorname{mean}(\mathrm{X} 13 \mathrm{~L} 1) ; \mathrm{t} 13 \mathrm{~L} 2=\operatorname{mean}(\mathrm{X} 13 \mathrm{~L} 2) ; \mathrm{t} 13 \mathrm{~L} 3=\operatorname{mean}(\mathrm{X} 13 \mathrm{~L} 3) ; \mathrm{t} 13 \mathrm{~L} 4=$ mean $(\mathrm{X} 13 \mathrm{~L} 4) ;$ $\mathrm{t} 13 \mathrm{~L} 5=\operatorname{mean}(\mathrm{X} 13 \mathrm{~L} 5) ; \mathrm{t} 13 \mathrm{~L} 6=\operatorname{mean}(\mathrm{X} 13 \mathrm{~L} 6) ; \mathrm{t} 13 \mathrm{~L} 7=$ mean $(X 13 \mathrm{~L} 7) ; \mathrm{t} 13 \mathrm{~L} 8=$ mean $(X 13 \mathrm{~L} 8)$; $\mathrm{t} 13 \mathrm{~L} 9=\operatorname{mean}(\mathrm{X} 13 \mathrm{~L} 9) ; \mathrm{t} 13 \mathrm{~L} 10=$ mean $(\mathrm{X} 13 \mathrm{~L} 10) ;$ sec13= [t13L1; t13L2; t13L3;t13L4; t13L5; t13L6;t13L7; t13L8; t13L9; t13L10] end

if section $==4$

X21L1=improfile(thermalimg. Frame, $\mathrm{x} 0$, y0); $\mathrm{X} 21 \mathrm{~L} 2=$ improfi1e (thermalimg. Frame, $\mathrm{x} 1, \mathrm{y} 1$ ); $\mathrm{X} 21 \mathrm{~L} 3=$ improfile(thermalimg. Frame, $\mathrm{x} 2$, y2); X21L4=improfile(thermalimg. Frame, X3, y3); t21L1=mean (X21L1); t21L2=mean (X21L2); t21L3=mean (X21L3); t21L4=mean(X21L4); $\sec 21=[t 21 L 1 ; t 21 L 2 ; t 21 L 3 ; t 21 L 4]$

end

if section $==5$

X22L1=improfile (thermalimg. Frame, $\mathrm{x} 0$, y0); $\mathrm{X} 22 \mathrm{~L} 2=$ improfile (thermalimg. Frame, $\mathrm{x} 1, \mathrm{y} 1$ ); X22L3=improfile(thermalimg. Frame, X2, y2); X22L4=improfile(thermalimg. Frame, X3, y3); X22L5=improfile(thermalimg. Frame, $\mathrm{X} 4, \mathrm{y} 4$ ); X22L6=improfile(thermalimg. Frame, X5, y5); X22L7=improfi1e(therma1img. Frame, X6,y6);

$\mathrm{t} 22 \mathrm{~L} 1=$ mean $(X 22 \mathrm{~L} 1) ; \mathrm{t} 22 \mathrm{~L} 2=$ mean $(X 22 \mathrm{~L} 2) ; \mathrm{t} 22 \mathrm{~L} 3=$ mean $(X 22 \mathrm{~L} 3) ; \mathrm{t} 22 \mathrm{~L} 4=$ mean $(X 22 \mathrm{~L} 4)$; $\mathrm{t} 22 \mathrm{~L} 5=\operatorname{mean}(X 22 \mathrm{~L} 5) ; \mathrm{t} 22 \mathrm{~L} 6=\operatorname{mean}(X 22 \mathrm{~L} 6) ; \mathrm{t} 22 \mathrm{~L} 7=\operatorname{mean}(X 22 \mathrm{~L} 7)$;

$\sec 22=[\mathrm{t} 22 \mathrm{~L} 1 ; \mathrm{t} 22 \mathrm{~L} 2 ; \mathrm{t} 22 \mathrm{~L} 3 ; \mathrm{t} 22 \mathrm{~L} 4 ; \mathrm{t} 22 \mathrm{~L} 5 ; \mathrm{t} 22 \mathrm{~L} 6 ; \mathrm{t} 22 \mathrm{~L} 7]$

end

if section $==6$

X23L1=improfile (thermalimg. Frame, $x 0, y 0$ ); X23L2=improfile (thermalimg. Frame, $x 1, y 1$ ); X23L3=improfi1e (thermalimg. Frame, $x 2$,y2); X23L4=improfile(thermalimg. Frame, x3, y3); X23L5=improfile (thermalimg. Frame, $x 4, y 4$ ); X23L6=improfile(thermalimg.Frame, X5, y5); X23L7=improfile (thermalimg. Frame, x6, y6); X23L8=improfile(thermalimg. Frame, $x 7, y 7$ ); X23L9=improfile(thermalimg.Frame, $x 8, y 8$ ); X23L10=improfi 1 e(thermalimg. Frame, $x 9$, y9); t23L1 = mean $(X 23 L 1) ; t 23 L 2=$ mean $(X 23 L 2) ; t 23 L 3=$ mean $(X 23 L 3) ; t 23 L 4=$ mean $(X 23 L 4)$; t23L5 $=$ mean $(X 23 L 5) ; t 23 L 6=$ mean $(X 23 L 6) ; t 23 L 7=$ mean $(X 23 L 7) ; t 23 L 8=$ mean $(X 23 L 8)$; t23L9= mean $(X 23 L 9) ;$ t23L10=mean $(X 23 L 10) ;$

sec23 $=$ [t23L1; t23L2; t23L3;t23L4;t23L5;t23L6;t23L7;t23L8;t23L9;t23L10] 


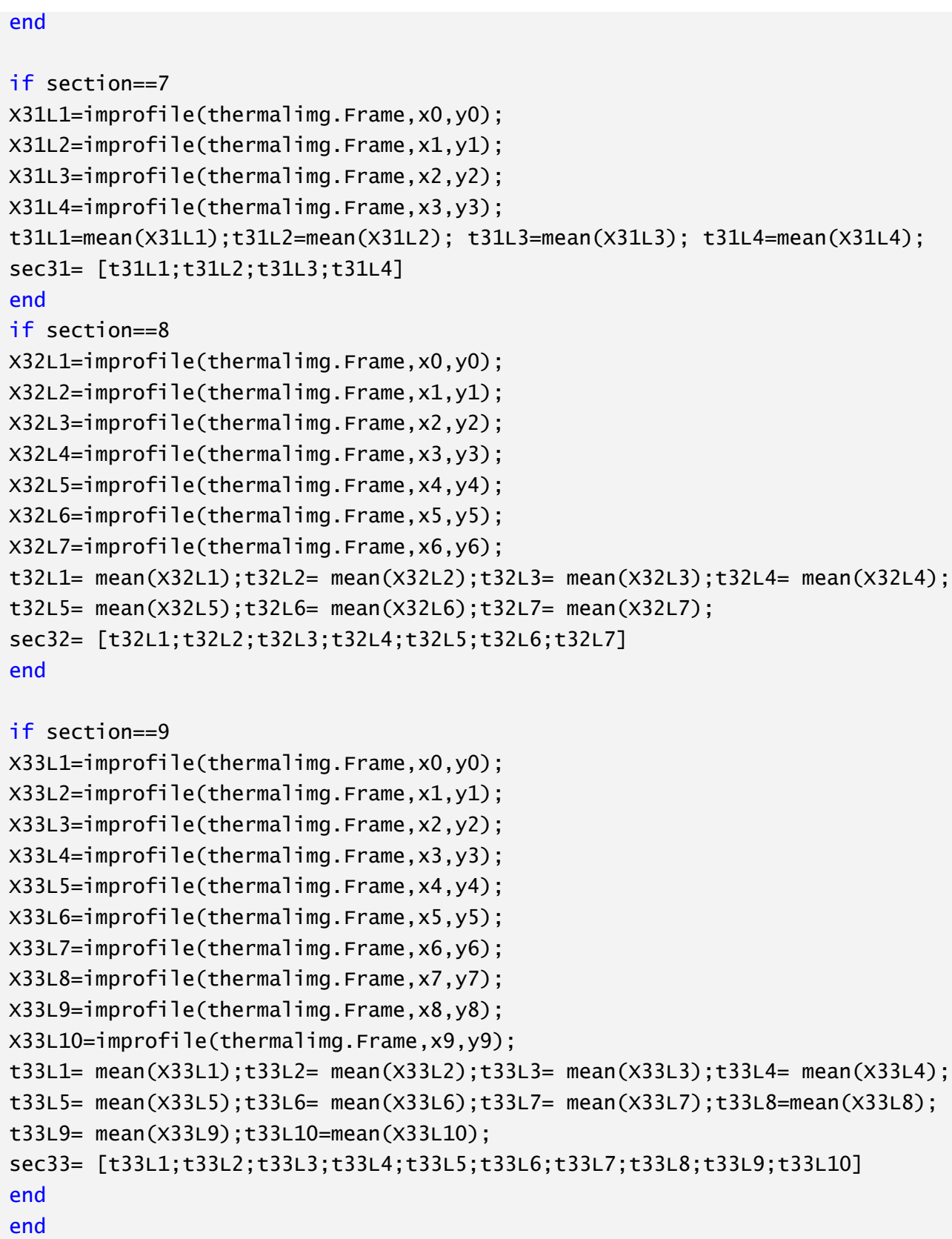

